\title{
Diversity of Bacterial and Archaeal Populations in Artificial Rumen Fermentors Fed Differing Pasture Diets
}

\author{
Smita Singh \\ West Virginia University
}

Follow this and additional works at: https://researchrepository.wvu.edu/etd

\section{Recommended Citation}

Singh, Smita, "Diversity of Bacterial and Archaeal Populations in Artificial Rumen Fermentors Fed Differing Pasture Diets" (2012). Graduate Theses, Dissertations, and Problem Reports. 4918.

https://researchrepository.wvu.edu/etd/4918

This Thesis is protected by copyright and/or related rights. It has been brought to you by the The Research Repository @ WVU with permission from the rights-holder(s). You are free to use this Thesis in any way that is permitted by the copyright and related rights legislation that applies to your use. For other uses you must obtain permission from the rights-holder(s) directly, unless additional rights are indicated by a Creative Commons license in the record and/ or on the work itself. This Thesis has been accepted for inclusion in WVU Graduate Theses, Dissertations, and Problem Reports collection by an authorized administrator of The Research Repository @ WVU. For more information, please contact researchrepository@mail.wvu.edu. 
Diversity of Bacterial and Archaeal Populations in Artificial Rumen

Fermentors Fed Differing Pasture Diets

\author{
by \\ Smita Singh \\ Thesis submitted to the \\ Davis College of Agriculture, Natural Resources, and Design \\ at West Virginia University \\ in partial fulfillment of the requirements \\ for the degree of \\ Master of Science \\ in \\ Applied and Environmental Microbiology \\ Alan J. Sexstone, PhD., Committee Chairperson \\ Gary K. Bissonnette, PhD. \\ Eugene E. Felton, PhD.
}

Division of Plant and Soil Sciences

Morgantown, West Virginia

2012

Keywords: Rumen; T-RFLP; Bacterial Diversity; Archaeal Diversity; Pasture; Teff; Triticale.

Copyright 2012 Smita Singh 


\title{
ABSTRACT
}

\section{Diversity of Bacterial and Archaeal Populations in Artificial Rumen Fermentors Fed Differing Pasture Diets}

\begin{abstract}
SMITA SINGH
Rumens harbor diverse groups of microorganisms. These microorganisms help ruminants in efficient digestion of a wide variety of feed materials. Most of these microorganisms are anaerobic and work symbiotically with the host. The amount of microbial diversity depends on the types of substrates present in the feed. Although some of these microorganisms have been cultured and characterized, the majority of them are unknown because they are unculturable. With the development of molecular techniques such as Denaturing Gradient Gel Electrophoresis (DGGE), Temperature Gradient Gel Electrophoresis (TGGE), Automated Ribosomal Intergenic Spacer Analysis (ARISA), Restriction Fragment Length Polymorphism (RFLP), Terminal Restriction Fragment Length Polymorphism (TRFLP) etc., now it is possible to quantify existing rumen microbial diversity, even if the microorganisms are not culturable.

Previous studies on rumen ecosystems have shown that microbial populations generally vary with diet. A majority of these studies emphasized changes in bacterial communities in relation to grain diets, and less emphasis was given to traditional pasture diets which provide the main cattle food in several developing countries, and also on effect of changes in diets on archaeal communities in the rumen ecosystem. To understand bacterial and archaeal diversity associated with different pasture diets, I amplified bacterial and archaeal 16S rRNA genes from rumen samples using a universal FAM labeled forward primer and a non-labeled reverse primer, and then these products were digested with different tetrameric restriction enzymes. T-RFLP profiles obtained from Hha I and Rsa I digested fragments from open canopy (OC) and wooded canopy (WC) pasture diets suggested that bacterial and archaeal community structures were not significantly different in these pasture diets and that harvest time of these diets had no effect on bacterial and archaeal community structure. T-RFLP profiles obtained from Hha I, Rsa I, and Hae III digested fragments from naturalized pasture early cut (NPEC), naturalized pasture late cut (NPLC), teff, and triticale diets showed highest bacterial and archaeal diversities in triticale and nplc diets respectively. Diet pairs npecteff and nplc-triticale shared more bacterial and archaeal community, and bacterial and archaeal communities associated with diet pairs npec-nplc, npec-triticale, nplc-teff, and teff-triticale were significantly different. This study will help in better understanding of the microbial diversity in cattle which in turn will help in optimal utilization of a wide variety of feeds.
\end{abstract}




\section{ACKNOWLEDGEMENTS}

There are several people without whom this thesis would not have been possible.

First of all, I would like to thank my supervisor Dr. Alan Sexstone for his guidance, encouragements, understanding, and advice throughout my time as his student at WVU.

Next, I would like to thank my committee members Drs. Gary Bissonnette and Eugene Felton for their suggestions which improved this thesis substantially. I would also like to thank Drs. Jim Neal and Bill Bryan, who were instrumental in sample collection along with Dr. Felton.

Apart from my committee, I would like to thank Drs. Letha Sooter, Jennifer Weidhaas, Daniel Panaccione, and Jianbo Yao. Dr. Sooter always encouraged me for scientific research and provided me opportunities to persue work on different exciting projects; Dr. Weidhaas provided step by step T-RFLP protocol, and Dr. Yao and Dr. Panaccione allowed open access to their laboratory equipments for me.

My sincere thanks goes to Greg Klinger for his help in multivariate analysis using $\mathrm{R}$ and WVU core genomics facility for capillary electrophoresis and help with T-RFLP data analyses.

I would like to thanks Greg (Boyce), Mariana, Taniya for their help and support.

Last but not the least I would like to thanks my parents, in-laws, husband and son for being always with me during my ups and down. 


\section{LIST OF TABLES}

Table 2.1 List of samples and their collection details. Each sample had one duplicate sample (not shown in table). Harvest 1, 2, 3 and 4 were conducted on 4/25/08, 5/5/08, $5 / 15 / 08$, and 6/11/08 respectively.

Table 2.2 Table showing richness, diversity, and evenness indices of bacterial and archaeal communities associated with open and wooded canopy diets.

Table 3.1 List of samples and their collection details. Feed types: 1.) Naturalized pasture early cut (npec), 2.) Naturalized pasture late cut (nplc), 3.) Teff grass (teff), and 4.) Triticale (tri).

Table 3.2 Table showing richness, diversity, and evenness indices of bacterial and archaeal communities associated with naturalized pasture early cut ( npec), teff, naturalized pasture late cut (nplc), and triticale (tri). 


\section{LIST OF FIGURES}

Figure 2.1 In-vitro single-flow continuous culture system.

Figure 2.2 Agarose gel electrophoresis image of PCR products obtained using a.) bacterial universal primers and b.) archaeal universal primers. Lane $L=100$ bp DNA ladder from New England Biolabs, lane $\mathrm{N}=$ Negative control. In figure 2.2a, lane1=R2F4, lane2=R2F4D, lane3=R1F12, lane4=R1F12D and in figure2.2b lane 1=R2F1, lane2=R2F1D, lane3=R2F2, lane 4=R2F2D, lane5= R2F3, lane6=R2F3D, lane7=R2F4, lane 8=R2F4D.

Figure 2.3 Venn diagram showing shared and unique bacterial T-RF's between open canopy (OC) and wooded canopy (WC) pasture diets a.) when digested with Hha I b.) when digested with Rsa I.

Figure 2.4 Comparison of Hha I digested bacterial T-RFLP profiles obtained from a single sample of open canopy (OC) and wooded canopy (WC) pasture diets. Red arrow highlight unique bacterial T-RF associated with wooden canopy pasture diets.

Figure 2.5 Venn diagram showing shared and unique archaeal T-RF's between open canopy (OC) and wooded canopy (WC) pasture diets a.) when digested with Hha I b.) when digested with Rsa I.

Figure 2.6 Comparison of Hha I digested archaeal T-RFLP profiles obtained from a single sample of open canopy (OC) and wooded canopy (WC) pasture diets. Red arrow highlights unique archaeal T-RF's associated with OC and WC pasture diets. 23

Figure 2.7 Unweighted Pair Group Method with Arithmetic Mean (UPGMA) tree of bacterial communities associated with open and wooded canopy pasture. T-RF's generated from Hha I and Rsa I digestion were combined for construction of UPGMA tree.

Figure 2.8 UPGMA tree of archaeal communities associated with open and wooded canopy pasture. T-RF's generated from Hha I and Rsa I digestion were combined for construction of UPGMA tree. 
Figure 2.9 UPGMA tree of bacterial communities associated with different harvest time. T-RF's generated from Hha I and Rsa I digestion were combined for construction of UPGMA tree.

Figure 2.10 Unweighted UniFrac based clustering of bacterial communities associated with different harvest time. UPGMA tree from figure 2.9 was used as an input file for construction of UniFrac tree.

Figure 2.11 UPGMA tree of archael communities associated with different harvest time. T-RF's generated from Hha I and Rsa I digestion were combined for construction of UPGMA tree.

Figure 2.12 Unweighted UniFrac based clustering of archaeal communities associated with different harvest time. UPGMA tree from figure 2.11 was used as an input file for construction of UniFrac tree.

Figure 2.13 UPGMA tree of bacterial communities associated with different replications. T-RF's generated from Hha I and Rsa I digestion were combined for construction of the UPGMA tree.

Figure 2.14 Unweighted UniFrac based clustering of bacterial communities associated with different replications. UPGMA tree from figure 2.13 was used as an input file for construction of the UniFrac tree.

Figure 2.15 UPGMA tree of archaeal communities associated with different replications. T-RF's generated from Hha I and Rsa I digestion were combined for construction of the UPGMA tree. 34

Figure 2.16 Unweighted UniFrac based clustering of Archaeal communities associated with different replications. UPGMA tree from figure 2.15 was used as an input file for construction of the UniFrac tree.

Figure 2.17 Nonmetric multidimensional scaling plot of a.) bacterial and b.) archaeal communities associated with open canopy (oc) and wooded canopy (wc) diets. Presence/absence data of T-RF's generated from Hha I and Rsa I digested PCR products were used for construction of the NMDS plot. 
Figure 2.18 Boxplot of ranked genetic dissimilarity for a.) bacterial and b.) archaeal communities associated with open and wooded canopy diets. Boxes represent median and interquartile ranges

Figure 2.19 Nonmetric multidimensional scaling plot of a.) bacterial and b.) archaeal communities associated with different harvest time. Presence/absence data of T-RF's generated from Hha I and Rsa I digested PCR products were used for construction of the NMDS plot.

Figure 2.20 Boxplot of ranked genetic dissimilarity for a.) bacterial and b.) archaeal communities associated with different harvest time. Boxes represent median and interquartile ranges. $\mathrm{H} 1=$ First harvest; $\mathrm{H} 2=S e c o n d$ harvest; $\mathrm{H} 3=$ Third harvest; $\mathrm{H} 4=$ =Fourth harvest. 40

Figure 2.21 Nonmetric multidimensional scaling plot of a.) bacterial and b.) archaeal communities associated with different replications. Presence/absence data of T-RF's generated from Hha I and Rsa I digested PCR products were used for construction of the NMDS plot.

Figure 2.22 Boxplot of ranked genetic dissimilarity for a.) bacterial and b.) archaeal communities associated with different replications. Boxes represent median and interquartile ranges. $\mathrm{R} 1=$ First replication; R2=Second replication; R3=Third replication.

Figure 3.1 Venn diagram showing shared and unique bacterial T-RF's between naturalized pasture early cut, naturalized pasture late cut, teff, and triticale pasture diets a.) when digested with Hha I, b.) when digested with Rsa I, and c.) when digested with Hae III

Figure 3.2 Comparison of Hha I digested bacterial T-RFLP profiles obtained from a single sample of npec, nplc, teff and triticale pasture diets. Red arrow highlights unique and shared bacterial T-RF's associated with different diets.

Figure 3.3 Venn diagram showing shared and unique archaeal T-RF's between naturalized pasture early cut (npec), naturalized pasture late cut (nplc), teff, and triticale 
pasture diets a.) when digested with Hha I, b.) when digested with Rsa I, and c.) when digested with Hae III.

Figure 3.4 Comparison of Hha I digested archaeal T-RFLP profiles obtained from a single sample of naturalized pasture early cut (npec), naturalized pasture late cut (nplc), teff, and triticale pasture diets. Red arrow highlights unique and shared archael T-RF's associated with different diets.

Figure 3.5 Unweighted Pair Group Method with Arithmetic Mean (UPGMA) tree of bacterial communities associated with different pasture diets. T-RF's generated from Hha I, Rsa I, and Hae III digestion were combined for construction of UPGMA tree. npec $=$ naturalized pasture early cut, $\mathrm{nplc}=$ naturalized pasture late cut, teff $=$ teff grass, and tri $=$ triticale. 58

Figure 3.6 Unweighted Pair Group Method with Arithmetic Mean (UPGMA) tree of archaeal communities associated with different pasture diets. T-RF's generated from Hha I, Rsa I, and Hae III digestion were combined for construction of UPGMA tree. npec $=$ naturalized pasture early cut, $\mathrm{nplc}=$ naturalized pasture late cut, teff $=$ teff grass, and tri $=$ triticale.

Figure 3.7 Unweighted UniFrac based clustering of bacterial communities associated with different diets. UPGMA tree from figure 3.5 was used as an input file for construction of UniFrac tree.

Figure 3.8 Unweighted UniFrac based clustering of archaeal communities associated with different diets. UPGMA tree from figure 3.6 was used as an input file for construction of UniFrac tree.

Figure 3.9 Nonmetric multidimensional scaling plot of a.) bacterial and b.) archaeal communities associated with npec (naturalized pasture early cut), nplc (naturalized pasture late cut), teff (teff grass), and tri (triticale) pasture diets. Presence/absence data of T-RF's generated from Hha I, Rsa I and Hae III digested PCR products were used for construction of the NMDS plot. 62

Figure 3.10 Boxplot of ranked genetic dissimilarity for a.) bacterial and b.) archaeal communities associated with npec (naturalized pasture early cut), nplc (naturalized 
pasture late cut), teff ( teff grass), and tri (triticale) pasture diets. Boxes represent median and interquartile ranges. Circle above box represent outliers......................... 63 


\section{TABLE OF CONTENTS}

ABSTRACT

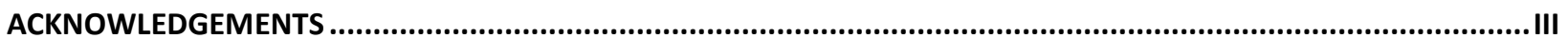

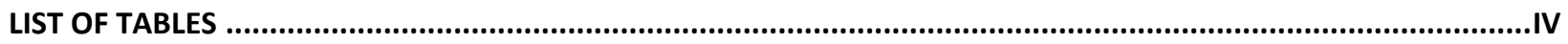

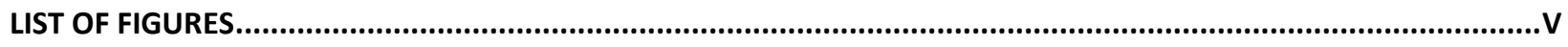

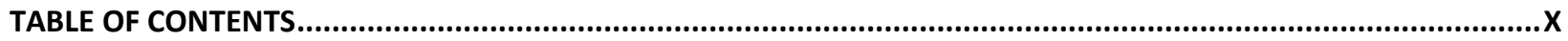

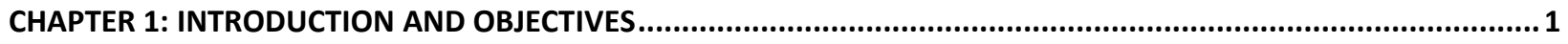

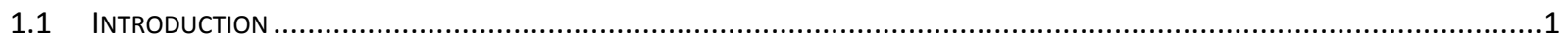

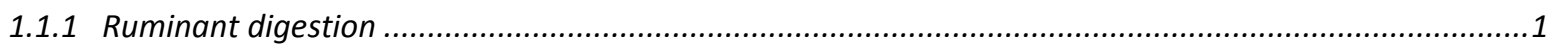

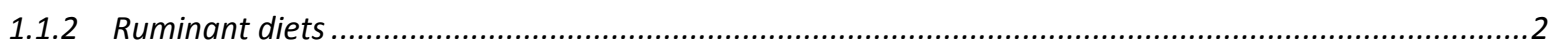

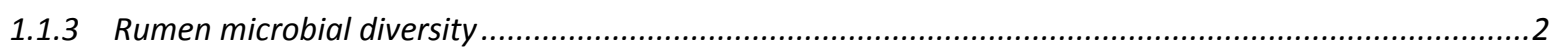

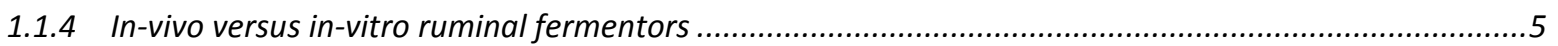

1.1.5 Molecular techniques for the estimation of microbial diversity ......................................................

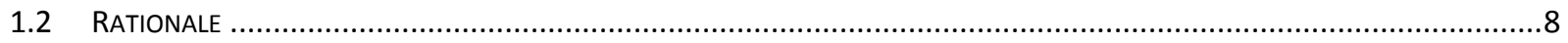

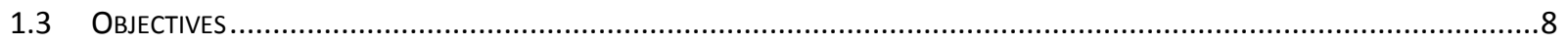

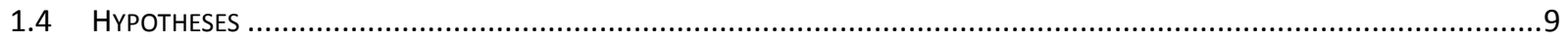

CHAPTER 2: DIVERSITY OF BACTERIAL AND ARCHAEAL POPULATIONS IN ARTIFICIAL RUMEN FERMENTORS FED

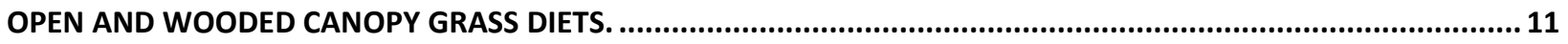

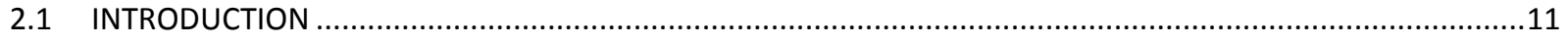

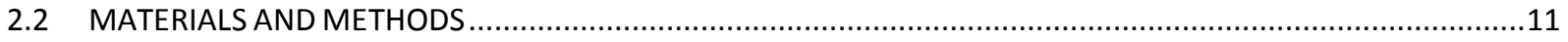

2.2.1 Sample collection / Rumen fermentors .......................................................................................11

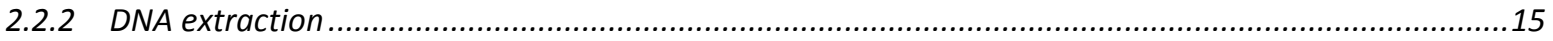

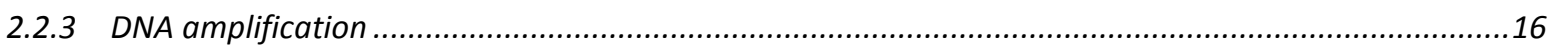

2.2.4 Terminal Restriction Fragment Length Polymorphism (T-RFLP) ...................................................17

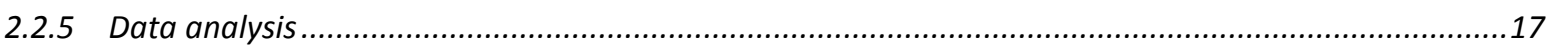

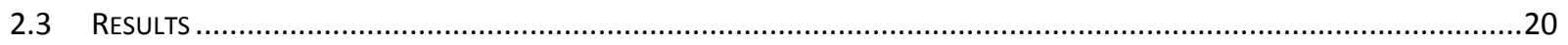

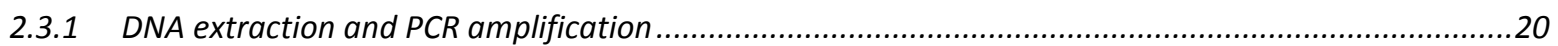

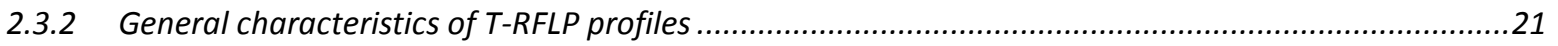

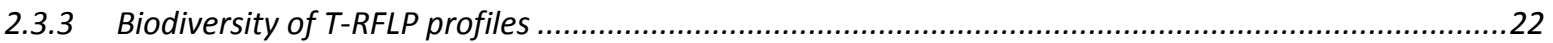

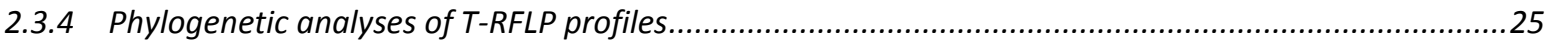

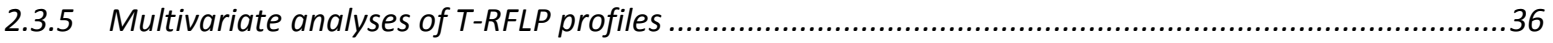

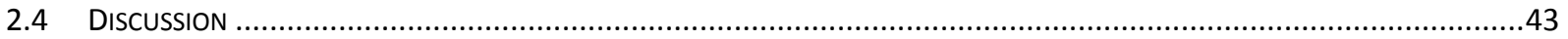


CHAPTER 3: DIVERSITY OF BACTERIAL AND ARCHAEAL POPULATIONS IN ARTIFICIAL RUMEN FERMENTORS FED

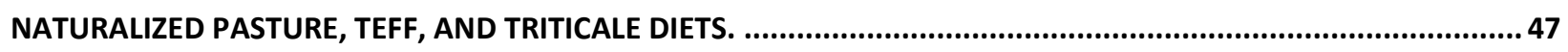

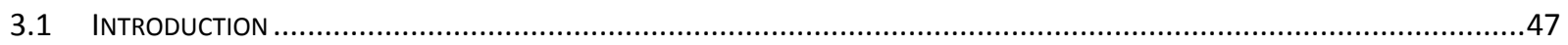

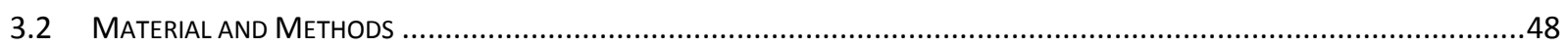

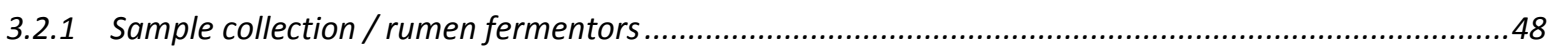

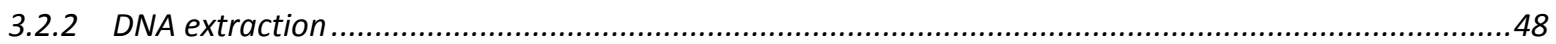

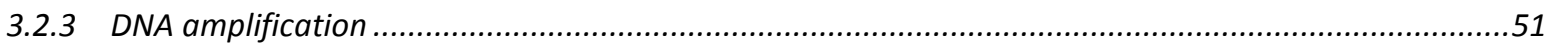

3.2.4 Terminal Restriction Fragment Length Polymorphism (T-RFLP)..................................................51

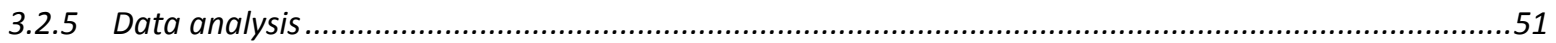

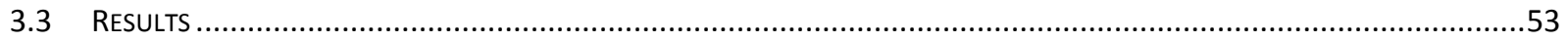

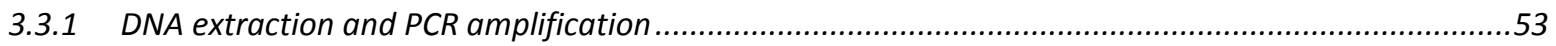

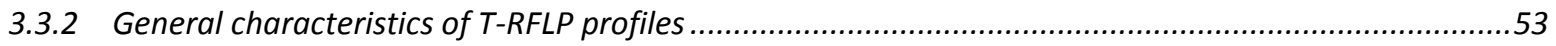

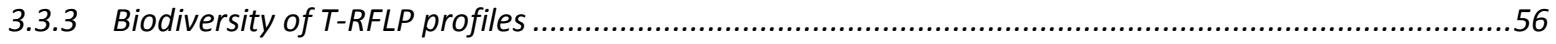

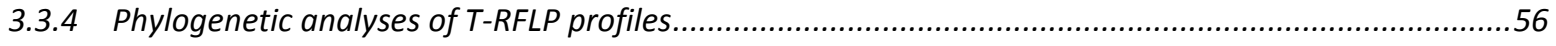

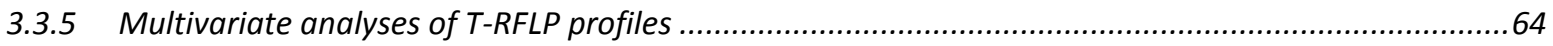

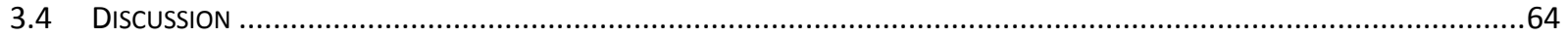

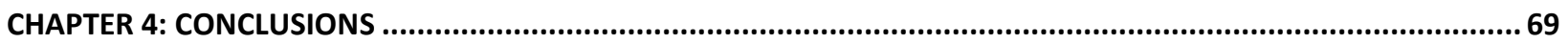

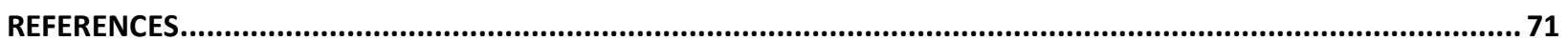




\section{CHAPTER 1: INTRODUCTION AND OBJECTIVES}

\subsection{INTRODUCTION}

\subsubsection{Ruminant digestion}

Ruminants make significant portion of domesticated and wild livestock and play very important role in sustainability of many villages in developing countries. The digestive system of ruminants is unique among mammals because they can efficiently utilize cellulose (Hungate, 1966). Cellulose of plant cell wall constitute more than $50 \%$ of total annual global carbon fixation and hence it is important to understand its efficient utilization (Enquist, et al., 2003). Efficient utilization of cellulose by ruminants is mainly due to their symbiotic relationships with microorganisms (Koike, et al., 2003). Anatomically, the ruminant's digestive system is similar to other mammals except the stomach. A ruminant's stomach has four chambers: rumen, reticulum, omasum, and abomasum. The rumen is the largest compartment (180-240 liters) in cattle and maintains an ideal environment for microbial fermentations (temperature $=38^{\circ} \mathrm{C}-42^{\circ} \mathrm{C}$; $\mathrm{pH}=6.4-7.2$; anaerobic condition) (Bryant, 1959). Microorganisms allow ruminants in digestion and utilization of low quality cellulose rich diets that are generally unsuitable for consumption by other mammals (Hungate, 1966). During the fermentation, cellulose is hydrolyzed to sugar and sugars are converted into volatile fatty acids (VFA): acetate, propionate, and butyrate in decreasing order (Elsden \& Phillipson, 1948). These VFAs are absorbed into bloodstream of the rumen wall and serve as main energy source of the ruminants. Ingested proteins are digested by proteases and peptidases of microbial origin. Fermentation end products are methane and carbon dioxide, which are released 
into atmosphere by eructation. Rumen microbes synthesize many B vitamins and serve as an additional food source for ruminants (Bryant, 1959).

\subsubsection{Ruminant diets}

Ruminants gain energy by utilization of several types of diets such as fresh and conserved forages, straws, grains, and many by-products of agriculture. Carbohydrates (fibrous or non-fibrous) and proteins constitute main component of ruminant's diets and also serves as a substrate for microbial fermentation. Carbohydrate is also main source of fats and sugar in cow milk. Both fibrous and non-fibrous carbohydrates have some advantages and disadvantages. Fibrous carbohydrate (cellulose and hemicellulose) is bulkier and hence its microbial fermentation is slower and it is retained in the rumen for longer period of time. Mature plants have more lignin contents in fiber and hence undergo slower fermentation than young plants. Longer fiber particles stimulate rumination process and hence help in faster fermentation. Non-fibrous carbohydrates (starch) undergo rapid fermentation, improve energy supplies, and determine bacterial protein production in the rumen. However, excess of non-fibrous carbohydrates impede fiber fermentation and hence balance of fibrous and non-fibrous carbohydrate diets is important for proper cattle growth and milk production.

\subsubsection{Rumen microbial diversity}

The numbers and diversity of rumen microorganisms is very high (bacteria: $10^{10}$. $10^{11} / \mathrm{ml}$; 50 genera; >200 species), (archaea: $10^{8}-10^{9} / \mathrm{ml} ; 5$ genera), (protozoan: $10^{4}-$ $10^{6} / \mathrm{ml} ; \approx 25$ genera), (fungi: $10^{3}-10^{5}$ zoospores $/ \mathrm{ml} ; 5$ genera), and (bacteriophage: $10^{8}$ - 10 $/ \mathrm{ml}$ ) (Bryant, 1959, Hobson, 1989, Miron, et al., 2001, Kamara, 2005, Kumar, et al., 
2009). The majorities of microbial populations are strictly obligate anaerobes and ciliate protozoan's which plays an important role in ruminant's digestion.

In terms of number, bacteria occupy the top position and are the most investigated micro-fauna of rumen (Fernando, et al., 2010). In general, rumen bacterial population are dominated by cellulolytic (Fibrobacter succinogenes, Ruminococcus spp., Clostridium sp., Eubacterium sp., Butyrivibrio fibrosolvens etc.) and amylolytic (Streptococcus bovis, Ruminobacter amylophilus, Prevotella ruminicola etc.) bacteria (Kamara, 2005). Mechanism of cellulose digestion is very different in Fibrobacter succinogenes and Ruminococcus spp. Ruminococcus produces both exoglucanases and endoglucanases which act together for cellulose digestion. Ruminococcus also produces multiprotein complexes cellulosome which acts as a facilitator for attachment of cellulases and bacterial cells to cellulose. Cellulose digestion process is different in F. succinogenes because they neither exhibit exoglucanese or cellulosome. Apart from these bacteria, there are group of bacteria in the rumen that helps in nitrogen utilization (Megasphaera elsdenii) and lipid degradation (Anaerovibrio lipolytica) (Kamara, 2005).

Among archaea seven species of methanogens (Methanobacterium formicicum, Methanobacterium bryanti, Methanobrevibacter ruminantium, Methanobrevibacter smithii, Methanomicrobium mobile, Methanosarcina barkeri and Methanoculleus olentangyi) have been reported (Joblin, et al., 1990, Jarvis, et al., 2000). Methanogens helps in making rumen fermentation a continuous process by consuming the fermentation products $\mathrm{H}_{2}$ and $\mathrm{CO}_{2}$. To get a continuous supply of $\mathrm{H}_{2}$, many rumen methanogens live in an epi- or endo-symbiotic relationship with rumen ciliated protozoans (Ushida, 2011). 
Although rumen protozoans constitute more than $50 \%$ of ruminal biomass and play an important role in ruminant's digestion by fermentation, they are not very critical for survival of the ruminants (Russell, 2002, Ushida, 2011). Morphologically rumen's ciliated protozoans have been divided into two types: 1 .) holotrich and 2.) entodiniomorphid. Holotrich protozoans generally help in amylase digestion whereas an entodiniomorphid protozoan generally helps in cellulose and hemicellulose digestion (Mould \& Thomas, 1958, Williams \& Coleman, 1985). Although more than 15 genera of holotrich protozoa are known from different ruminants, Isotricha and Oligoisotricha are commonly encountered holotrich protozoans in cattle's rumen (Clarke, 1964, Dehority, et al., 1983, Kamara, 2005). There are several known genera of entodiniomorphid protozoans from ruminants rumen but species belonging to genera Entodinium, Ostracodinium, Polyplastron, Metadinium, Epidinium etc. are commonly encountered in cattle's rumen (Kamara, 2005).

Rumen fungi play an important role in fiber digestion of the ruminants (Kamara, 2005). The first confirmed existence of fungi in rumen was reported by Orpin in midseventies (Orpin, 1975). Since then several genera of fungi have been reported from various ruminants. Species belonging to genera Neocallimastrix, Sphaeromonas, Orpinomyces, Anaeromyces, Ruminomyces etc. are commonly encountered in cattle's rumen (Kamara, 2005). Bacteriophages are present in large number in rumen. They lyse rumen bacterial cells and hence helps ruminant by providing readily available bacterial proteins (Kamara, 2005). 


\subsubsection{In-vivo versus in-vitro ruminal fermentors}

In past, most studies on ruminal system were carried-out with fistulated animals (Clarke \& Menna, 1961, Emmanuel, 1974, Lund, 1974). These studies were expensive, laborious, and not strictly controlled because of the complexity of rumen system. Use of in-vitro rumen fermentors gained popularity during last few decades (Fellner, et al., 1997, Cardozo, et al., 2004, Busquet, et al., 2005, Carro, et al., 2009), mainly because of the above reasons and also because of increased awareness among scientist on ethical use of animals in research. There are several types of in-vitro rumen fermentors, but two most common one are continuous-flow fermentors (Hoover, et al., 1976) and semi-continuous Rusitec fermentors (Czerkawski \& Breckenridge, 1977). Both systems have some advantages and disadvantages. Continuous-flow fermentors allow higher dilution rates, feeding rates and feeding frequencies than Rusitec fermentors but are less efficient in protozoan population maintenance (Czerkawski \& Breckenridge, 1977, Carro, et al., 2009). In-vitro rumen fermentors generally give reasonable estimate of rumen fermentation. Hannah et al. (1986) observed similar organic matter digestibility, amino acid and crude protein degradability when they compared in-vitro rumen fermentors with in-vivo rumen fermentation.

\subsubsection{Molecular techniques for the estimation of microbial diversity}

As discussed above, microbes in the rumen are diverse and are very important for efficient utilization of nutrients from ruminant's diet. Traditional culture based techniques are not suitable for precise estimation of rumen microbial diversity because many rumen microbes are un-culturable (Liu, et al., 1997, Fernando, et al., 2010). Even for those that can be cultured, there is a possibility of an error because many species 
(Prevotella ruminicola, Butyrivibrio fibrisolvens and Ruminococcus) although diverse looks morphologically and biochemically very similar (Kamara, 2005) and there is a chance that change in environmental condition from original during cultivation may alter bacterial community structure (Liu, et al., 1997). To overcome the limitations of culture based methods, several culture-independent methods have been proposed for estimation of microbial diversity. The most important among them are 16S rDNA cloning and sequencing (Bond, et al., 1995), denaturing gradient gel electrophoresis (DGGE) (Muyzer, et al., 1993, Kocherginskaya, et al., 2001), restriction fragment length polymorphism (RFLP) (Avgustin, et al., 1994), and terminal restriction fragment length polymorphism (T-RFLP) (Liu, et al., 1997, Ridwan, et al., 2009).

$16 \mathrm{~S}$ rDNA library cloning and sequencing is a culture independent method but construction and screening of bacterial clones are very time consuming and labor intensive (Liu, et al., 1997).

DGGE is a culture and cloning independent electrophoresis based method which uses PCR amplified 16S rRNA gene for microbial profiling. Because DGGE gel contain denaturing reagent in increasing concentration towards the anode it helps in separation of $16 \mathrm{~S}$ rDNA pcr product of similar size based on sequence heterogeneity and hence helps in microbial diversity estimation. It also helps in identification of dominant microbes because thick bands can be easily excised from the gel and then can be sequenced for microbial identity. DGGE is easy, fast, and comparatively cheap method. Main disadvantages of DGGE are poor resolution of the band on the gel and overlapping of faint bands by thick bands in some cases. 
RFLP is an easy culture, cloning and sequencing independent method, where 16S rDNA are amplified using universal primers and then digested with different restriction enzymes for the microbial profiling using gel electrophoresis. RFLP analyses produces large number of bands on polyacrylamide gels, which can be used for differentiation of microbial communities associated with different environments, but RFLP have limited use if one want to know a specific phylogenetic groups associated with a particular environment or species richness or evenness.

T-RFLP is culture, cloning and sequencing independent microbial profiling method like RFLP, but in this method either one or both primers are fluorescently labeled which helps in tracking of terminal fragments and hence in species identification. In T-RFLP method, DNA are PCR amplified for 16S rRNA gene using universal primers, amplified products are cleaned and digested by different restriction enzymes, digested products are separated using capillary electrophoresis. Because primers are fluorescently labeled, only terminal fragments are visible on electropherogram. Size of different terminal fragments are calculated based on fluorescently labeled DNA ladder of known sizes that are run along with the digested products. Software generated T-RFLP profile helps in comparison between samples both in terms species richness (presence or absence of a peaks) and species abundance (relative intensity of peaks from the T-RFLP profiles can be used for estimation of abundance of each terminal fragments in the sample). T-RFLP is highly adaptable, fast and reproducible method (Osborn, et al., 2000). In some cases different species may produce terminal fragments of same size which may cause underestimation of microbial diversity (Engebretson \& Moyer, 2003). Many studies have 
used T-RFLP method for microbial diversity estimation (Liu, et al., 1997, Nagashima, et al., 2003, Danovaro, et al., 2006, Singh, et al., 2006, Ridwan, et al., 2009).

\subsection{RATIONALE}

As discussed above, in the last 50 years, our understanding of ruminant's digestion and nutritional requirements have significantly improved and these scientific discoveries have been utilized by farmers for better nutritional management of ruminants (Krause, et al., 2003). Microorganism plays very important role in efficient utilization of nutrients for ruminants. Microbial composition of rumen generally changes with diet and sometimes abrupt change in diet can cause adverse effects on ruminants. This study will be carried out to see if most commonly used local pasture has any effect on bacterial and archaeal diversity. We chose only bacteria and archaea for this study because they are the most abundant micro-fauna in the rumen and play very significant role in ruminant digestion. Protozoan's are very unstable in artificial rumen fermentors and hence were not considered in this study. We chose open (100\% sunlight) and wooded (shaded) canopy forage diets for first experiment (chapter 2), because with shading nutritive value of forage improves and we wanted to know if it has any effect on microbial diversity. We chose naturalized pasture (early and late cut) and supplemental grasses (teff, triticale) in the second study (chapter 3) because they have different nutritive quality and we wanted to know if that has any effect on bacterial and archaeal composition in rumen.

\subsection{OBJECTIVES}

Main objective of this study are to:

i.) standardize T-RFLP method for estimation of microbial diversity, 
ii.) estimate bacterial diversity of artificial rumen digester fed with differing pasture diet (open canopy pasture, wooded canopy pasture, naturalized pasture early cut, naturalized pasture late cut, teff and triticale)

iii.) estimate archaeal diversity of artificial rumen digester fed with differing pasture diet (open canopy pasture (OC), wooded canopy pasture(WC), naturalized pasture early cut (NPEC), naturalized pasture late cut (NPLC), teff and triticale).

To accomplish these objectives, I used T-RFLP fingerprinting method, which has several advantages over currently available cloning, culture based and culture independent methods (see above). Main limitation of this method is underestimation of microbial diversity mainly because a.) different microbes may have conserved terminal restriction sites which will lead to similar terminal fragments for different organisms, and b.) T-RFLP is a PCR based method that utilizes conserved primers, it is possible that some microbe may not get amplification because of difference is conserved primer site in these taxa. Next-generation pyrosequencing of $16 \mathrm{~S}$ rDNA can solve first problem of conserved restriction sites in different taxa, but it is still very expensive and require more technical manpower in data analyses.

\subsection{HYPOTHESES}

My hypotheses are:

i.) Open canopy and wooded canopy pasture diet will have different bacterial and archaeal population structure and diversity.

ii.) NPEC and NPLC pasture will have significantly different bacterial and archaeal community structure 
iii.) Diet pair NPLC -Triticale and NPEC-Teff will have similar bacterial and archaeal composition because of similarity in their nutritive quality. 


\section{CHAPTER 2: DIVERSITY OF BACTERIAL AND ARCHAEAL POPULATIONS IN ARTIFICIAL RUMEN FERMENTORS FED OPEN AND WOODED CANOPY GRASS DIETS.}

\section{$2.1 \quad$ INTRODUCTION}

Approximately $40 \%$ of farmland in Appalachian region is occupied by woodlots. Forage production in these woodlots will save ever-shrinking agricultural land for farming purposes and will provide additional income to the farmers. Presence of trees creates shaded area which in turn changes morphology, anatomy, and chemical composition of forage grass and affects both quality and quantity of forage (Kephart \& Buxton, 1993, Lin, et al., 2001). Shaded grass have increased leaf area ratio (LAR), deceased specific leaf weight (SLW), decreased cell wall concentration, increased stem length, higher nitrogen concentration, increased crude protein (CP) and increased digestible dry matter compared to non-shaded or open (100\% sun-light) grasses (Kephart, et al., 1992, Kephart \& Buxton, 1993, Lin, et al., 2001). Kephart and Buxton (1993) observed decrease in neutral detergent fiber (NDF) whereas Lin et al., (2001) observed increase in NDF with shade. These morphological, anatomical and chemical changes increases forage quality of shaded grass compared to non-shaded grass (Kephart \& Buxton, 1993, Lin, et al., 2001). The objective of this study was to evaluate rumen bacterial and archaeal populations associated with change in nutritive quality of open and wooded canopy forage diets.

\subsection{MATERIALS AND METHODS}

2.2.1 Sample collection / Rumen fermentors 
Single-flow continuous culture artificial rumen fermentors (Meng et al. (1999) were used for estimation of bacterial and archaeal diversity associated with open canopy (full sunlight) and wooded canopy (shaded) forage diets. Briefly, an individual fermentor consisted of a 2 liter capacity jar with an effluent outlet at the top, which allowed the fermentor volume to be maintained at $1.46 \mathrm{~L}$ (Figure 2.1). Fermentor temperature was maintained at $39^{\circ} \mathrm{C}$ using a water bath equipped with a thermostatically controlled heater (Model 730, Fisher Scientific, Pittsburgh, PA) and a magnetic stirrer. Rumen fluid from two fistulated Holstein cows was collected and pooled, strained through a layer of cheesecloth, and then added to each of 12 fermentors through their overflow ports. Fermentors were fed $50 \mathrm{~g}$ of dry material (DM) per day at 6 hours intervals. An anaerobic environment similar to rumen was maintained in each fermentor using a continuous supply of carbon dioxide and anaerobic buffer. Buffer solution contained ingredients as described in Slyter (1990) and were delivered continuously to each fermentors by a peristaltic pump (Masterflex model 7520-10, Cole Palmer Instrument Co., Chicago, IL).

Two forage treatments (open canopy pasture and wooded canopy pasture) were harvested at 4 separate times during late April through mid-June, 2008 from pastures located near Beaver, WV. Forages were harvested during weeks of 4/25/08 (harvest 1), 5/5/08 (harvest 2), 5/15/08 (harvest 3), and 6/11/08 (harvest 4) from same open and wooded canopy pastures. Forages from each harvest time were added into two fermentors (replications $1 \& 2$ ) as shown in Table 2.1. Mixture of open canopy and wooded canopy forage diets from each harvest time were added into a single fermentor (replication 3) as shown in Table 2.1. 
Table 2.1 List of samples and their collection details. Each sample had one duplicate sample (not shown in table). Harvest 1, 2, 3 and 4 were conducted on 4/25/08, 5/5/08, 5/15/08, and 6/11/08 respectively.

\begin{tabular}{|c|c|c|c|c|c|c|}
\hline Sr. \# & Sample name & Diet name & Run \# & Fermentor \# & Harvest \# & Replication \# \\
\hline 1 & R1F1 & Open canopy & 1 & 1 & 1 & 1 \\
\hline 2 & $\mathrm{R} 1 \mathrm{~F} 2$ & Wooded canopy & 1 & 2 & 1 & 1 \\
\hline 3 & R1F3 & Open canopy & 1 & 3 & 2 & 1 \\
\hline 4 & $\mathrm{R} 1 \mathrm{~F} 4$ & Wooded canopy & 1 & 4 & 2 & 1 \\
\hline 5 & R1F5 & Open canopy & 1 & 5 & 3 & 1 \\
\hline 6 & R1F6 & Wooded canopy & 1 & 6 & 3 & 1 \\
\hline 7 & $\mathrm{R} 1 \mathrm{~F} 7$ & Open canopy & 1 & 7 & 4 & 1 \\
\hline 8 & R1F8 & Wooded canopy & 1 & 8 & 4 & 1 \\
\hline 9 & $\mathrm{R} 1 \mathrm{~F} 9$ & Open canopy & 1 & 9 & 1 & 2 \\
\hline 10 & $\mathrm{R} 1 \mathrm{~F} 10$ & Wooded canopy & 1 & 10 & 1 & 2 \\
\hline 11 & $\mathrm{R} 1 \mathrm{~F} 11$ & Open canopy & 1 & 11 & 2 & 2 \\
\hline 12 & $\mathrm{R} 1 \mathrm{~F} 12$ & Wooded canopy & 1 & 12 & 2 & 2 \\
\hline 13 & $\mathrm{R} 2 \mathrm{~F} 1$ & Open canopy & 2 & 1 & 3 & 2 \\
\hline 14 & $\mathrm{R} 2 \mathrm{~F} 2$ & Wooded canopy & 2 & 2 & 3 & 2 \\
\hline 15 & R2F3 & Open canopy & 2 & 3 & 4 & 2 \\
\hline
\end{tabular}




\begin{tabular}{|c|c|c|c|c|c|c|}
\hline 16 & $\mathrm{R} 2 \mathrm{~F} 4$ & Wooded canopy & 2 & 4 & 4 & 2 \\
\hline 17 & R2F5 & Open canopy & 2 & 5 & 1 & 3 \\
\hline 18 & R2F6 & Wooded canopy & 2 & 6 & 1 & 3 \\
\hline 19 & R2F7 & Open canopy & 2 & 7 & 2 & 3 \\
\hline 20 & R2F8 & Wooded canopy & 2 & 8 & 2 & 3 \\
\hline 21 & R2F9 & Open canopy & 2 & 9 & 3 & 3 \\
\hline 22 & $\mathrm{R} 2 \mathrm{~F} 10$ & Wooded canopy & 2 & 10 & 3 & 3 \\
\hline 23 & $\mathrm{R} 2 \mathrm{~F} 11$ & Open canopy & 2 & 11 & 4 & 3 \\
\hline 24 & R2F12 & Wooded canopy & 2 & 12 & 4 & 3 \\
\hline
\end{tabular}


Collected samples $(1.2 \mathrm{ml}$ from each fermentor after 10 days of the forage addition) were mixed with $3 \mathrm{ml}$ glycerol and stored at $-20^{\circ} \mathrm{C}$ till further processing.

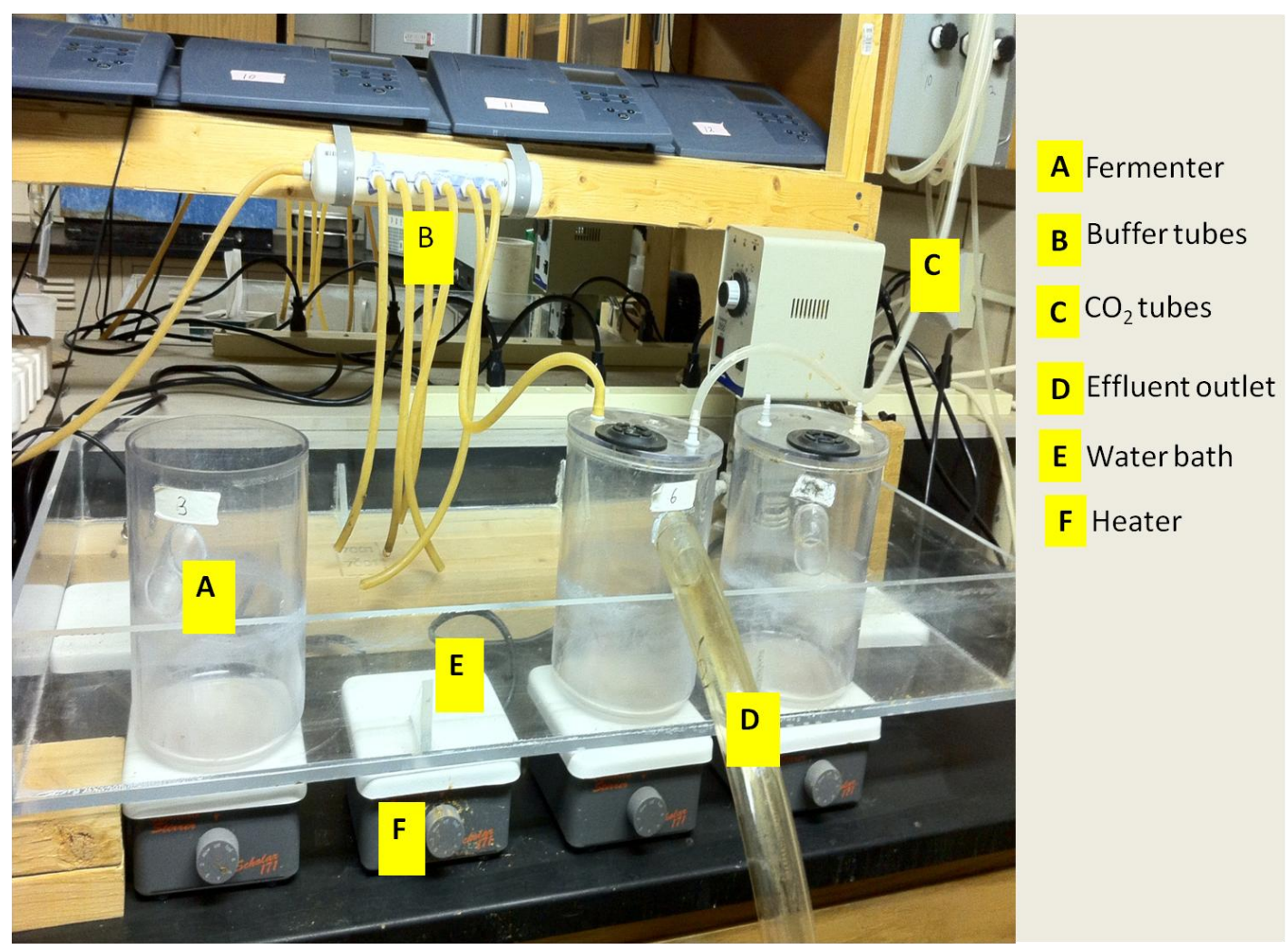

Figure 2.1 In-vitro single-flow continuous culture system.

\subsubsection{DNA extraction}

Glycerol preserved rumen samples were mixed with $10 \mathrm{ml}$ of $5 \%$ sodium chloride solution and then centrifuged at $4^{\circ} \mathrm{C}$ and $4000 \mathrm{rpm}$ for 20 minutes. Centrifuged samples were incubated overnight at $4^{\circ} \mathrm{C}$ and then supernatant was discarded. Pellet $(250 \mu \mathrm{l})$ from each sample was used for DNA extraction using Power Soil DNA Isolation Kit (Mo Bio Laboratories Inc. CA), following protocol as suggested by the manufacturer. Extracted DNA was quantified using NanoDrop spectrophotometer (Thermo scientific, 
DE, USA) and genomic DNA quality was checked on $1 \%$ agarose gel with $2 \mu$ of extracted DNA in each well.

\subsubsection{DNA amplification}

Approximately 1325 bp of bacterial $16 \mathrm{~S}$ ribosomal RNA (16S rRNA) gene was amplified using 6-carboxyfluoscein (6-FAM) labeled forward primer 63f (5'CAGGCCTAACACATGCAAGTC-3') and unlabeled reverse primer1387r (5'GGGCGGWGTGTACAAGGC-3'), as mentioned in Marchesi et al. (1998). Each PCR reaction consisted of $2 \mu \mathrm{l}$ of template DNA (10-20 ng/ul), $5 \mu \mathrm{l}$ of 10X PCR buffer, $4 \mu \mathrm{l}$ of $25 \mathrm{mM} \mathrm{MgCl} 2,1.5 \mu \mathrm{l}$ of $10 \mathrm{mM}$ dNTP's, $2 \mu \mathrm{l}$ of each primer $(20 \mathrm{pmol} / \mu \mathrm{l}), 1.0 \mu \mathrm{l}$ of Taq polymerase $(1 \mathrm{U} / \mu \mathrm{l})$, and rest water to make $50 \mu$ total volume. Bacterial $16 \mathrm{~S}$ rRNA gene was amplified using touchdown PCR protocol in Thermo Hybaid thermocycler (Thermo Scientific, DE, USA). DNA was initially denatured at $94^{\circ} \mathrm{C}$ for 5 minutes, followed by 7 cycle of $94^{\circ} \mathrm{C}$ for 30 seconds; $61^{\circ} \mathrm{C}$ to $56^{\circ} \mathrm{C}\left(1^{\circ} \mathrm{C}\right.$ decrease with each cycle) for 30 seconds; $72^{\circ} \mathrm{C}$ for 90 seconds, followed by 22 cycle of $94^{\circ} \mathrm{C}$ for 30 seconds; $55^{\circ} \mathrm{C}$ for 30 seconds; $72^{\circ} \mathrm{C}$ for 90 seconds, followed by final extension of $72^{\circ} \mathrm{C}$ for 7 minutes.

Approximately 800 bp of archaeal 16S rRNA gene was also amplified from all samples using 6-FAM labeled forward primer Ar109f (5- AC(G/T)GCTCAGTAACACGT3') and unlabeled reverse primer Ar912r (5'CTCCCCCGCCAATTCCTTTA-3') as mentioned in Devine (2010). Archaeal specific PCR reaction mixture composition was same as bacterial PCR reaction mixture (see above) but instead of $4 \mathrm{ul}, 5 \mathrm{ul}$ of $\mathrm{MgCl}_{2}$ (25 mM) was used. PCR protocol for archaeal 16S rRNA gene was same as mentioned in Devine (2010). 


\subsubsection{Terminal Restriction Fragment Length Polymorphism (T-RFLP)}

Amplified product were cleaned using a QIAquick PCR Purification Kit (Qiagen Inc., CA, USA), and cleaned products were quantified using NanoDrop spectrophotometer (Thermo scientific, DE USA). $500 \mathrm{ng}$ of cleaned PCR product was digested separately in $20 \mu$ total volume by Hha I and Rsa I restriction enzymes, as per manufacturer's protocol (New England Biolabs, MA, USA). $1.5 \mu$ l of digested product was mixed with $0.5 \mu \mathrm{l}$ of LIZ-labeled GS500 internal size standard (Applied Biosystems, CA, USA) and rest Hi-Di formamide (Applied Biosystems, CA, USA) for a total volume of $10 \mu \mathrm{l}$. This mixture was denatured at $95^{\circ} \mathrm{C}$ for 3 minutes, followed by cooling in ice for 5 minutes. Terminal restriction fragments were separated by capillary electrophoresis in ABI 3730x/ genetic analyzer (Applied Biosystems, CA, USA). Terminal fragments from duplicate samples were also run along with the original samples using capillary electrophoresis in ABI 3730xI genetic analyzer (Applied Biosystems, CA, USA).

\subsubsection{Data analysis}

Raw data from capillary electrophoresis were analyzed for T-RFLP profile using GeneMapper® software version 4.0 (Applied Biosystems, CA, USA). Terminal restriction fragments (T-RFs) of size $35 \mathrm{bp}$ to $500 \mathrm{bp}$ were selected manually. Terminal fragment length and height of peaks were treated as number and abundance of bacterial/archaeal phylotypes respectively and, were exported to excel sheet for further analysis. Only those peaks (length and height) were considered true that was present in both original and duplicate samples and rest were deleted from further analysis. Peak length and height from original and duplicate samples were averaged and made one for 
each sample. Presence/absence (1/0) data were created based on average length and average abundance profiles.

Presence/absence data was used for construction of Unweighted Pair Group Method with Arithmetic Mean (UPGMA) tree using default parameters in PAUP* v.4.0b10 (Swofford, 2003). Same UPGMA tree was used as an input tree file for unweighted UniFrac (Lozupone, et al., 2006) based clustering of bacterial and archaeal community associated with different treatments. P-test was performed using 1000 permutations for each pair of samples (diets, harvests, replicates) with Bonferroni correction for multiple comparison and for all samples together in UniFrac (Lozupone, et al., 2006). All trees were edited using FigTree v1.3.1 (http://tree.bio.ed.ac.uk/).

Same presence/absence data was used for construction of analysis of similarity (ANOSIM) and nonmetric multidimensional scaling (NMDS) plot using default parameters of Vegan package in $R$ v. 2.13.0 (R, 2011) (see below for sample R-codes). For ANOSIM, Global R test statistics (which measures strength of the results) was used, where $\mathrm{R}=1$ signifies that two groups have different microbial community, and $\mathrm{R}=0$ signifies that two groups have identical bacterial community structure.

\section{R-code used for ANOSIM and NMDS analyses:}

$>$ library (vegan)

$>$ bac_old = read.table ("C:\|Users $\| S M I T A$

SINGH||Desktop||TAMU||smital|Smita_2012||Research||smita_1_30_12||old|INMDS_ba c_arc_oldllb_old_hha_rsa_nmds.csv",header=T,sep =",")

$>$ bac_old_dist $=$ vegdist (bac_old[,5:180], method = "bray")

>bac_old_anosim = anosim (bac_old_dist, bac_old\$diet, perm=999)

>plot(bac_old_anosim) 
$>$ bac_old_nmds=metaMDS(bac_old[,5:180])

Run 0 stress 0.1169503

Run 1 stress 0.1169506

... procrustes: rmse 0.0005220548 max resid 0.001874143

$\star \star \star$ Solution reached

> plot(bac_old_nmds\$points, type=" $n ")$

$>$ text(bac_old_nmds\$points, labels=bac_old\$Replicate, cex=0.6)

Distinctive peak numbers from each sample were counted as species richness

(S). Abundance profile (height) from each datasets was used for calculation of

Shannon-Wiener diversity $\left(H^{\prime}\right)$, Simpson's diversity (D), Shannon evenness $(E)$ and Simpson evenness $\left(E_{1 / D}\right)$ indices using equations as given below:

$$
\begin{array}{ll}
\mathrm{H}^{\prime} & =-\sum(\mathrm{pi})^{*}(\log 2 \mathrm{pi}) \\
\mathrm{D} & =1-\sum(\mathrm{pi}) 2 \\
\mathrm{E} & =\mathrm{H}^{\prime} / \mathrm{H}_{\max } \\
\mathrm{E}_{1 / \mathrm{D}} & =(1 / \mathrm{D}) / \mathrm{S}
\end{array}
$$

Where,

$$
\begin{aligned}
& \mathrm{Pi}=\text { Proportion of an individual peak height relative to the sum of all peak } \\
& \text { heights. } \\
& \mathrm{S}=\text { Species richness (total number of peaks present in each sample). } \\
& \mathrm{H}_{\max }=\log 2(\mathrm{~S}) .
\end{aligned}
$$

For easy comparison between samples, Simpson's index of diversity (1-D) was calculated instead of the original formulation of the Simpson's index (D), so that the value of the index increases with increasing diversity. 


\section{$2.3 \quad$ RESULTS}

2.3.1 DNA extraction and PCR amplification

DNA concentration ranged from $3 \mathrm{ng} / \mu \mathrm{l}$ to $17 \mathrm{ng} / \mu \mathrm{l}$. Bacterial universal primers yielded PCR product of approximately 1325 bp size (Figure 2.2a), whereas Archaeal universal primer pair yielded PCR product of approximately 800 bp size (Figure 2.2b).

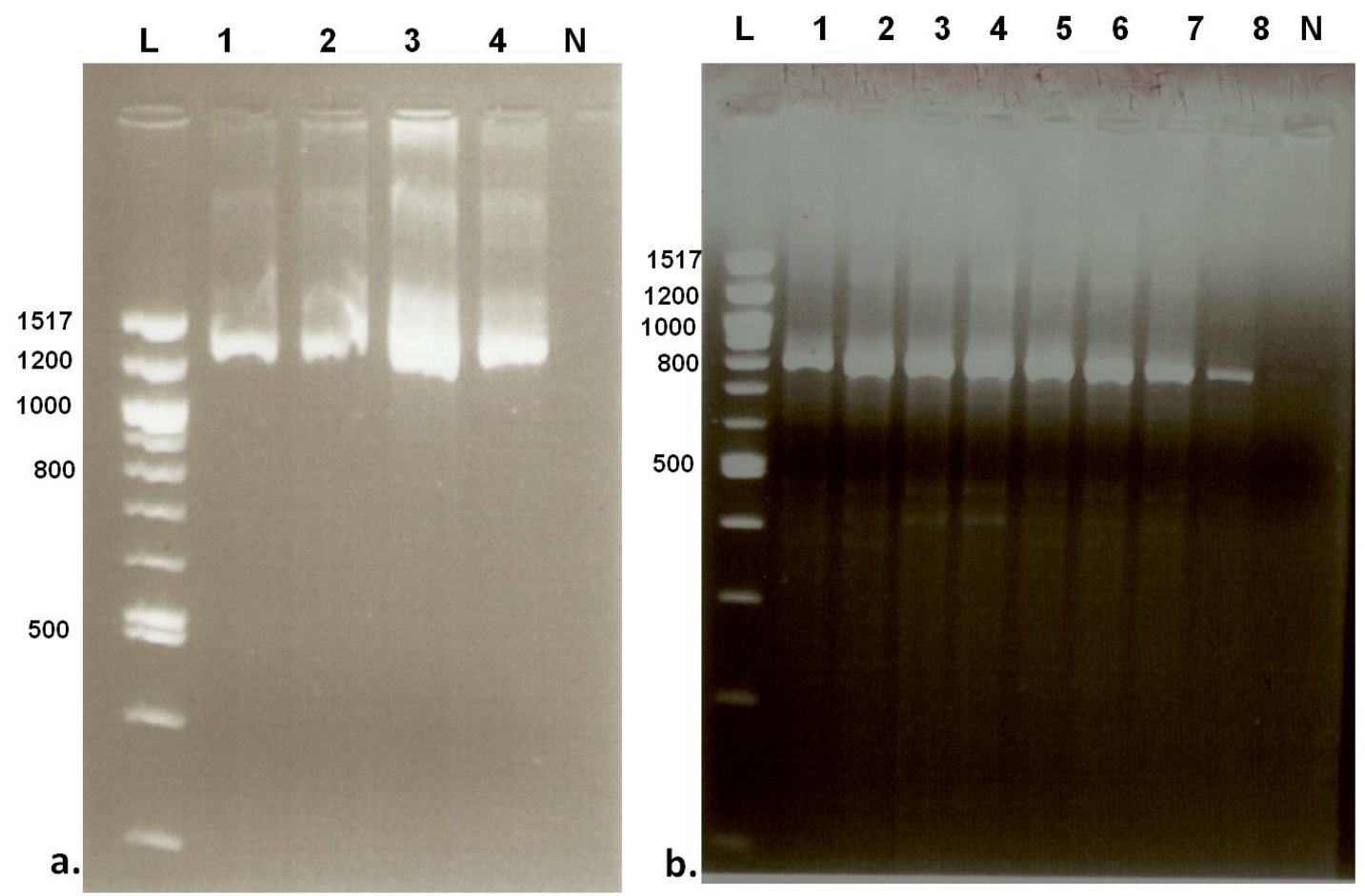

Figure 2.2 Agarose gel electrophoresis image of PCR products obtained using a.) bacterial universal primers and b.) archaeal universal primers. Lane $L=100$ bp DNA ladder from New England Biolabs, lane $\mathrm{N}=$ Negative control. In figure 2.2a, lane $1=R 2 F 4$, lane2 $=R 2 F 4 D$, lane $=R 1 F 12$, lane $4=R 1 F 12 D$ and in figure2.2b lane 1=R2F1, lane2=R2F1D, lane3=R2F2, lane 4=R2F2D, lane5= R2F3, lane6=R2F3D, lane7=R2F4, lane 8=R2F4D.

PCR product from two samples R1F1 and R1F2 using archaeal primers were very weak and didn't yield T-RFLP profile and hence were not used in any analyses. 


\subsubsection{General characteristics of T-RFLP profiles}

A total of 73 and 102 different T-RF's, each representing different bacterial groups, were present in Hha I and Rsa I digested samples respectively. Among Hha I generated fragments, 10 were unique to open canopy and 9 were unique to wooded canopy (Figures.2.3a \& 2.4). Similarly, among Rsa I generated fragments, 16 were unique to open canopy and 9 were unique to wooden canopy fed fermentors (Figs.2.3b).

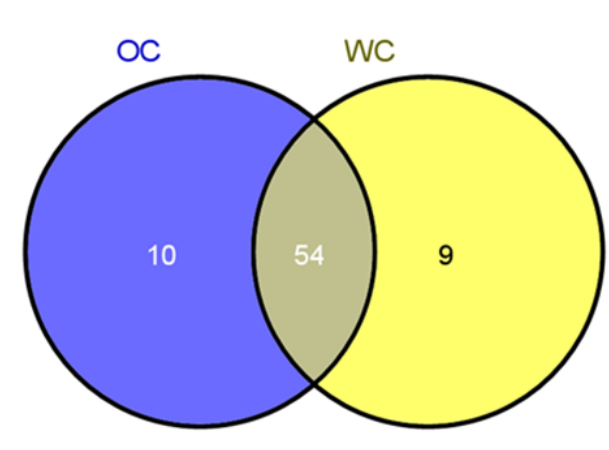

a.

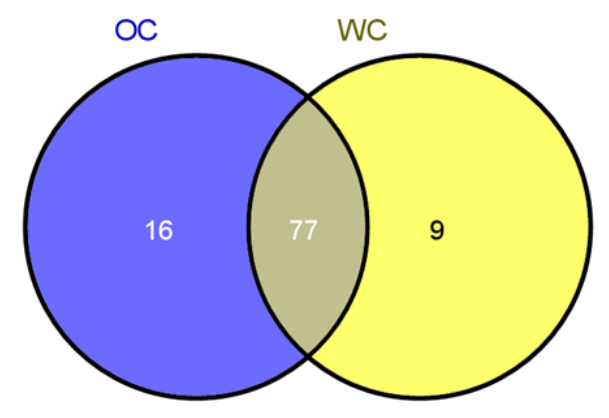

b.

Figure 2.3 Venn diagram showing shared and unique bacterial T-RF's between open canopy (OC) and wooded canopy (WC) pasture diets a.) when digested with Hha I b.) when digested with Rsa I.

PCR product obtained using archaeal primers yielded 42 and 36 T-RF's after digestion with Hha I and Rsa I respectively. Among Hha I generated fragments, 11 were unique to open canopy and 7 were unique to wooded canopy (Figures $2.5 \mathrm{a} \& 2.6$ ). Similarly, among Rsa I generated fragments, 6 terminal fragments were unique to open canopy and 2 terminal fragments were unique to wooded canopy (Figure 2.5b). 


\subsubsection{Biodiversity of T-RFLP profiles}

Shannon-Weiner and Simpson diversity indices were used for determination of bacterial and archaeal diversity associated with open canopy and wooded canopy forage diets. In general open canopy forage diet had higher bacterial and archaeal richness and diversity (both Shannon and Simpson) than wooded canopy forage diets (Table 2.2). Shannon and Simpson evenness indices were almost same for both open and wooded canopy diets.

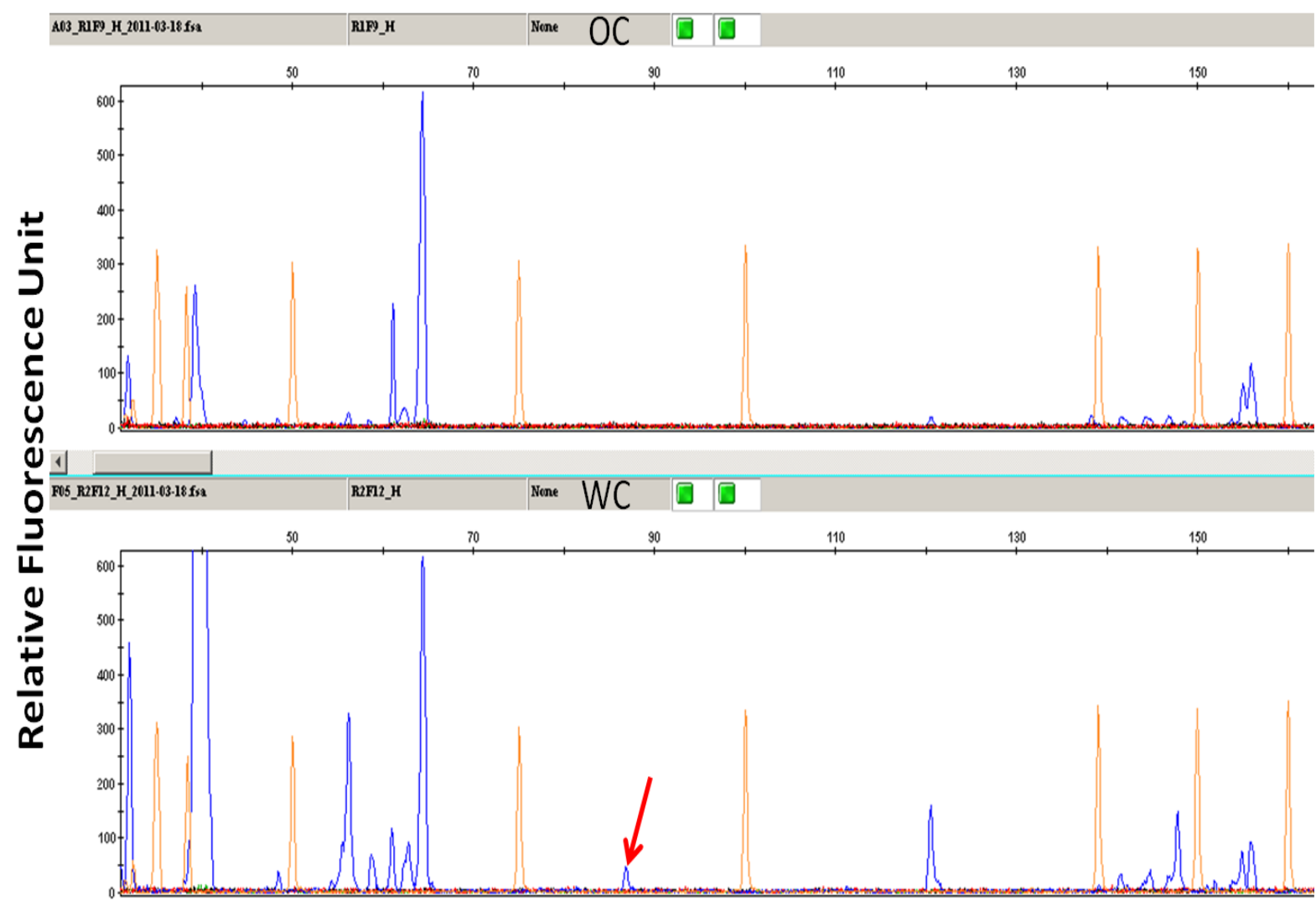

Fragment size (bp)

Figure 2.4 Comparison of Hha / digested bacterial T-RFLP profiles obtained from a single sample of open canopy (OC) and wooded canopy (WC) pasture diets. Red arrow highlight unique bacterial T-RF associated with wooden canopy pasture diets. 


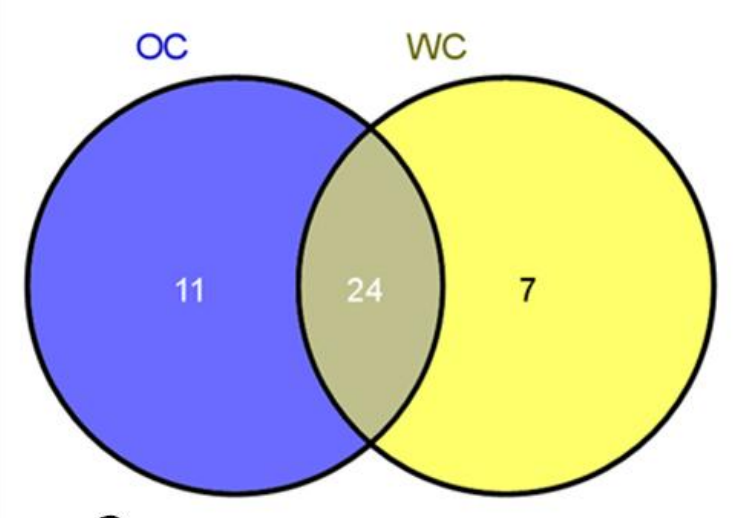

a.

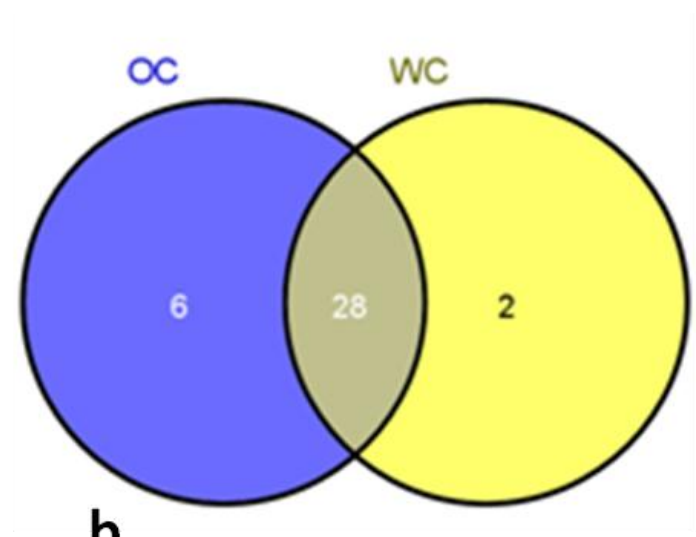

b.

Figure 2.5 Venn diagram showing shared and unique archaeal T-RF's between open canopy (OC) and wooded canopy (WC) pasture diets a.) when digested with Hha I b.) when digested with Rsa I.

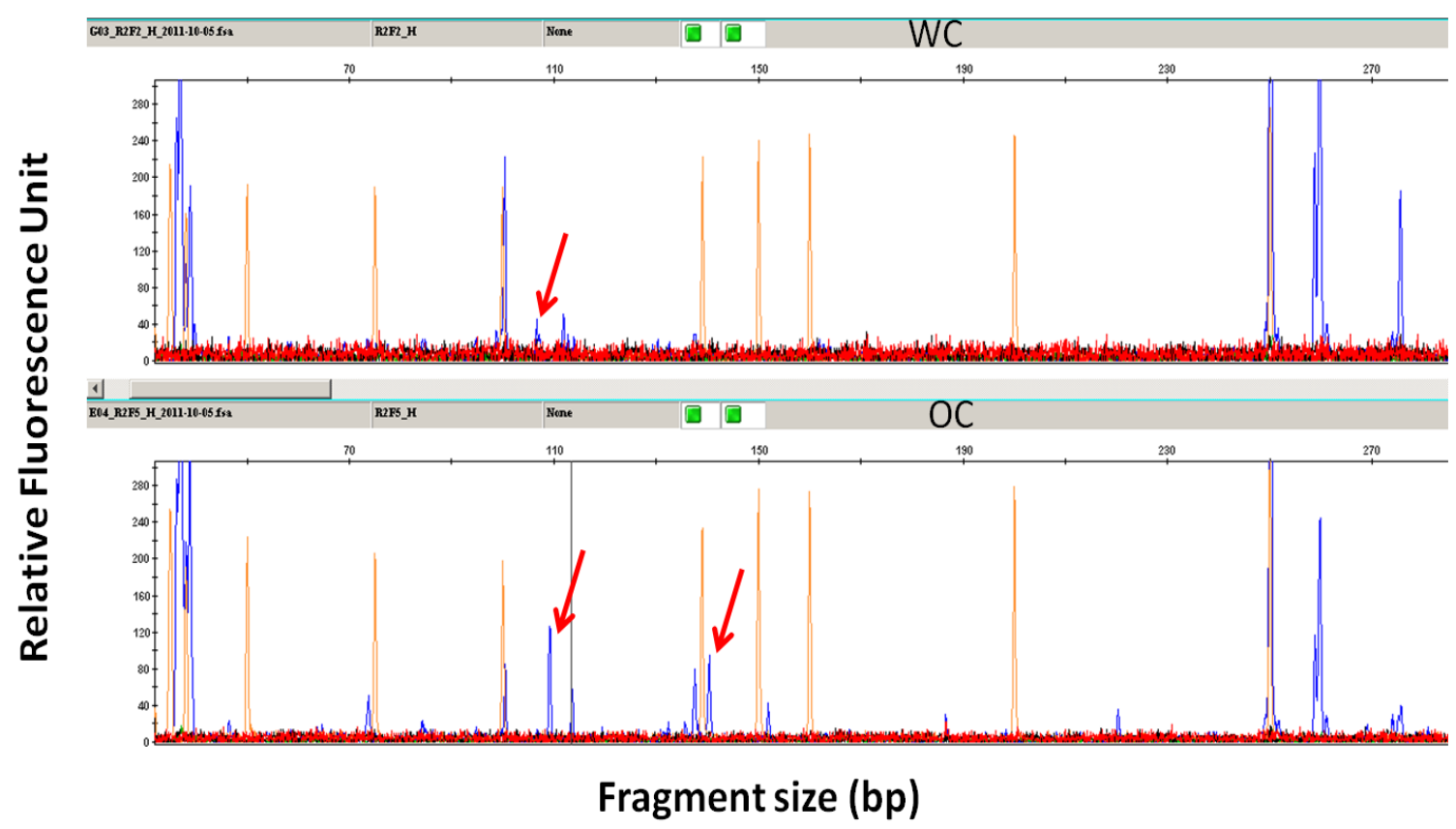

Figure 2.6 Comparison of Hha I digested archaeal T-RFLP profiles obtained from a single sample of open canopy (OC) and wooded canopy (WC) pasture diets. Red arrow highlights unique archaeal T-RF's associated with OC and WC pasture diets. 
Table 2.2 Table showing richness, diversity, and evenness indices of bacterial and archaeal communities associated with open and wooded canopy diets.

\begin{tabular}{|c|c|c|c|c|c|c|c|c|c|c|}
\hline \multirow[t]{2}{*}{ Sample name } & \multicolumn{2}{|c|}{ Richness (S) } & \multicolumn{2}{|c|}{$\begin{array}{l}\text { Shannon } \\
\text { diversity (H') }\end{array}$} & \multicolumn{2}{|c|}{$\begin{array}{l}\text { Simpson's index of } \\
\text { diversity (1-D) }\end{array}$} & \multicolumn{2}{|c|}{$\begin{array}{l}\text { Shannon } \\
\text { Evenness (E) }\end{array}$} & \multicolumn{2}{|c|}{$\begin{array}{l}\text { Simpson's } \\
\text { Evenness (E(1/D)) }\end{array}$} \\
\hline & Hhal & Rsal & Hhal & Rsa I & Hhal & Rsal & Hhal & Rsal & Hhal & Rsal \\
\hline \multicolumn{11}{|l|}{ Bacteria } \\
\hline Open canopy & 26.83 & 32.82 & 3.23 & 3.69 & 0.82 & 0.82 & 0.69 & 0.74 & 0.24 & 0.23 \\
\hline Wooded canopy & 26.42 & 30.09 & 2.97 & 3.37 & 0.79 & 0.76 & 0.65 & 0.69 & 0.19 & 0.22 \\
\hline \multicolumn{11}{|l|}{ Archaea } \\
\hline Open canopy & 11.64 & 11.55 & 2.43 & 2.26 & 0.71 & 0.66 & 0.71 & 0.65 & 0.40 & 0.32 \\
\hline Wooded canopy & 10.55 & 11.18 & 2.29 & 2.29 & 0.69 & 0.67 & 0.70 & 0.68 & 0.42 & 0.37 \\
\hline
\end{tabular}




\subsubsection{Phylogenetic analyses of T-RFLP profiles}

Unweighted Pair Group Method with Arithmetic Mean (UPGMA) tree using combined T-RF's profile from Hha I and Rsa I suggests bacterial and archaeal communities associated with open canopy and wooded canopy pasture diets are not very different (Figures $2.7 \& 2.8$ ).

UniFrac based P-test with Bonferroni correction for multiple comparison suggests that bacterial communities associated with different harvest times are also not significantly different (P-value $>0.1)$. Unweighted UniFrac based clustering of harvest time indicates that first $(\mathrm{H} 1)$ and fourth $(\mathrm{H} 4)$ harvest times have more similar bacterial community structure than either third $(\mathrm{H} 3)$ or second $(\mathrm{H} 2)$ harvest time and $\mathrm{H} 1, \mathrm{H} 4$, and $\mathrm{H} 3$ share more bacterial species with each other than $\mathrm{H} 2$ (Figures 2.9 \& 2.10).

Archaeal communities associated with second harvest time $(\mathrm{H} 2)$ and fourth harvest time $(\mathrm{H} 4)$ were very different $(\mathrm{P}$-value $=0.05-0.1)$, but archaeal communities associated with other harvest times were not significantly different $(P$-value $>0.1)$. Unweighted UniFrac based clustering suggests that first $(\mathrm{H} 1)$ and second $(\mathrm{H} 2)$ harvest times have similar archaeal communities and third $(\mathrm{H} 3)$ and fourth $(\mathrm{H} 4)$ have more similar archaeal communities (Figures $2.11 \& 2.12$ ). 


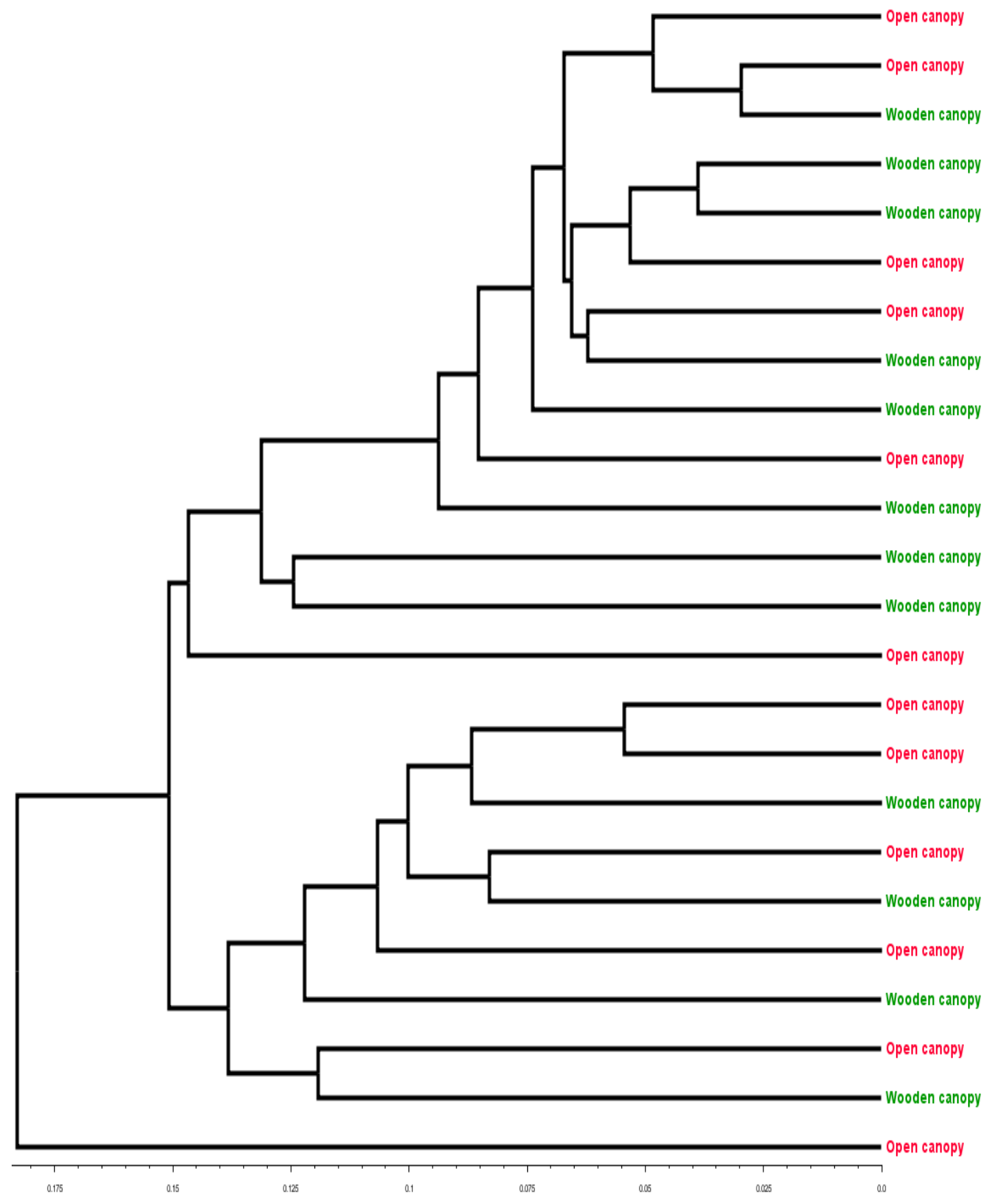

Figure 2.7 Unweighted Pair Group Method with Arithmetic Mean (UPGMA) tree of bacterial communities associated with open and wooded canopy pasture. T-RF's generated from Hha I and Rsa I digestion were combined for construction of UPGMA tree. 


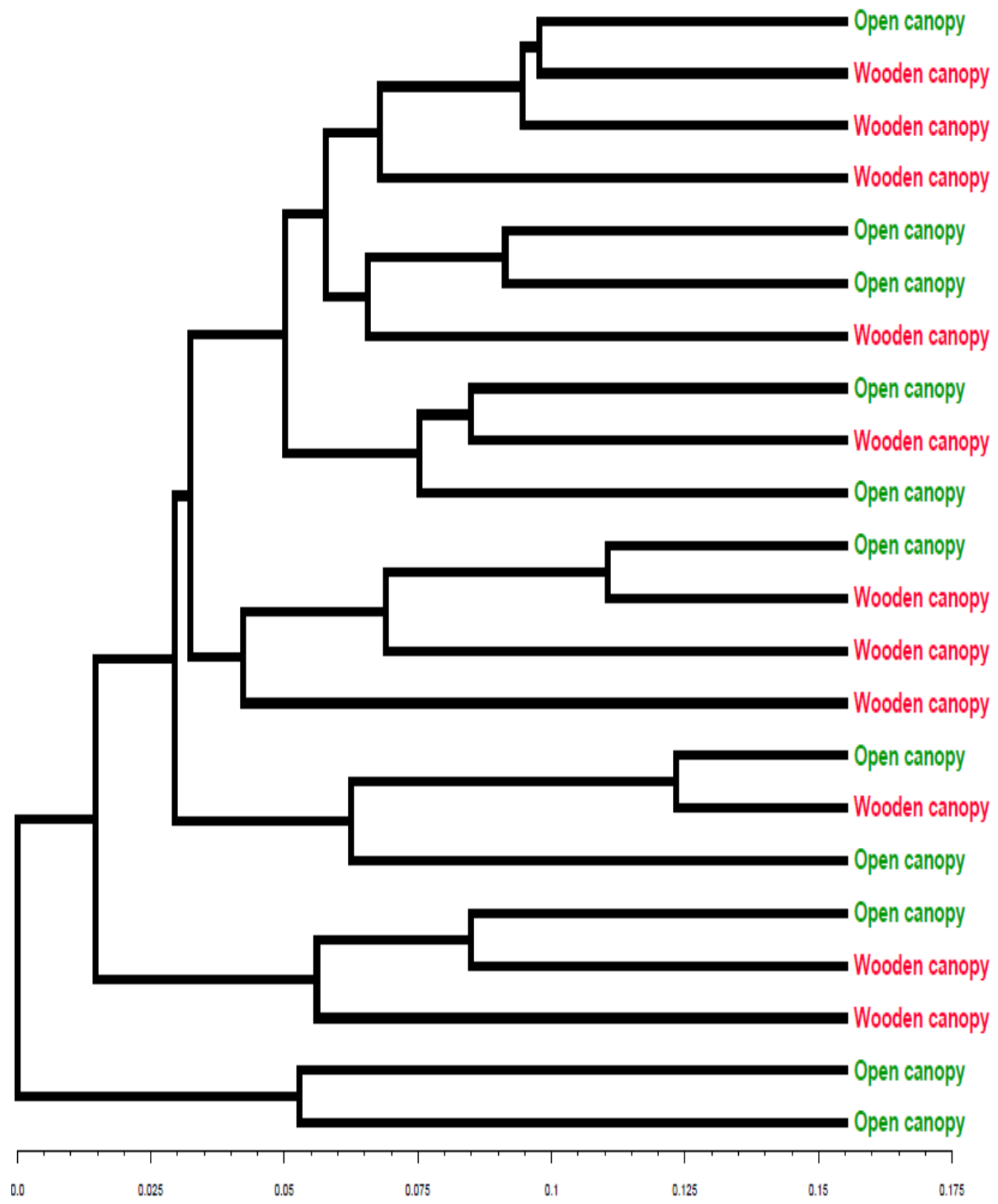

Figure 2.8 UPGMA tree of archaeal communities associated with open and wooded canopy pasture. T-RF's generated from Hha I and Rsa I digestion were combined for construction of UPGMA tree. 


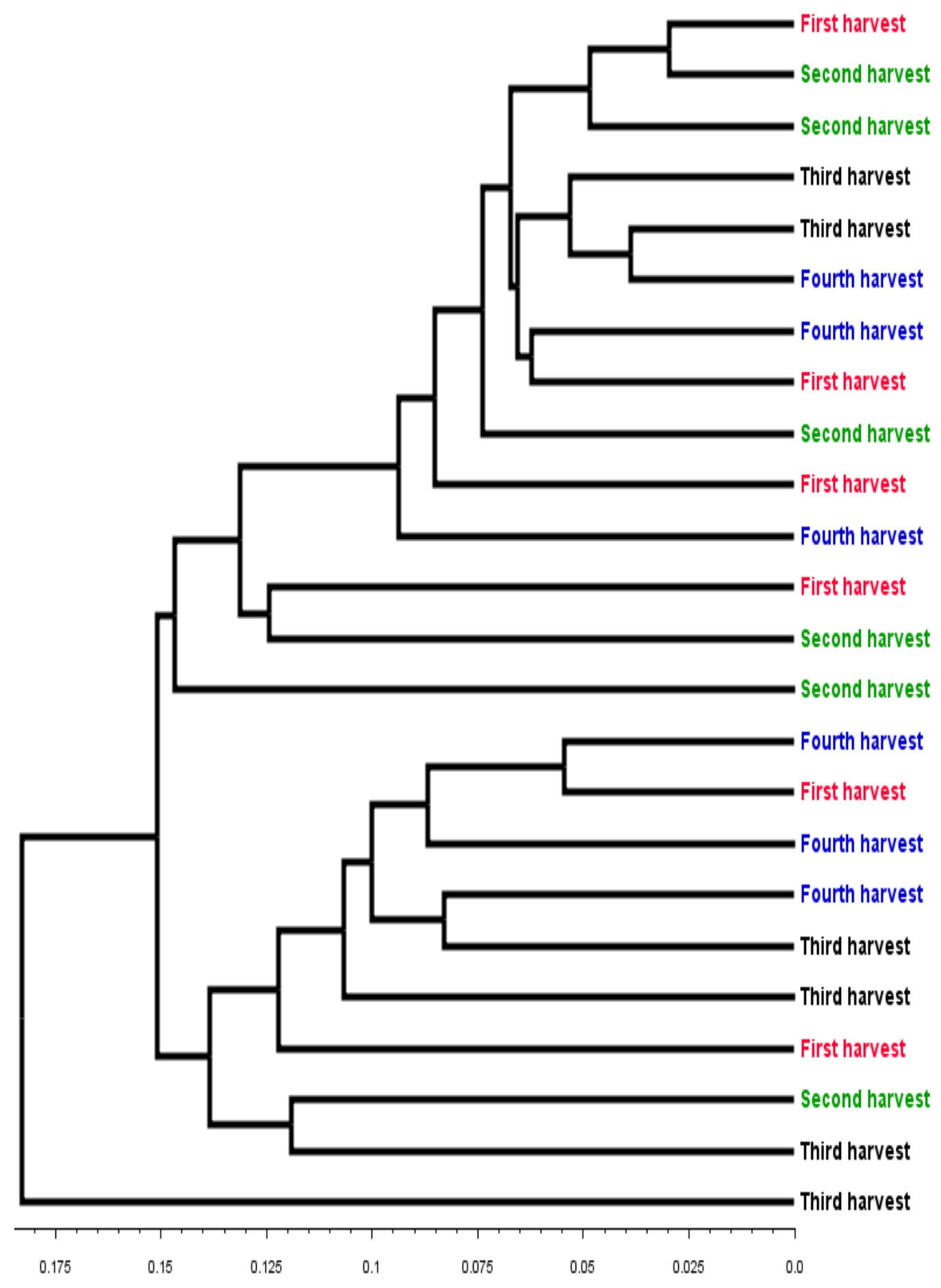

Figure 2.9 UPGMA tree of bacterial communities associated with different harvest time. T-RF's generated from Hha I and Rsa I digestion were combined for construction of UPGMA tree. 
First harvest (H1)

Fourth harvest ( $(\mathrm{H} 4)$

Third harvest (H3)

Second harvest (H2)

1.0

0.1

0.2

0.3

0.4

0.5

Figure 2.10 Unweighted UniFrac based clustering of bacterial communities associated with different harvest time. UPGMA tree from figure 2.9 was used as an input file for construction of UniFrac tree. 


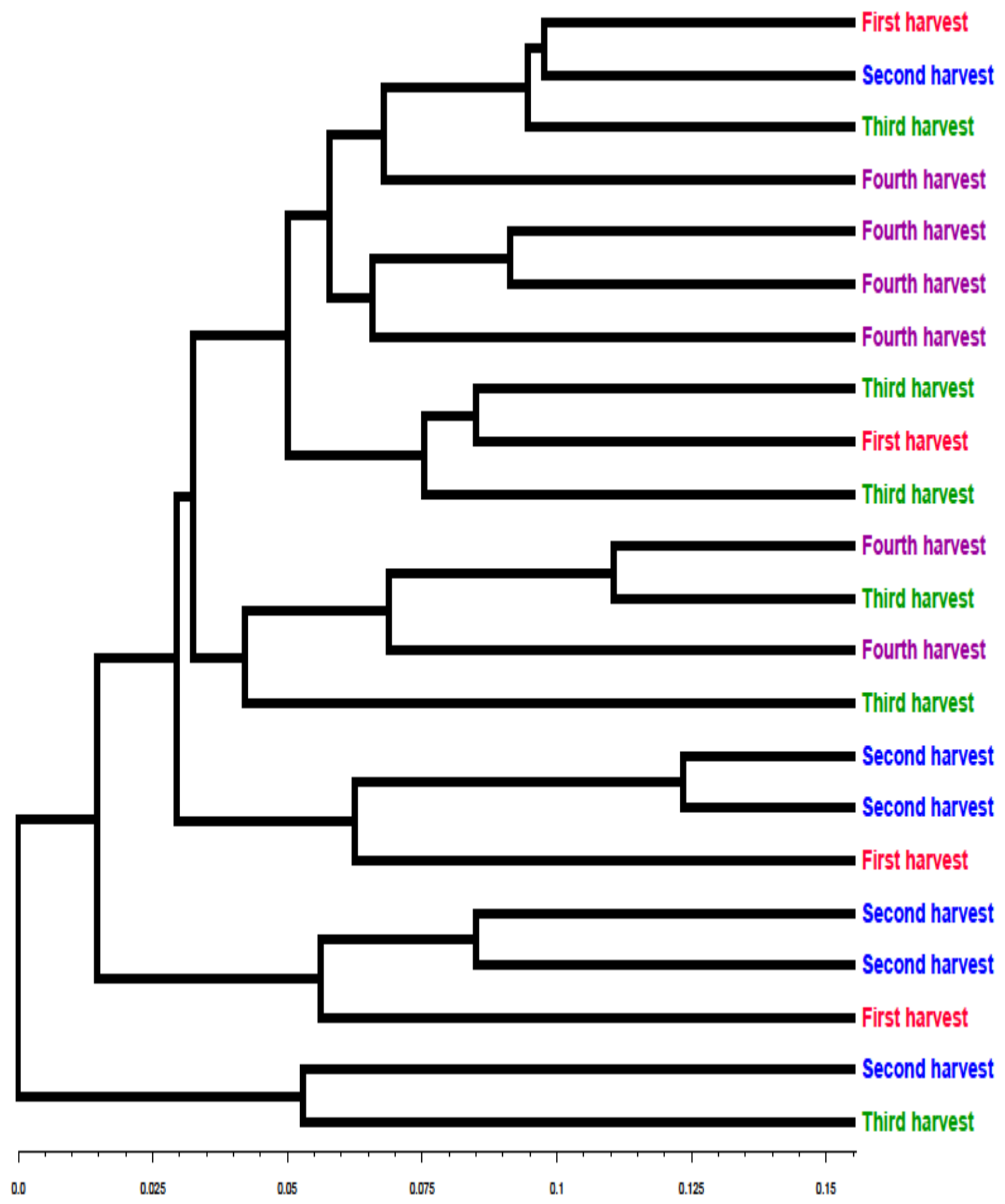

Figure 2.11 UPGMA tree of archael communities associated with different harvest time. T-RF's generated from Hha I and Rsa I digestion were combined for construction of UPGMA tree. 


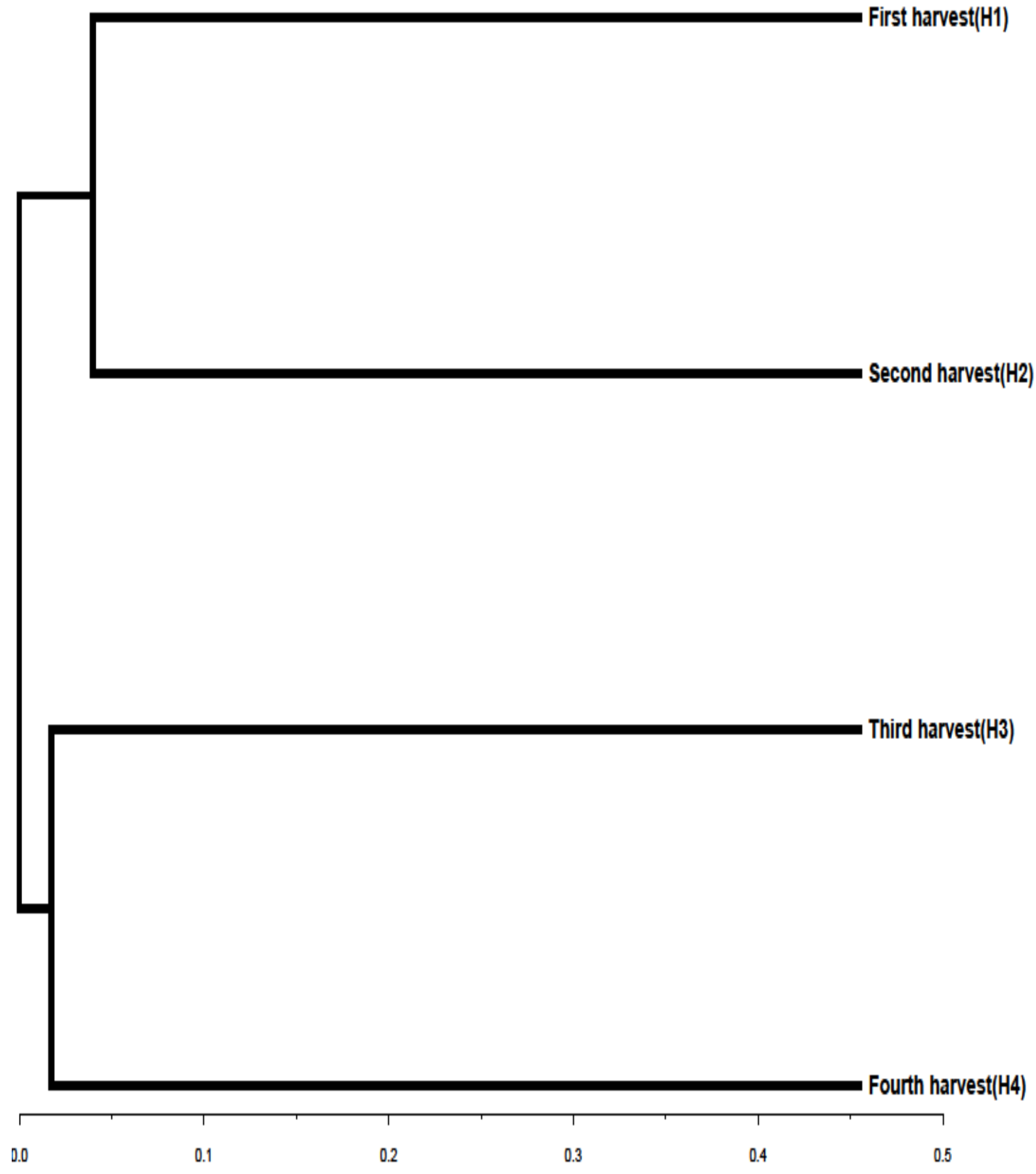

Figure 2.12 Unweighted UniFrac based clustering of archaeal communities associated with different harvest time. UPGMA tree from figure 2.11 was used as an input file for construction of UniFrac tree. 


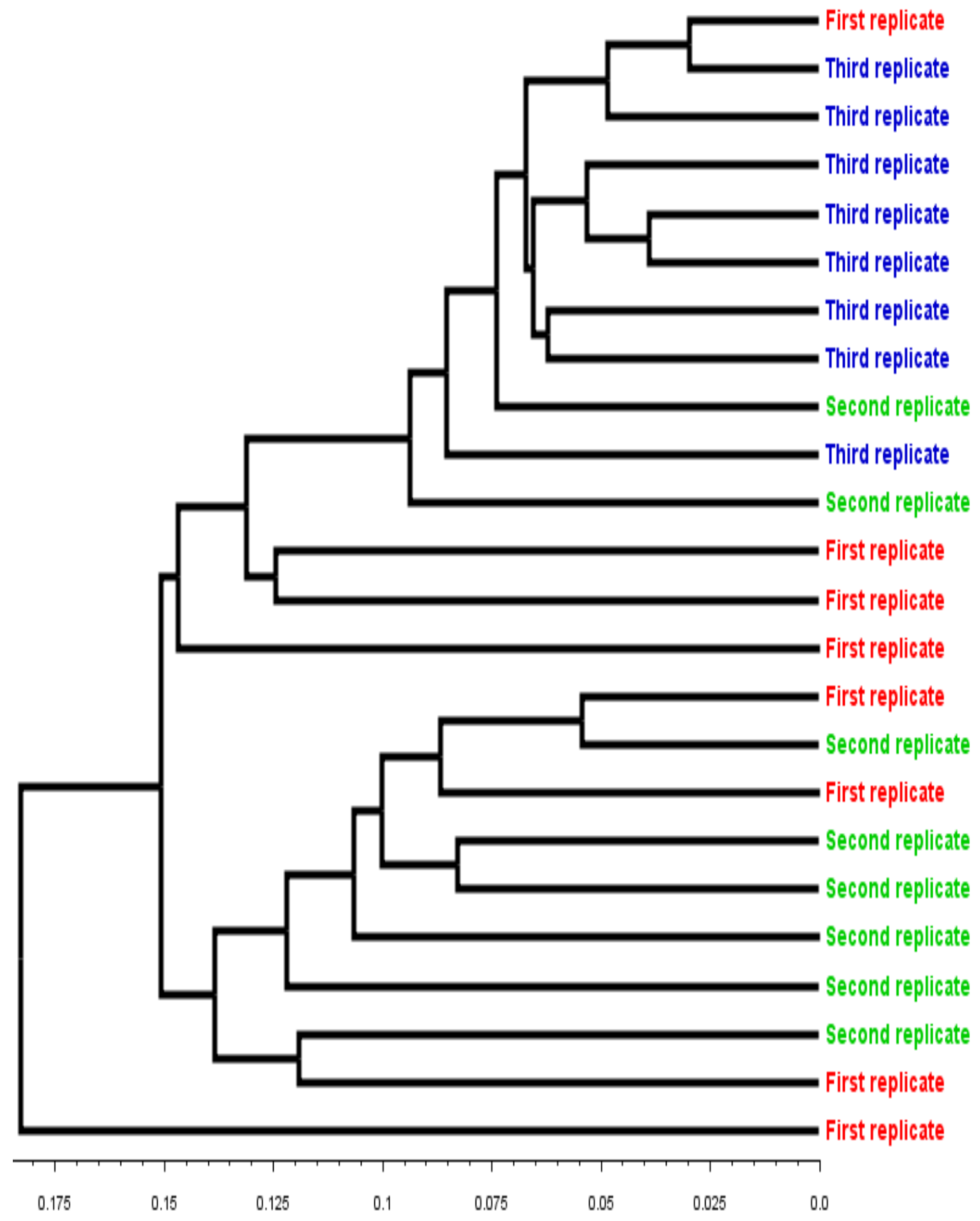

Figure 2.13 UPGMA tree of bacterial communities associated with different replications. T-RF's generated from Hha I and Rsa I digestion were combined for construction of the UPGMA tree. 
Figure 2.14 Unweighted UniFrac based clustering of bacterial communities associated with different replications. UPGMA tree from figure 2.13 was used as an input file for construction of the UniFrac tree. 


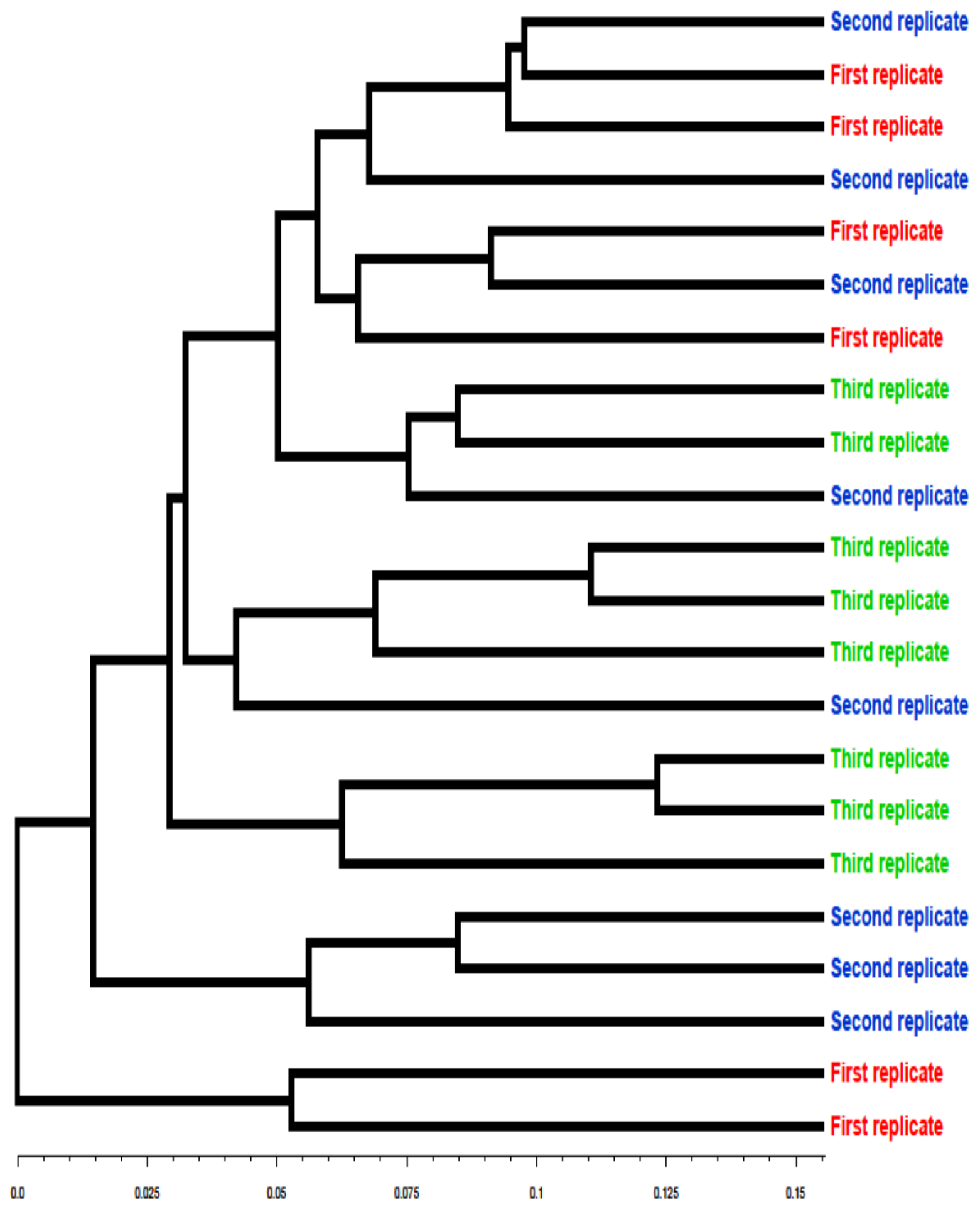

Figure 2.15 UPGMA tree of archaeal communities associated with different replications. T-RF's generated from Hha I and Rsa I digestion were combined for construction of the UPGMA tree. 


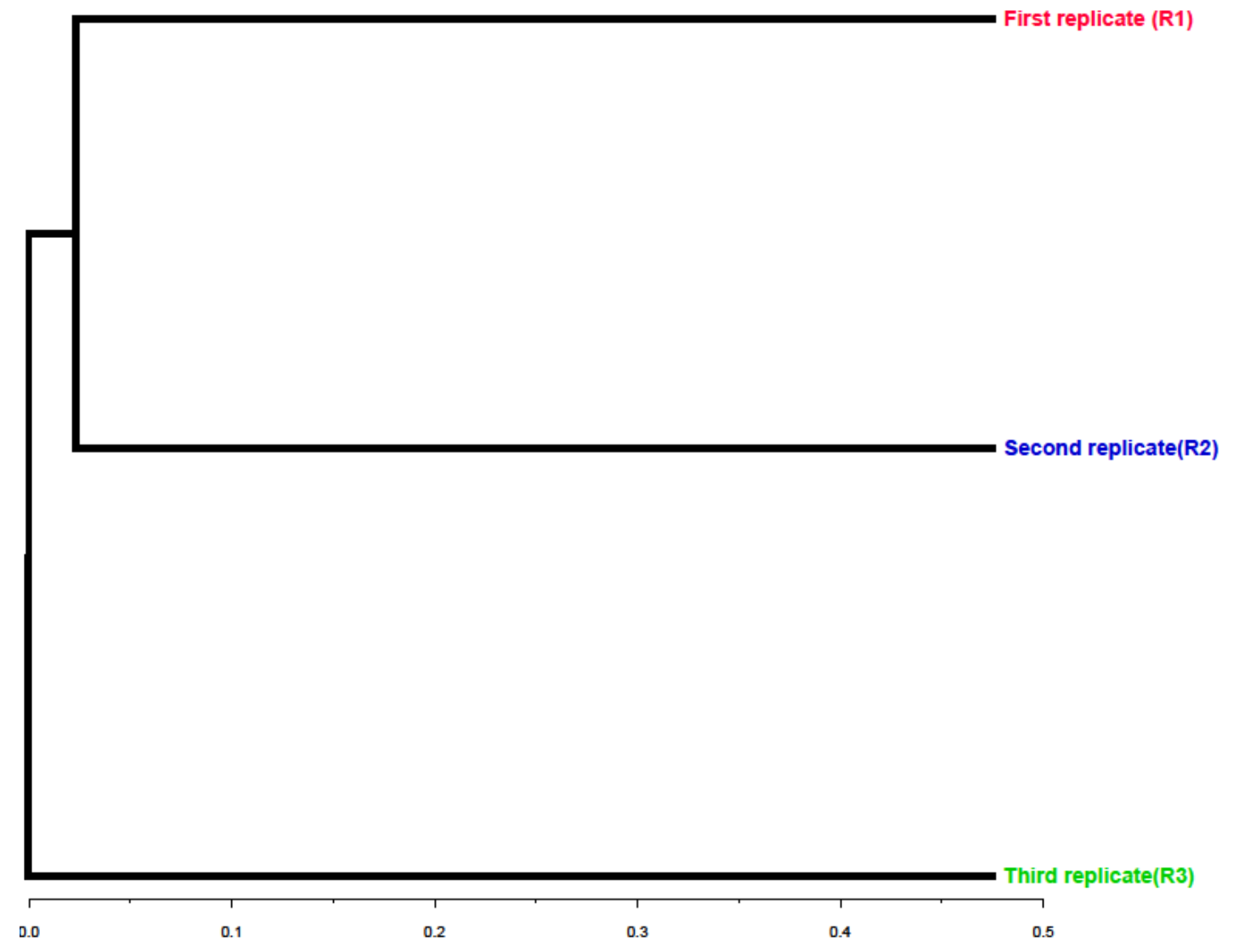

Figure 2.16 Unweighted UniFrac based clustering of Archaeal communities associated with different replications. UPGMA tree from figure 2.15 was used as an input file for construction of the UniFrac tree.

UniFrac based P-test with Bonferroni correction for multiple comparison suggests that bacterial communities associated with first replication (R1) and third replication (R3) are significantly different $(P$-value $=0.01-0.05)$. Bacterial communities associated with other pairs of replicates are not significantly different $(P$-value $>0.05)$. Unweighted UniFrac based clustering of replicates suggests that bacterial communities associated with R1 and R2 (second replicate) are more similar to each other than to R3 (Figures $2.13 \& 2.14)$

Archaeal communities associated with first replication (R1) and third replication (R3) and second replication (R2) and third replication (R3) were significantly different 
$(P$-value $=0.01-0.05)$ but same was not true between $R 1$ and $R 2(P$-value $>0.10)$ in UniFrac based P-test with Bonferroni correction for multiple comparison. Unweighted UniFrac based clustering of replicates suggests that archaeal communities associated with $\mathrm{R} 1$ and $\mathrm{R} 2$ (second replicate) are more similar to each other than to R3 as was observed with bacterial communities (Figures 2.15 \& 2.16).

\subsubsection{Multivariate analyses of T-RFLP profiles}

Nonmetric multidimensional scaling (NMDS) of T-RF's profiles generated from combined presence/absence data of Hha I and Rsa I digested PCR products demonstrate that bacterial and archaeal communities associated with open and wooded canopy diets are not distinct from one another (Figures 2.17a \& 2.17b), an observation that was already confirmed by UPGMA clustering (Figs. $2.7 \& 2.8$ ).

The degree of separation of bacterial communities associated with open and wooded canopy diets based on $\mathrm{R}$-value (where $\mathrm{R}=1$ indicate complete separation between groups) were unclear and statistically non-significant (anosim R-value $=-0.045$ and $p$-value $=0.748$, and same was true for archaeal communities associated with open and wooded canopy diets (anosim R-value $=-0.034$ and $p$-value $=0.692$ ) (Figures $2.18 a \& 2.18 b)$. 


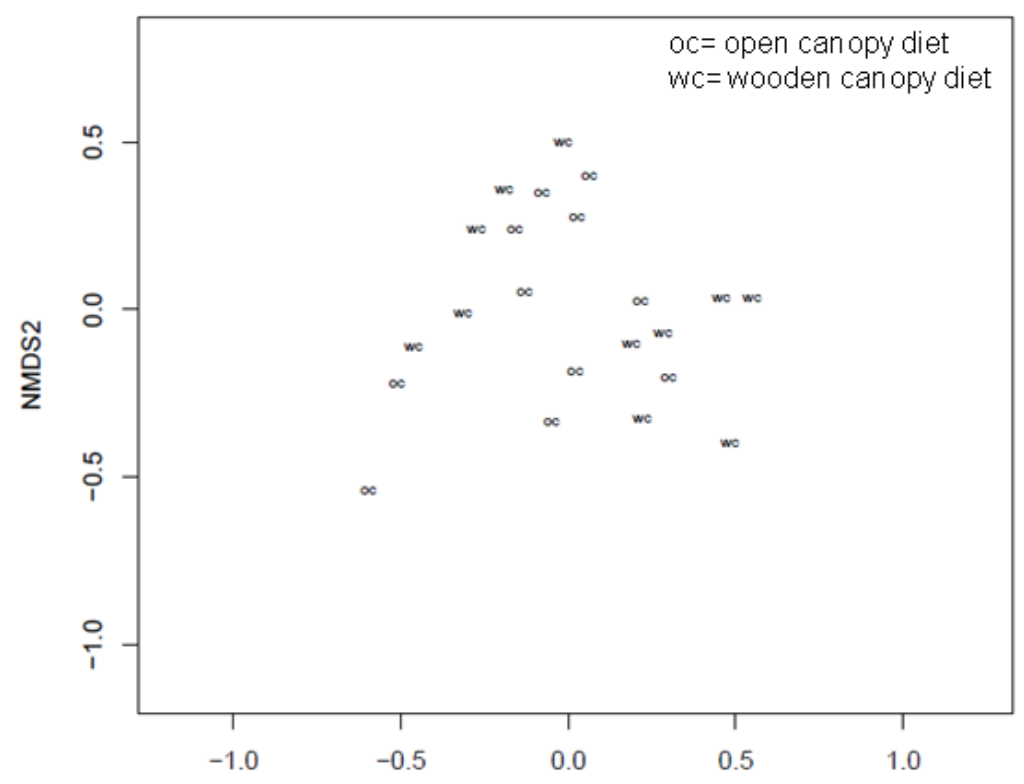

a.

NMDS1

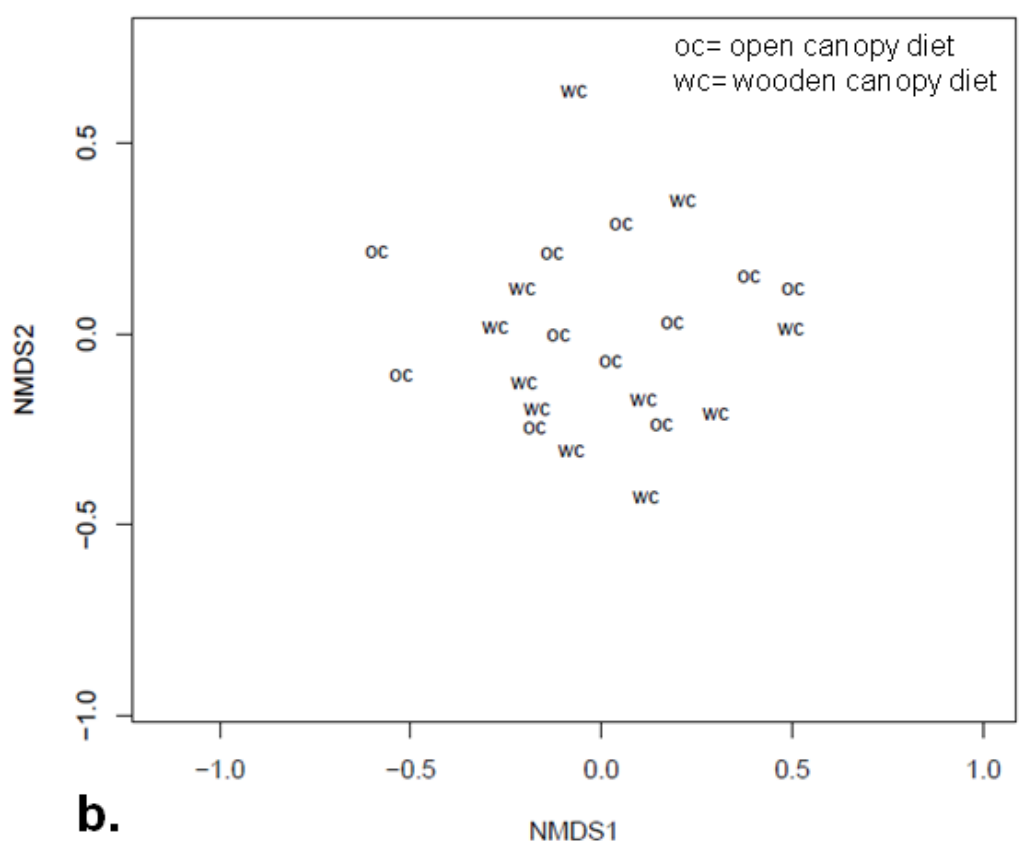

Figure 2.17 Nonmetric multidimensional scaling plot of a.) bacterial and b.) archaeal communities associated with open canopy (oc) and wooded canopy (wc) diets. Presence/absence data of T-RF's generated from Hha I and Rsa I digested PCR products were used for construction of the NMDS plot. 


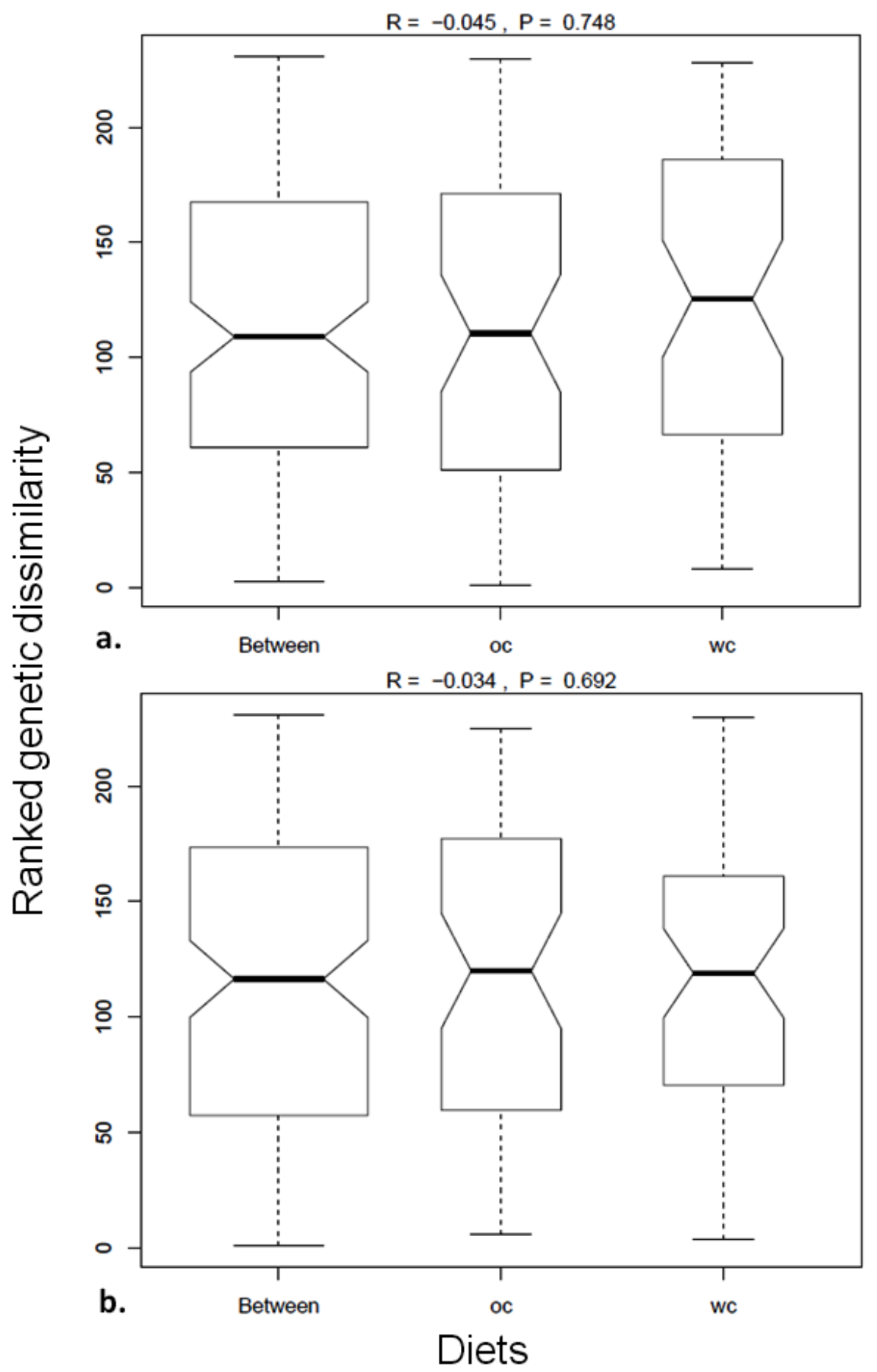

Figure 2.18 Boxplot of ranked genetic dissimilarity for a.) bacterial and b.) archaeal communities associated with open and wooded canopy diets. Boxes represent median and interquartile ranges. 

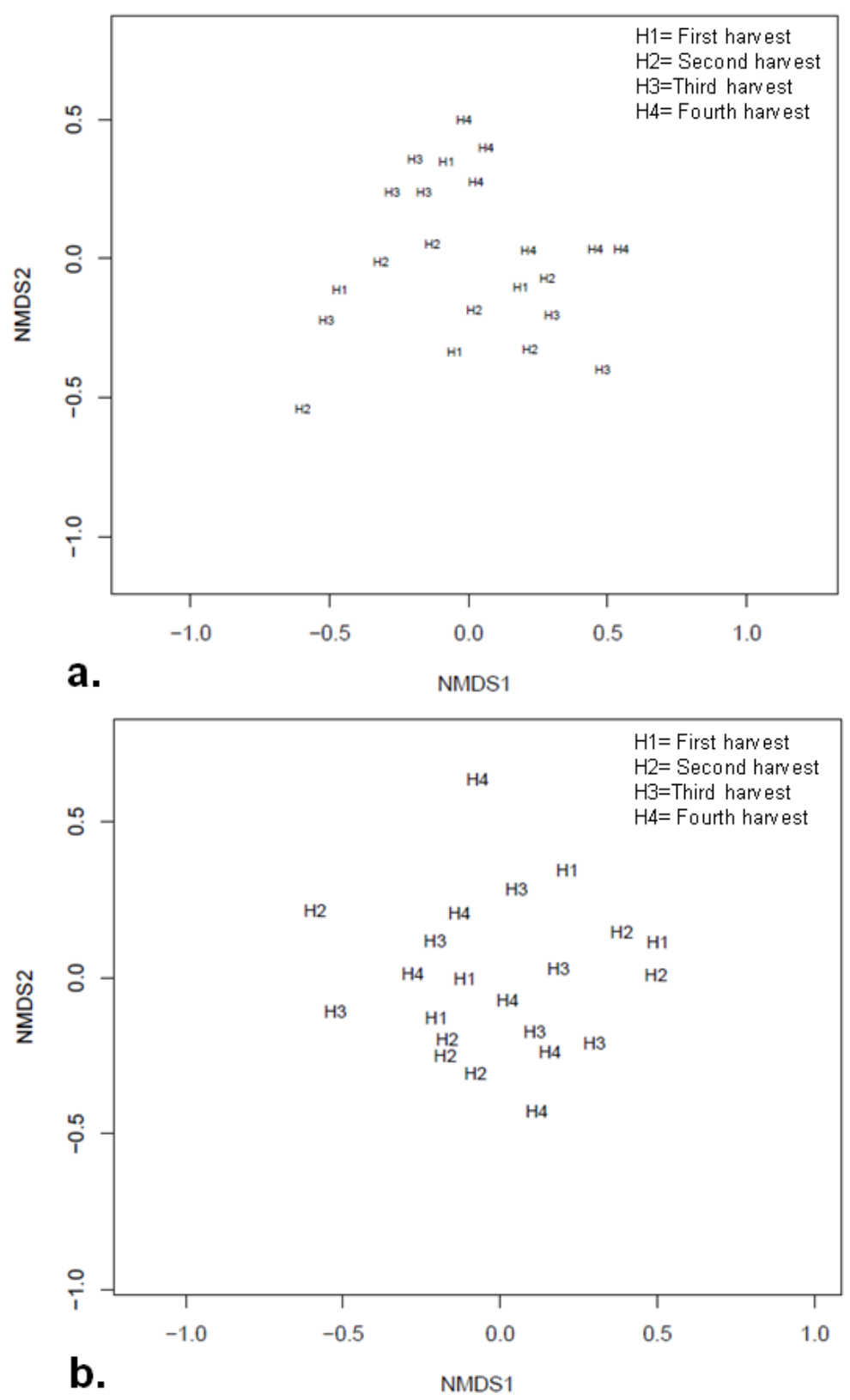

Figure 2.19 Nonmetric multidimensional scaling plot of a.) bacterial and b.) archaeal communities associated with different harvest time. Presence/absence data of T-RF's generated from Hha I and Rsa I digested PCR products were used for construction of the NMDS plot. 


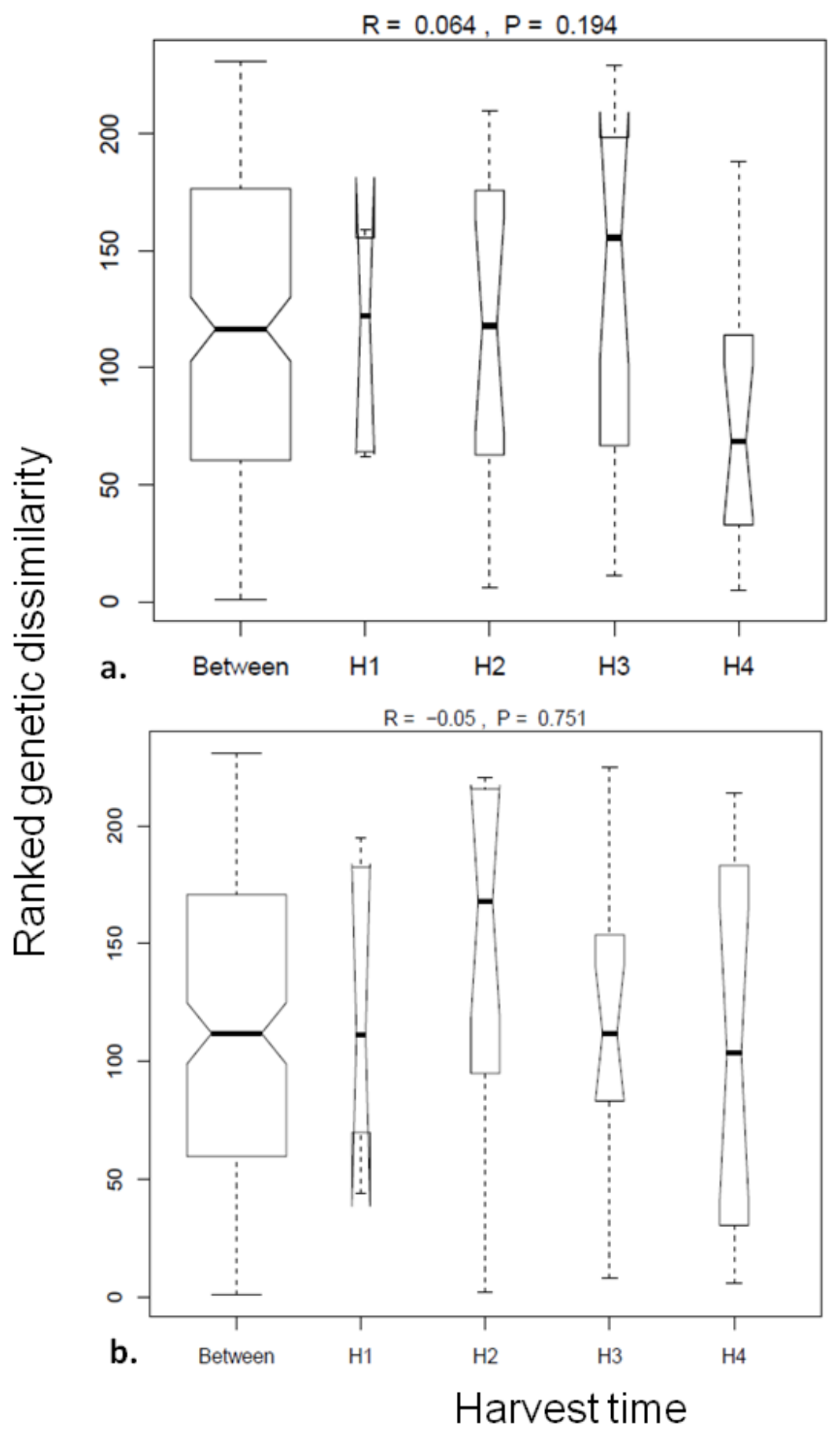

Figure 2.20 Boxplot of ranked genetic dissimilarity for a.) bacterial and b.) archaeal communities associated with different harvest time. Boxes represent median and interquartile ranges. $\mathrm{H} 1=$ First harvest; $\mathrm{H} 2=$ Second harvest; $\mathrm{H} 3=$ Third harvest; $\mathrm{H} 4=$ =Fourth harvest. 


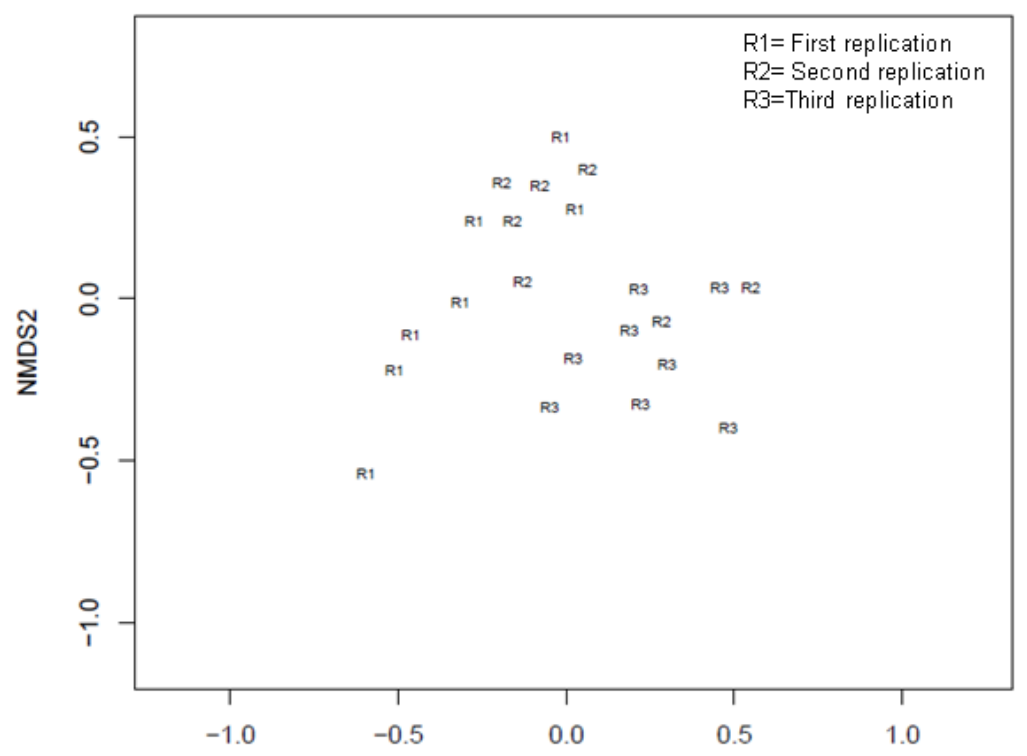

a.

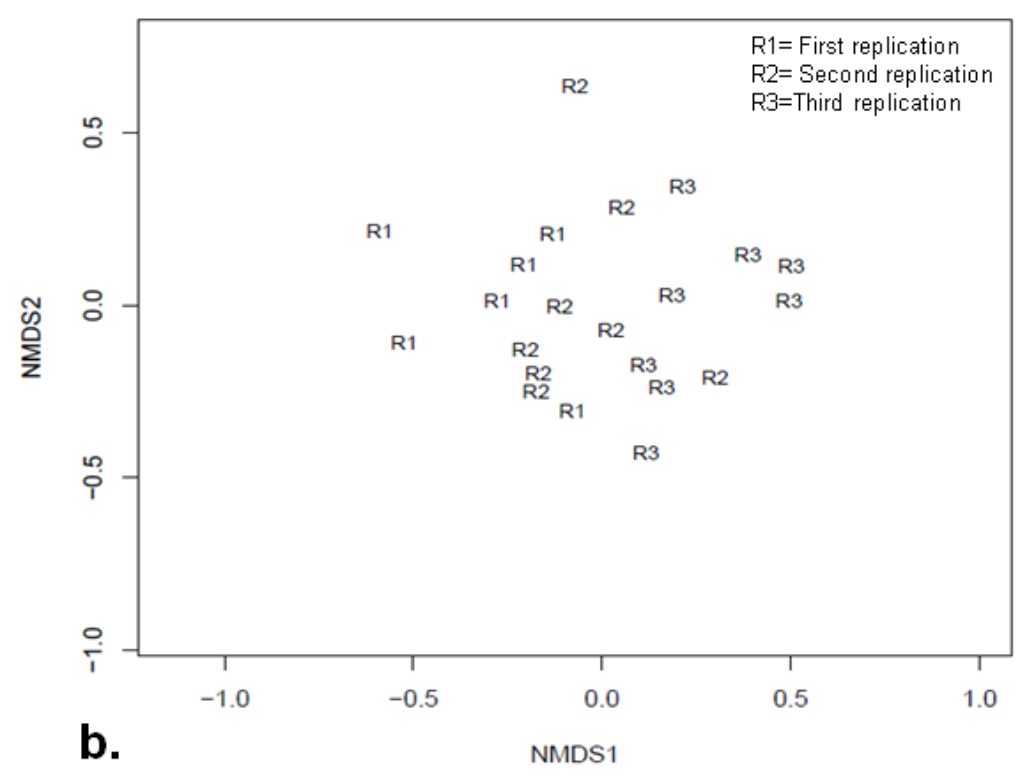

Figure 2.21 Nonmetric multidimensional scaling plot of a.) bacterial and b.) archaeal communities associated with different replications. Presence/absence data of T-RF's generated from Hha I and Rsa I digested PCR products were used for construction of the NMDS plot. 


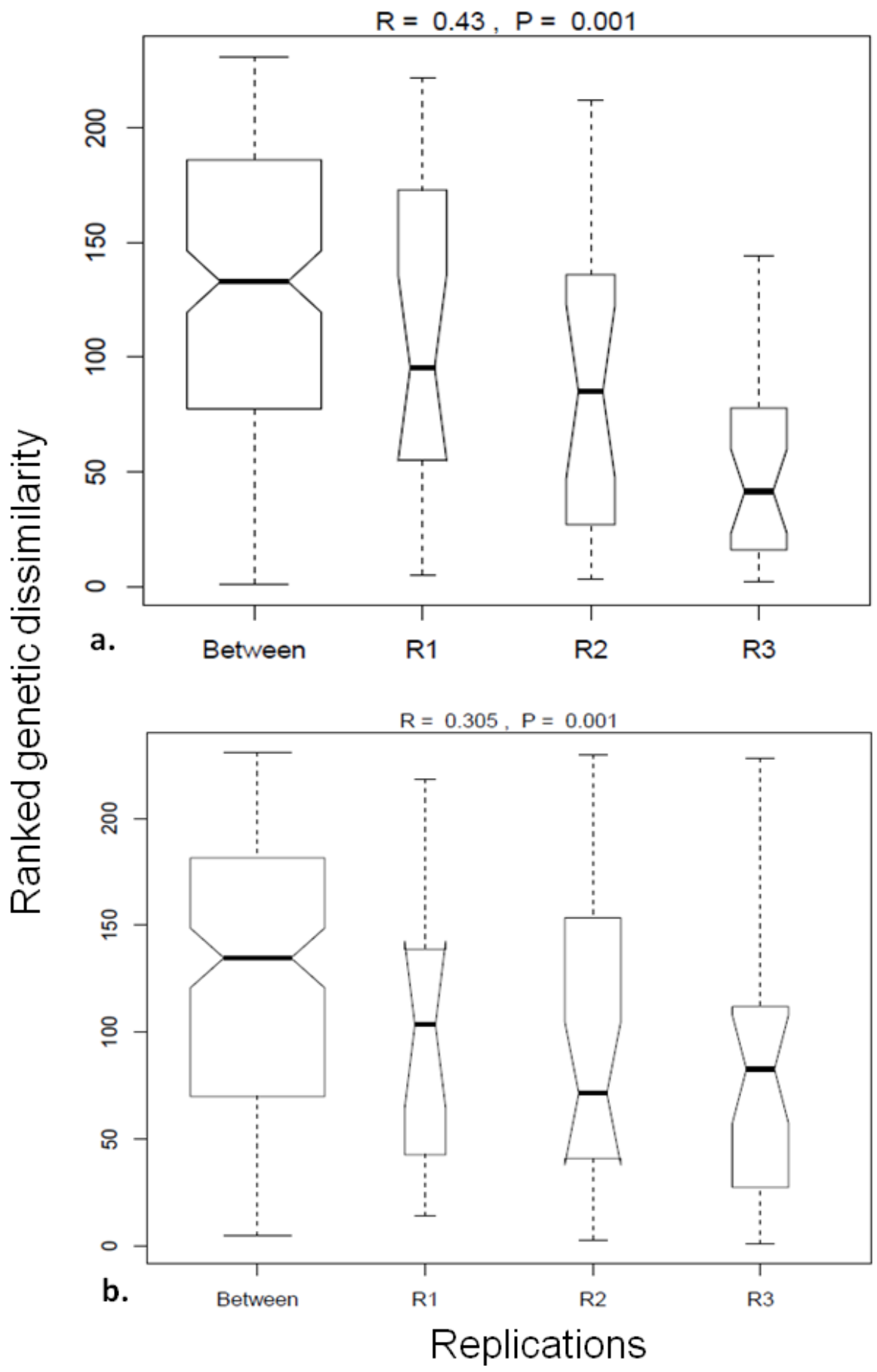

Figure 2.22 Boxplot of ranked genetic dissimilarity for a.) bacterial and b.) archaeal communities associated with different replications. Boxes represent median and interquartile ranges. $\mathrm{R} 1=$ First replication; $\mathrm{R} 2=\mathrm{Second}$ replication; $\mathrm{R} 3=$ Third replication. 
Similarly, bacterial and archaeal communities associated with different harvest time were also not significantly different (Figures 2.19a, 2.19b, 2.20a, and 2.20b). NMDS plots of different replications suggests that first and second replicate samples have more similar bacterial and archaeal community structure than to third replicate samples (Figures 2.21a and 2.21b), a result similar to one observed in UniFrac based clustering (Figures 2.13 to 2.16). Both bacterial and archaeal communities associated with different replications were significantly separated from one another (Figures 2.22a; R-value $=0.43 ; p$-value $=0.001$ and $2.22 b$-value $=0.305 ; p$-value $=0.001)$.

\subsection{DISCUSSION}

The bovine rumen is a classical example of host-microbe symbiotic relationship and any disturbance in this strongly balanced ecosystem can cause disease to the animal (Khafipour, et al., 2009). This balance in the rumen ecosystem can get affected by several factors; the most important among them is the type of diets ruminants eat (Khafipour, et al., 2009, Fernando, et al., 2010). Previous studies on rumen ecosystems have shown that microbial populations are generally stable across different animals (Jami \& Mizrahi, 2012), location and sampling time points (Li, et al., 2009), but it varies with diets they eat (Tajima, et al., 2001, Khafipour, et al., 2009, Li, et al., 2009, Fernando, et al., 2010). Majority of these studies emphasized on change in bacterial community in relation to grain diets (Khafipour, et al., 2009, Fernando, et al., 2010), and less emphasis was given on traditional pasture diets which is the main cattle food in several developing countries, and also on effect of change in diets on archaeal communities in the rumen ecosystem. Change in microbial population with diets is of 
great importance to cattle owners, because it increases energy density, improve feed efficiency, and average daily gain (ADG) (Bevans, et al., 2005).

In this study we examined effect of open canopy and wooded canopy forage diets on rumen bacterial and archaeal community structure using Hha I and Rsa I digested terminal restriction fragments. We showed that 1.) although bacterial and archaeal community associated with open and wooded canopy diets are not very different from each other, each diets had some unique bacterial and archaeal species 2.) open canopy forage diets generally had slightly higher bacterial and archaeal richness and diversity than wooded canopy forage diets, 3.) bacterial and archaeal community associated with different harvest time were not significantly different, 4.) there was significant difference in bacterial and archaeal communities associated with first and third replications. Archaeal community was significantly different also in between second and third replications, and 5.) bacterial and archaeal community associated with first (R1) and second (R2) replications were more similar to each other than to third replication (R3).

Our results indicate that nutritional difference between open and wooded canopy forage diets don't have a major impact on rumen bacterial and archaeal composition. As expected, bacterial diversity was much higher than archaeal diversity in both diets. These results also suggest to us that different harvest time didn't alter nutritional composition of these diets significantly, and hence we didn't observe any difference in bacterial and archaeal communities associated with different harvest time. This observation is similar to one made by Li et al. (2009), where they didn't find significant change in rumen bacterial composition with change in sampling time. Slightly higher 
bacterial and archaeal diversity associated with open canopy diets may be linked to its poor forage quality compared to wooded canopy diets. Bacterial and archaeal community differed significantly between first (R1) and third (R3) replicates in anosim (bacteria $R=0.43, P=0.01$ : archaea $R=0.305, P=0.01$ ) and in UniFrac based $P$ test ( $p$ value $<0.05$ ) because third replicate was pseudo replicate and comprised of mixture of open and wooded canopy forage diets. Same was true for archaeal community structure between R2 and R3.

Our study has several strengths. We measured rumen bacterial and archaeal community change with open and wooden canopy diets with emphasis on effect of harvest time over a period of three months. Several studies have shown effect of different diets on rumen microbial community structure (Tajima, et al., 2001, Khafipour, et al., 2009, Li, et al., 2009, Fernando, et al., 2010), but to our knowledge none have measured bacterial and archaeal diversity associated with open and wooden canopy forage diets and also on harvest time. We used in-vitro single flow continuous (artificial) fermentors for this experiment, which allowed us in having better control over several parameters that are not possible to control in natural rumen fermentors. Experiments using artificial fermentors are less stressing to animal and are also ethically well accepted among scientific community.

This study has some limitations. Although we had duplicate for each sample, we didn't run PCR in duplicate or triplicate for each sample before restriction digestion. Duplicate or triplicate PCR run helps in avoiding PCR bias (Marsh, et al., 2000, Tajima, et al., 2001) against less abundant microbes, and pooling of duplicate or triplicate PCR products helps in improving sensitivity of PCR for detection of minor communities 
(Raymond, et al., 2011). Also for this study we used only two restriction enzymes namely Hha I and Rsa I, which may not have detected all bacterial diversity associated with open and wooded canopy forage diets in the rumen. It is known from previous studies that no restriction enzyme alone can reveal more than $70 \%$ of total species in complex communities such as rumen (Engebretson \& Moyer, 2003). Thus, for future studies more than two restriction enzymes should be chosen for better coverage of microbial communities associated with open and wooden canopy forage diets. We used high throughput DNA fingerprinting based approach for the measurement of bacterial and archaeal community structure in response to open and wooden canopy forage intake. Use of 16S rDNA based 454 pyrosequencing for estimation of rumen bacterial diversity have gained popularity among scientific community in recent years (Pitta, et al., 2010, Jami \& Mizrahi, 2012, Lee, et al., 2012, Li, et al., 2012), but it is still very expensive for large scale replicated studies, like this one. 454-pyrosequeicng cost is decreasing every day, and hopefully in future, repetition of this study with 454pryrosequencing will give more detail information about bacterial community structure associated with open and wooded canopy forage diets. 


\section{CHAPTER 3: DIVERSITY OF BACTERIAL AND ARCHAEAL POPULATIONS IN ARTIFICIAL RUMEN FERMENTORS FED NATURALIZED PASTURE, TEFF, AND TRITICALE DIETS.}

\subsection{INTRODUCTION}

Several carbohydrate based diets such as naturalized pasture, teff grass, triticale etc. are common source of ruminant's nutrition. Naturalized pasture differs from pastureland in absence of cultural management and provides a valuable source of forage for ruminants. Teff is a self-pollinating annual grass that can be harvested multiple times in a year and has high forage quality. Teff is preferred as forage because of its better palatability, fast growth, drought tolerance, wide adaptations etc. On average teff grass contains $9-14 \%$ protein, $32-38 \%$ acid detergent fiber (ADF), and 53$65 \%$ neutral detergent fiber. Teff hay is high in calcium and several other nutrients such as iron, phosphorous, copper, aluminum, barium, and thiamine. As with other forage, teff's fiber content increases with maturity. Triticale is a grain diet and a hybrid product of wheat and rye. It is a high energy $(12.6 \mathrm{MJ} / \mathrm{kg} \mathrm{DM})$ and medium protein $(12.9 \%$ as fed) based animal diet and is similar in nutritive value to wheat, but it is much softer than wheat. Triticale contains higher concentration of chloroplast and non-structural carbohydrate whereas naturalized pasture late cut contains least amount of nonstructural carbohydrate. Teff and naturalized pasture early cut (npec) have intermediate amount of non-structural carbohydrate. Fiber digestion in the rumen is not optimal because several studies have shown that fiber in feces of ruminants is fermentable (Krause, et al., 2003). As rumen microbes are mainly responsible for rumen fermentation, better management of microbial population in the rumen may help in optimal fermentation of rumen diets. 
Microbial diversity in rumen depends on several factors, the most important among them is the type of food ruminants eat (Fernando, et al., 2010, Monteils, et al., 2012). This change in microbial composition with food is mainly because of change in nutrient availability, $\mathrm{pH}$, digesta flow, antimicrobial ingredients etc. (Busquet, et al., 2005, Monteils, et al., 2012). Digestive disorders due to decrease in $\mathrm{pH}$ have been observed in ruminants, with abrupt change in feed from forage diet to high-grain diet (van Kessel \& Russell, 1996, Klieve, et al., 2003, Khafipour, et al., 2009). Although there are several study on change in microbial community structure with grain diets, literature on effect of pasture diets on rumen bacterial and archaeal community is limited or negligible. The main aim of this study was to see how bacterial and archaeal population changes with change in naturalized (npec, nplc) and supplemental grasses (teff and triticale).

\subsection{MATERIAL AND METHODS}

\subsubsection{Sample collection / rumen fermentors}

In this study artificial rumen fermentors (single-flow continuous culture system) were used for estimation of bacterial and archaeal diversity in response to four pasture diets (naturalized pasture early cut (npec), naturalized pasture late cut (nplc), teff grass (teff) and triticale (tri)) using fermentors arrangement similar to one described by Meng et al. (1999) and as described in section 2.2.1. Six replicates for each diet were used as shown in Table 3.1 and sample collection procedure was same as previously described in section 2.2.1.

\subsubsection{DNA extraction}

DNA extraction protocol was same as previously described in section 2.2.2. 
Table 3.1 List of samples and their collection details. Feed types: 1.) Naturalized pasture early cut (npec), 2.) Naturalized pasture late cut (nplc), 3.) Teff grass (teff), and 4.) Triticale (tri).

\begin{tabular}{lllll}
\hline Sr. \# & Sample name & Diet name & Run \# & Fermenter \# \\
\hline 1 & r1_1_npec & npec & 1 & 1 \\
2 & r1_2_npec & npec & 1 & 2 \\
3 & r1_3_npec & npec & 1 & 3 \\
4 & r1_4_teff & teff & 1 & 4 \\
5 & r1_5_teff & teff & 1 & 5 \\
6 & r1_6_teff & teff & 1 & 6 \\
7 & r1_7_npec & npec & 1 & 7 \\
8 & r1_8_npec & npec & 1 & 8 \\
9 & r1_9_npec & npec & 1 & 9 \\
10 & r1_10_teff & teff & 1 & 10 \\
11 & r1_11_teff & teff & 1 & 11 \\
12 & r1_12_teff & teff & 2 & 12 \\
13 & r2_1_nplc & nplc & 2 & 1 \\
14 & r2_2_nplc & nplc &
\end{tabular}




\begin{tabular}{lllll}
15 & r2_3_nplc & nplc & 2 & 3 \\
16 & r2_4_tri & tri & 2 & 4 \\
17 & r2_5_tri & tri & 2 & 5 \\
18 & r2_6_tri & tri & 2 & 6 \\
19 & r2_7_nplc & nplc & 2 & 7 \\
20 & r2_8_nplc & nplc & 2 & 8 \\
21 & r2_9_nplc & nplc & 2 & 9 \\
22 & r2_10_tri & tri & 2 & 10 \\
23 & r2_11_tri & tri & 2 & 11 \\
24 & r2_12_tri & tri & & 12 \\
\hline
\end{tabular}




\subsubsection{DNA amplification}

DNA amplification protocol was same as described in section 2.2.3, except for this experiment there were no duplicate samples but each sample was amplified in triplicate and pooled for purification and restriction digestion.

\subsubsection{Terminal Restriction Fragment Length Polymorphism (T-RFLP)}

Triplicate PCR products from each sample were pooled and cleaned using a QIAquick PCR Purification Kit (Qiagen Inc., CA, USA) and quantified using NanoDrop spectrophotometer (Thermo scientific, DE USA).

Approximately $500 \mathrm{ng}$ of cleaned PCR product was digested separately in $20 \mu \mathrm{l}$ total volume by Hha I, Rsa I, and Hae III restriction enzymes, as per manufacturer's protocol (New England Biolabs, MA, USA). $1.5 \mu \mathrm{l}$ of digested product was mixed with $0.5 \mu \mathrm{l}$ of LIZ-labeled GS500 internal size standard (Applied Biosystems, CA, USA) and rest $\mathrm{Hi}$-Di formamide (Applied Biosystems, CA, USA) for a total volume of $10 \mu \mathrm{l}$. This mixture was denatured at $95^{\circ} \mathrm{C}$ for 3 minutes, followed by cooling in ice for 5 minutes. Terminal restriction fragments were separated by capillary electrophoresis in ABI $3730 x I$ genetic analyzer (Applied Biosystems, CA, USA). Terminal fragments from each sample were separated thrice using capillary electrophoresis in ABI 3730x/ genetic analyzer (Applied Biosystems, CA, USA).

\subsubsection{Data analysis}

Raw data from capillary electrophoresis were analyzed for T-RFLP profile using GeneMapper® software version 4.0 (Applied Biosystems, CA, USA). Terminal restriction fragments (T-RFs) of size $35 \mathrm{bp}$ to $500 \mathrm{bp}$ and height above 30 RFU were 
considered for further analysis., mainly to avoid noisy TRFs due to primer dimer and also to include only those fragments that falls in the linear range of the size standard. Terminal fragment length and height of peaks were treated as number and abundance of bacterial/archaeal phylotypes respectively and, were exported to excel sheet for further analysis. Only those peaks (length and height) were considered true that were present in triplicate samples and rest was deleted from further analysis. Peak length and height from triplicate samples were pooled and averaged.

Presence/absence (1/0) data were created based on average length and average abundance profiles. Presence/absence data was used for construction of Unweighted Pair Group Method with Arithmetic Mean (UPGMA) tree using default parameters in PAUP* v.4.0b10 (Swofford, 2003). Same UPGMA tree was used as an input tree file for unweighted UniFrac (Lozupone, et al., 2006) based clustering of bacterial and archaeal community associated with different diets. P-test was performed using 1000 permutations for each pair of diets with Bonferroni correction for multiple comparison (Lozupone, et al., 2006). All trees were edited using FigTree v1.3.1 (http://tree.bio.ed.ac.uk/).

Same presence/absence data was used for construction of ANOSIM box plot and NMDS plots using Vegan package in $R$ v. $2.13 .0(R, 2011)$ following protocol as described in section 2.2.5.

Distinctive peak numbers from each sample were counted as species richness (S). Abundance profile (peak height) from each datasets was used for calculation of Shannon-Wiener diversity (H'), Simpson's diversity (D), Shannon evenness (E) and 
Simpson evenness $\left(E_{1 / D}\right)$ indices using equations and protocol as described in section 2.2 .5

\subsection{RESULTS}

3.3.1 DNA extraction and PCR amplification

DNA concentration of samples was in the same range as was observed in section 2.3.1. Sizes of PCR product for bacterial and archaeal 16S rRNA gene were same as observed in section 2.3.1. PCR product from one sample (b_r1_7_npec) using bacterial primers was very weak and didn't yield T-RFLP profile and hence was not used in any analyses.

\subsubsection{General characteristics of T-RFLP profiles}

A total of 76, 90 and 20 different T-RF's, each representing different bacterial groups, were present in Hha I, Rsa I, and Hae III digested bacterial samples respectively. Among Hha I generated bacterial fragments $1,3,4$, and 16 fragments were unique to npec, teff, nplc, and tri diets respectively (Figures 3.1a \& 3.2). Similarly, among Rsa I generated fragments, 0, 5, 7, and 12 fragments were unique to npec, teff, nplc, and tri diets respectively (Figure 3.1b). Among Hae III generated fragments 1, 5, 1, and 3 fragments were unique to npec, teff, nplc, and tri diets respectively (Figure 3.1c). 


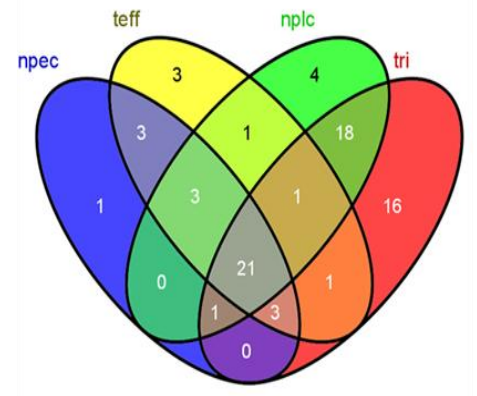

a.

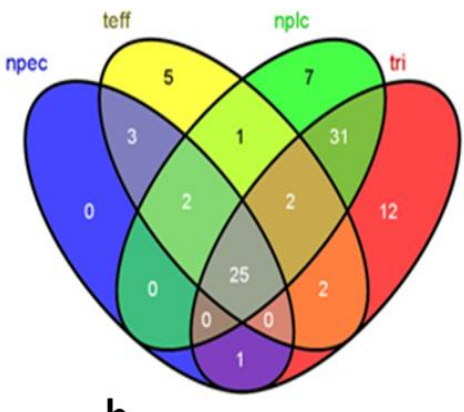

b.

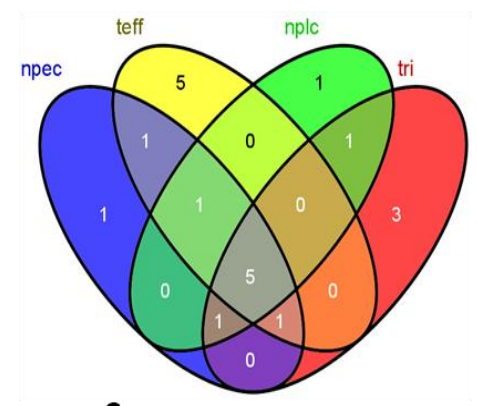

C.

Figure 3.1 Venn diagram showing shared and unique bacterial T-RF's between naturalized pasture early cut, naturalized pasture late cut, teff, and triticale pasture diets a.) when digested with Hha I, b.) when digested with Rsa I, and c.) when digested with Hae III.

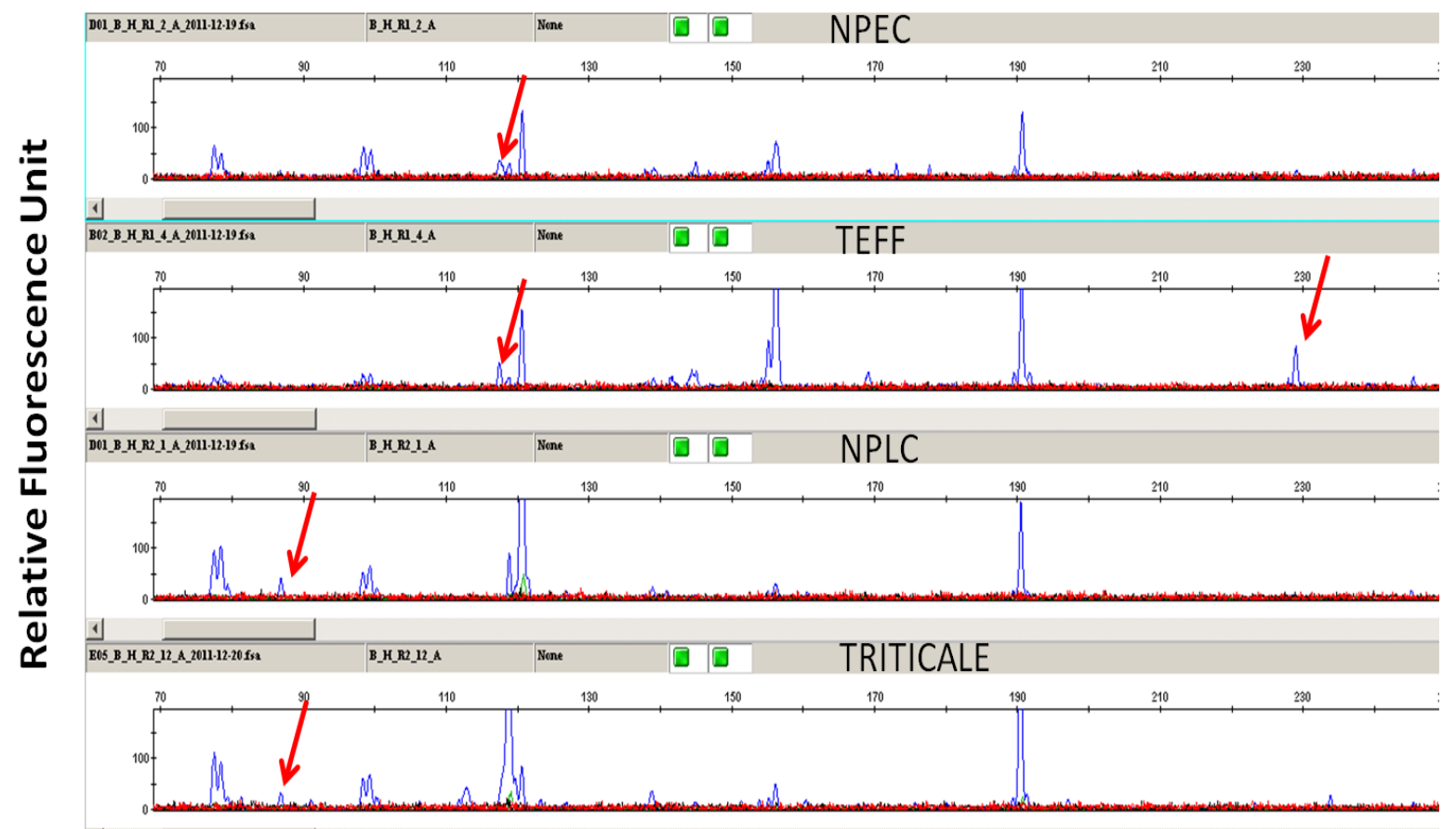

Fragment size (bp)

Figure 3.2 Comparison of Hha I digested bacterial T-RFLP profiles obtained from a single sample of npec, nplc, teff and triticale pasture diets. Red arrow highlights unique and shared bacterial T-RF's associated with different diets. 


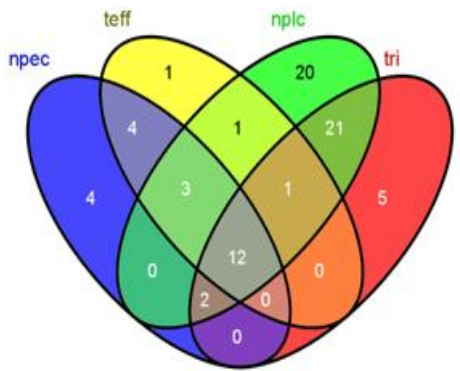

a.

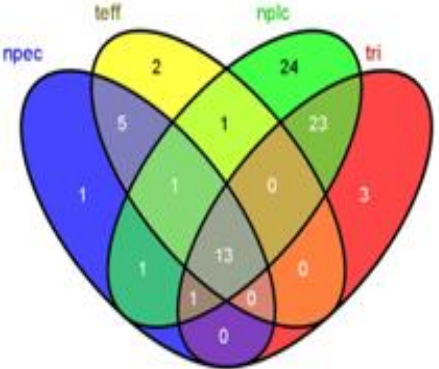

b.

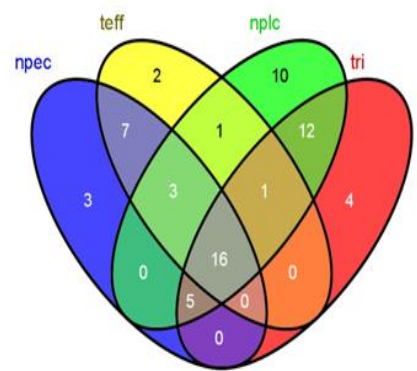

C.

Figure 3.3 Venn diagram showing shared and unique archaeal T-RF's between naturalized pasture early cut (npec), naturalized pasture late cut (nplc), teff, and triticale pasture diets a.) when digested with Hha I, b.) when digested with Rsa I, and c.) when digested with Hae III.

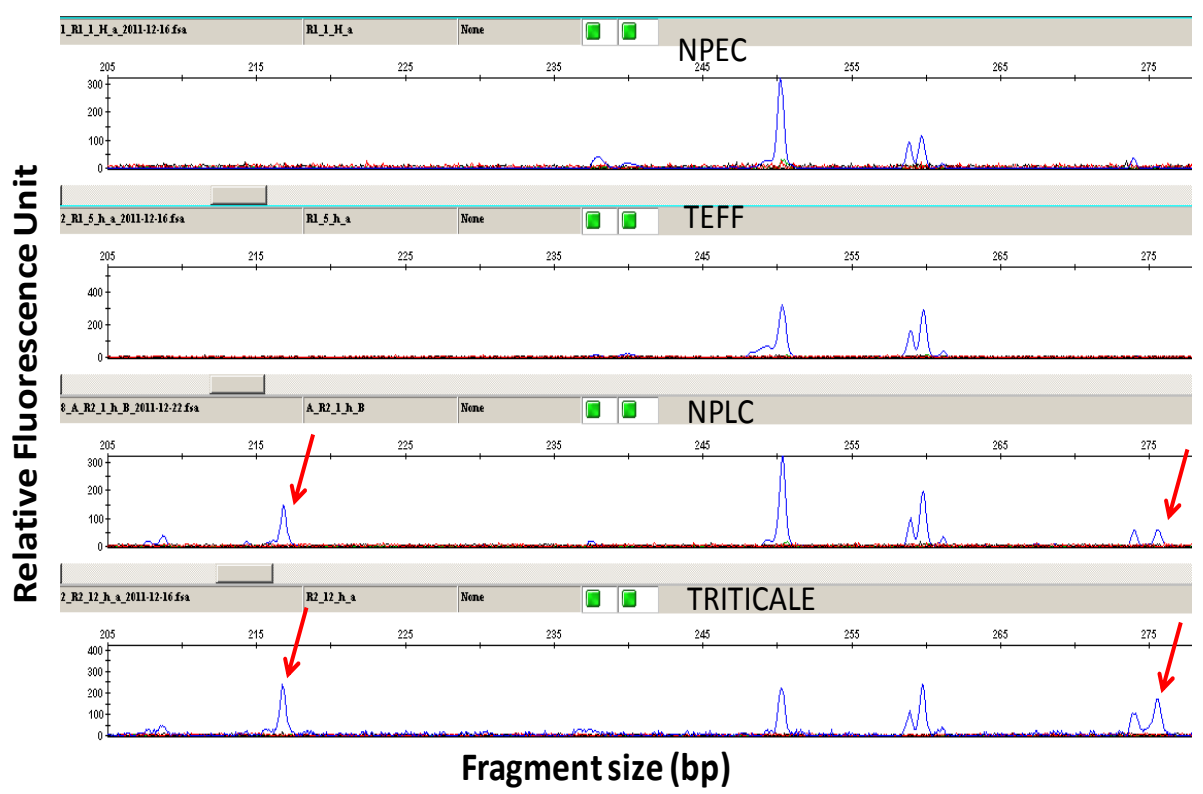

Figure 3.4 Comparison of Hha I digested archaeal T-RFLP profiles obtained from a single sample of naturalized pasture early cut (npec), naturalized pasture late cut (nplc), teff, and triticale pasture diets. Red arrow highlights unique and shared archael T-RF's associated with different diets. 
PCR product obtained using archaeal primers yielded 73, 74, and 63 T-RF's after digestion with Hha I, Rsa I, and Hae III respectively. Among Hha I generated fragments $4,1,20$, and 5 fragments were unique to npec, teff, nplc, and tri respectively (Figures 3.3a \& 3.4). Similarly, among Rsa I generated fragments $1,2,24$, and 3 fragments were unique to npec, teff, nplc, and tri diets respectively (Figure 3.3b). Among Hae III generated fragments $3,2,10$, and 4 fragments were unique to npec, teff, nplc, and tri diets respectively (Figure 3.3c).

\subsubsection{Biodiversity of T-RFLP profiles}

Shannon-Weiner and Simpson diversity indices were used for determination of bacterial and archaeal diversity associated with four diets. In general triticale had highest bacterial richness and diversity (both Shannon and Simpson) than other diets included in this study but same was not true for archaeal communities (Table 3.2). Archaeal richness and diversity was much higher for nplc diet compared to other diets included in this study (Table 3.2). Bacterial community associated with npec diet was more evenly distributed than other diets included in this study (see Shannon and Simpson evenness indices value in table 3.2) but same was not true for archaeal communities. Archaeal communities associated with triticale diet were more evenly distributed than other three diets included in this study.

\subsubsection{Phylogenetic analyses of T-RFLP profiles}

Unweighted Pair Group Method with Arithmetic Mean (UPGMA) tree using combined T-RF's profile from Hha I, Rsa I and Hae III suggests that bacterial and archaeal communities associated with npec and teff are more similar to each other than to other two diets (Figures 3.5 \& 3.6). 
Table 3.2 Table showing richness, diversity, and evenness indices of bacterial and archaeal communities associated with naturalized pasture early cut ( npec), teff, naturalized pasture late cut (nplc), and triticale (tri).

\begin{tabular}{|c|c|c|c|c|c|c|c|c|c|c|c|c|c|c|c|}
\hline \multirow[t]{2}{*}{$\begin{array}{l}\text { Sample } \\
\text { name }\end{array}$} & \multicolumn{3}{|c|}{ Richness (S) } & \multicolumn{3}{|c|}{$\begin{array}{c}\text { Shannon diversity } \\
\left(\mathrm{H}^{\prime}\right)\end{array}$} & \multicolumn{3}{|c|}{$\begin{array}{l}\text { Simpson's index of } \\
\text { diversity (1-D) }\end{array}$} & \multicolumn{3}{|c|}{$\begin{array}{c}\text { Shannon Evenness } \\
\text { (E) }\end{array}$} & \multicolumn{3}{|c|}{$\begin{array}{c}\text { Simpson's } \\
\text { Evenness (E(1/D)) }\end{array}$} \\
\hline & Hae III & Hha I & Rsa I & Hae III & Hha I & Rsa I & Hae III & Hha I & Rsa I & Hae III & Hha I & Rsa I & Hae III & Hha I & Rsa I \\
\hline \multicolumn{16}{|l|}{ Bacteria } \\
\hline npec & 5.40 & 18.20 & 18.40 & 0.57 & 3.61 & 3.51 & 0.16 & 0.89 & 0.88 & 0.25 & 0.88 & 0.85 & 0.25 & 0.54 & 0.47 \\
\hline teff & 7.00 & 23.33 & 21.00 & 0.69 & 3.71 & 3.72 & 0.19 & 0.87 & 0.90 & 0.25 & 0.82 & 0.85 & 0.19 & 0.34 & 0.49 \\
\hline nplc & 6.17 & 29.00 & 35.17 & 0.53 & 4.01 & 3.76 & 0.14 & 0.90 & 0.88 & 0.20 & 0.83 & 0.74 & 0.20 & 0.35 & 0.25 \\
\hline tri & 6.33 & 32.83 & 37.67 & 0.45 & 4.19 & 3.86 & 0.12 & 0.91 & 0.88 & 0.16 & 0.84 & 0.75 & 0.18 & 0.35 & 0.24 \\
\hline \multicolumn{16}{|l|}{ Archaea } \\
\hline npec & 19.17 & 16.17 & 14.00 & 3.60 & 3.51 & 3.18 & 0.88 & 0.88 & 0.83 & 0.87 & 0.89 & 0.84 & 0.51 & 0.57 & 0.47 \\
\hline teff & 16.67 & 14.50 & 14.00 & 3.56 & 3.37 & 3.19 & 0.89 & 0.88 & 0.84 & 0.88 & 0.88 & 0.85 & 0.56 & 0.58 & 0.46 \\
\hline nplc & 21.50 & 29.50 & 28.00 & 4.05 & 4.36 & 4.14 & 0.92 & 0.93 & 0.91 & 0.94 & 0.92 & 0.90 & 0.69 & 0.59 & 0.49 \\
\hline tri & 17.33 & 17.67 & 16.50 & 3.78 & 3.76 & 3.69 & 0.91 & 0.91 & 0.90 & 0.95 & 0.94 & 0.94 & 0.76 & 0.71 & 0.72 \\
\hline
\end{tabular}




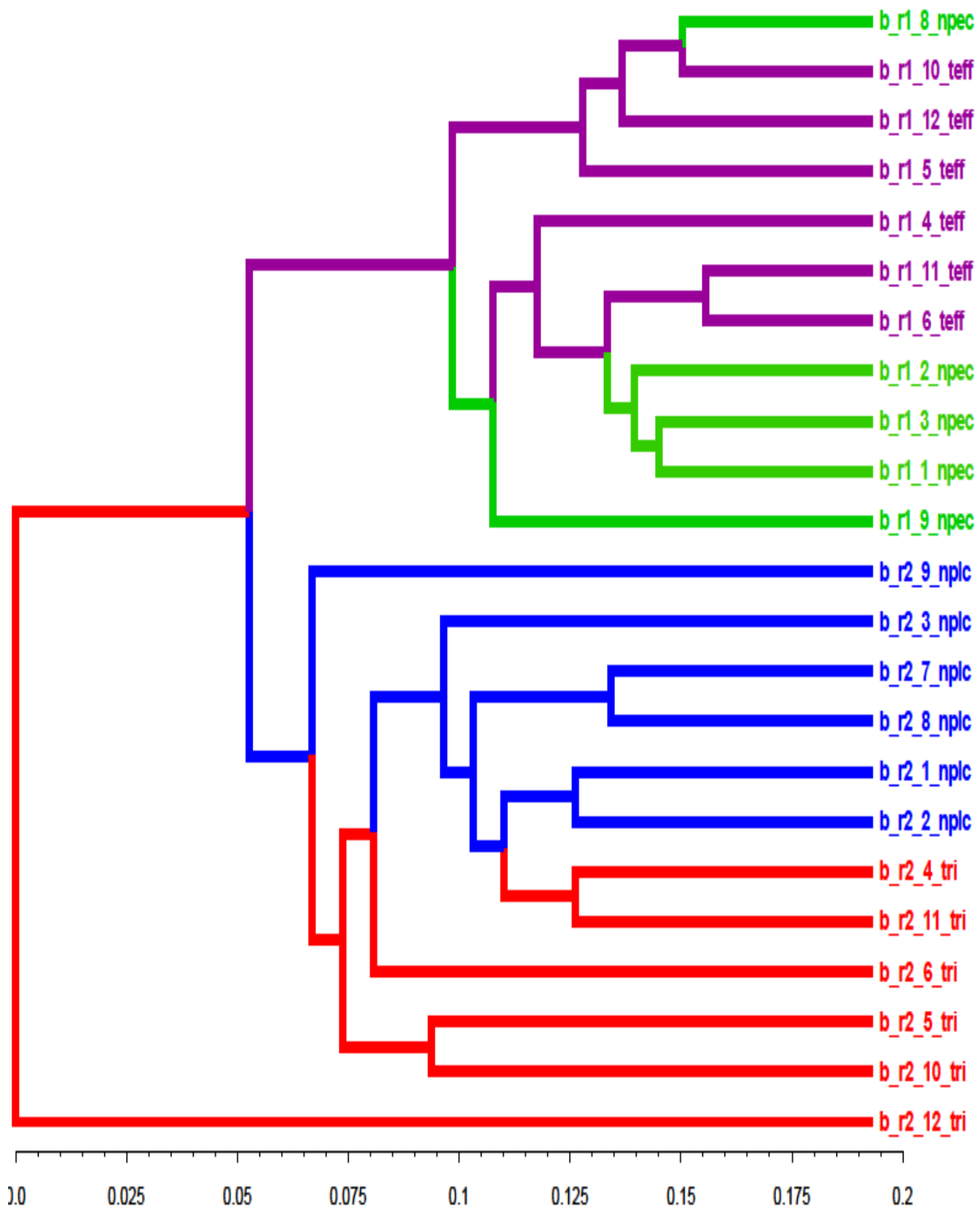

Figure 3.5 Unweighted Pair Group Method with Arithmetic Mean (UPGMA) tree of bacterial communities associated with different pasture diets. T-RF's generated from Hha I, Rsa I, and Hae III digestion were combined for construction of UPGMA tree. npec $=$ naturalized pasture early cut, $\mathrm{nplc}=$ naturalized pasture late cut, teff $=$ teff grass, and tri $=$ triticale. 


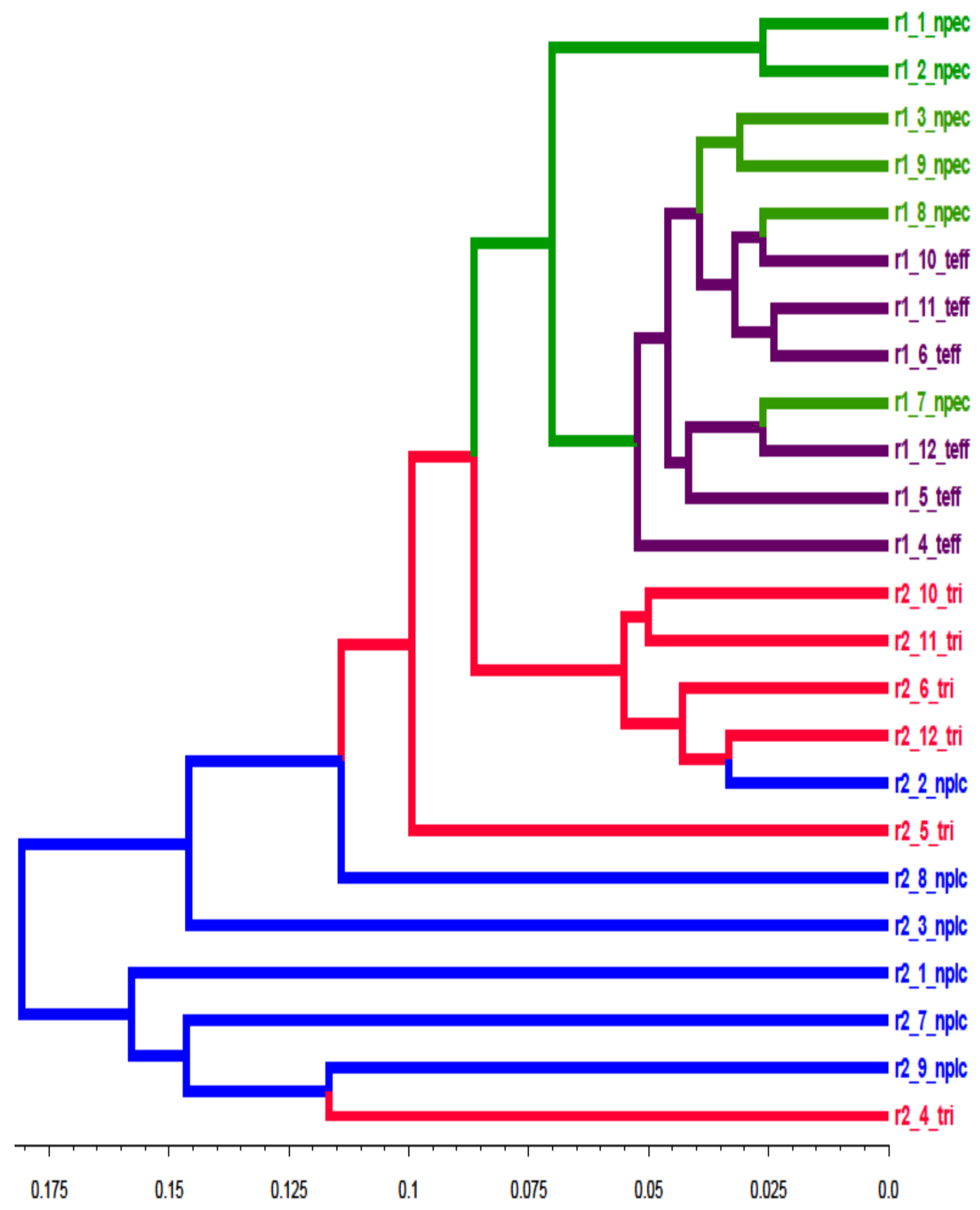

Figure 3.6 Unweighted Pair Group Method with Arithmetic Mean (UPGMA) tree of archaeal communities associated with different pasture diets. T-RF's generated from Hha I, Rsa I, and Hae III digestion were combined for construction of UPGMA tree. npec $=$ naturalized pasture early cut, $\mathrm{nplc}=$ naturalized pasture late cut, teff $=$ teff grass, and tri $=$ triticale. 


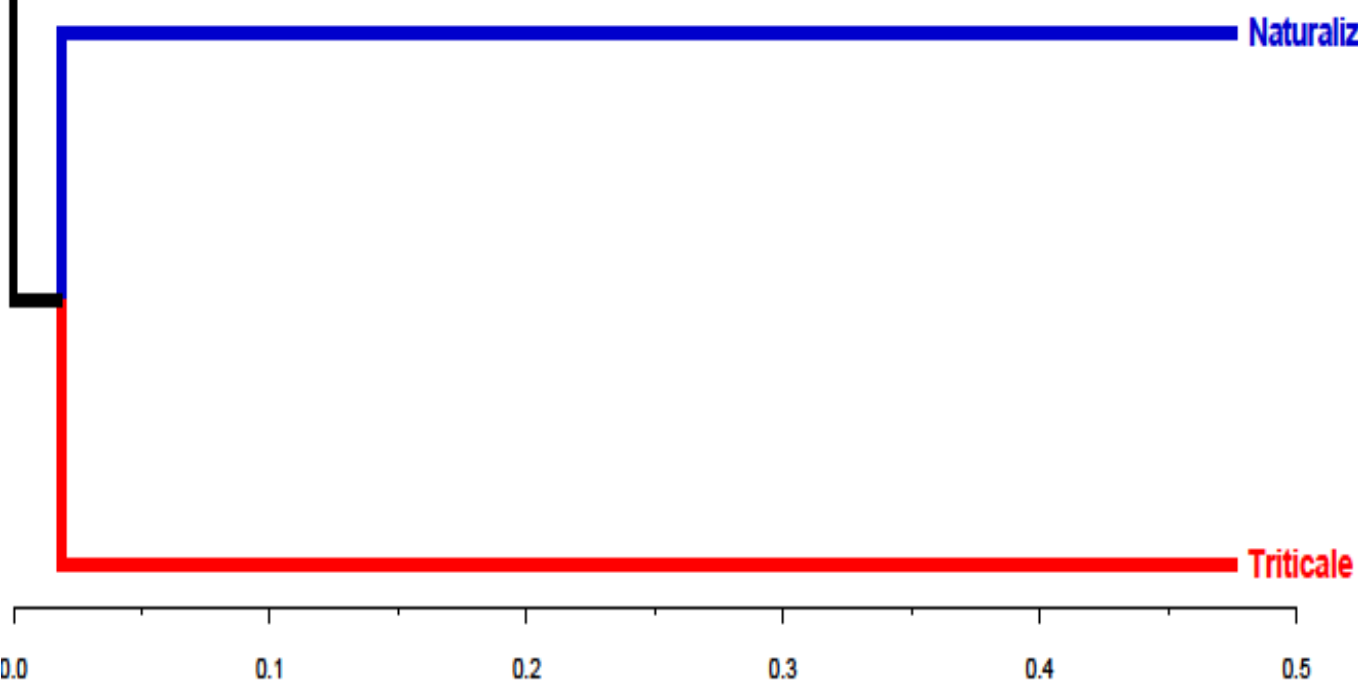

Figure 3.7 Unweighted UniFrac based clustering of bacterial communities associated with different diets. UPGMA tree from figure 3.5 was used as an input file for construction of UniFrac tree. 


\begin{tabular}{ll|l|l|l|l|}
\hline & & & & & \\
0.0 & 0.1 & 0.3 & 0.4 & 0.5
\end{tabular}

Figure 3.8 Unweighted UniFrac based clustering of archaeal communities associated with different diets. UPGMA tree from figure 3.6 was used as an input file for construction of UniFrac tree. 


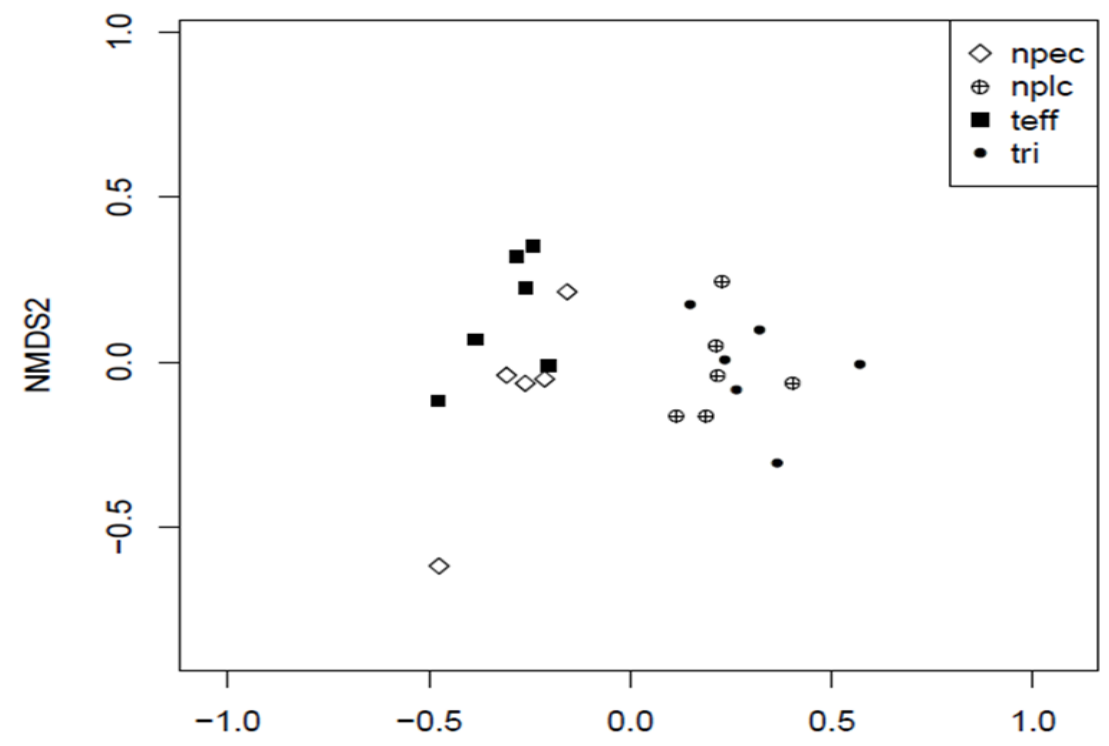

a.

NMDS1

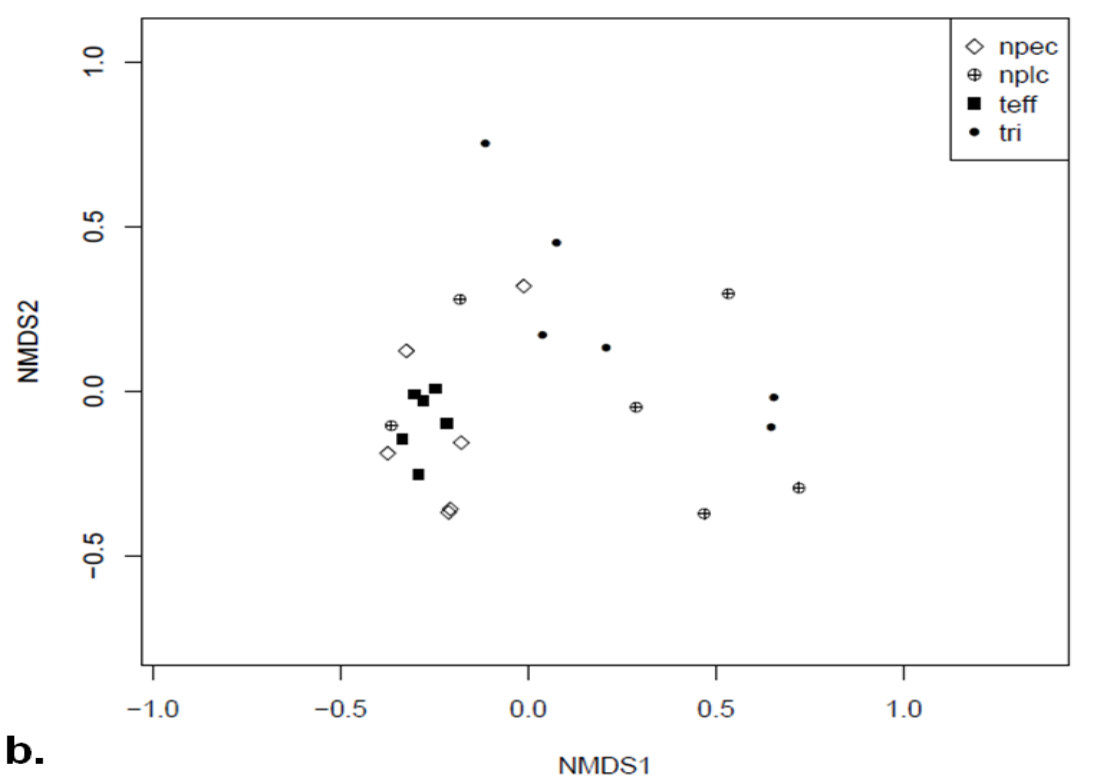

Figure 3.9 Nonmetric multidimensional scaling plot of a.) bacterial and b.) archaeal communities associated with npec (naturalized pasture early cut), nplc (naturalized pasture late cut), teff (teff grass), and tri (triticale) pasture diets. Presence/absence data of T-RF's generated from Hha I, Rsa I and Hae III digested PCR products were used for construction of the NMDS plot. 


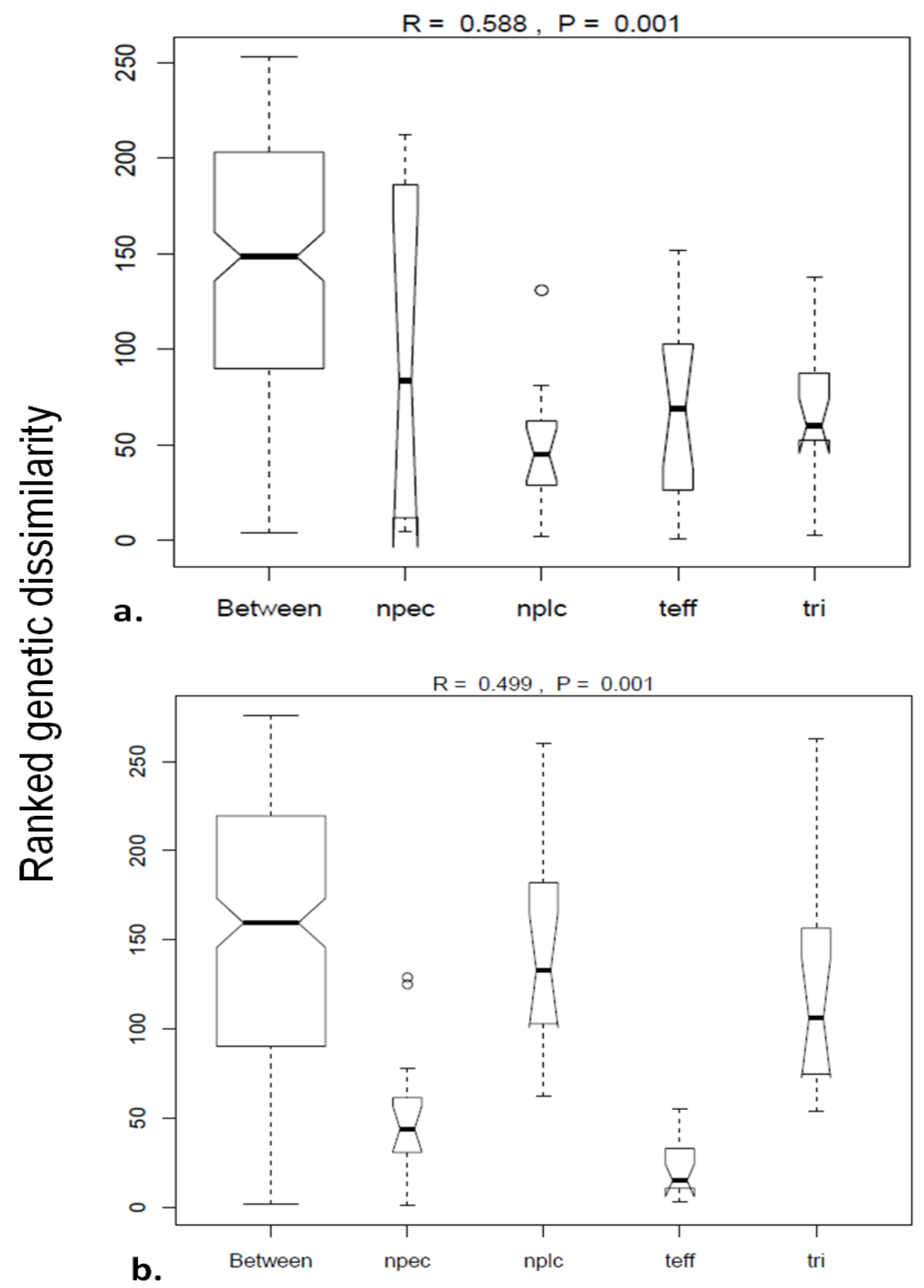

Diets

Figure 3.10 Boxplot of ranked genetic dissimilarity for a.) bacterial and b.) archaeal communities associated with npec (naturalized pasture early cut), nplc (naturalized pasture late cut), teff ( teff grass), and tri (triticale) pasture diets. Boxes represent median and interquartile ranges. Circle above box represent outliers. 
Similarly, bacterial and archaeal community associated nplc and triticale were more similar to each other than to other two diets included in this study (Figures 3.5 \& 3.6). Similar relationships were observed for both bacterial and archaeal communities associated different pasture diets included in this study in UniFrac based clustering (Figures 3.7 \& 3.8). Bacterial and archaeal communities associated with diet pairs npecnplc, npec-triticale, nplc-teff, and teff-triticale were suggested to be very different ( $p$ value $\leq 0.06$ ) in UniFrac based P-test with Bonferroni correction for multiple comparisons.

\subsubsection{Multivariate analyses of T-RFLP profiles}

Nonmetric multidimensional scaling (NMDS) of T-RF's profiles generated from combined presence/absence data of Hha I, Rsa I and Hae III digested PCR products demonstrate that bacterial and archaeal communities associated npec and teff are clustered together and bacterial and archaeal communities associated nplc and triticale diets are also clustered together (Figures 3.9a \& 3.9b), an observation that was already confirmed by UPGMA clustering (Figures 3.5 \& 3.6). Anosim results suggests that bacterial and archaeal communities were very distinct and significantly different between different pasture diets (Figure 3.10a: $\mathrm{R}$-value $=0.588, \mathrm{p}$-value $=0.001$; Figure 3.10b: R-value=0.499, $p$-value $=0.001)$.

\subsection{DISCUSSION}

In this study we examined effect of four pasture diets (naturalized pasture early cut (npec), naturalized pasture late cut (nplc), teff grass (teff), and triticale (tri)), on rumen bacterial and archaeal community structure using Hha I, Rsa I, and Hhe III digested terminal restriction fragments (T-RF's). We showed that, 1.) each diet and 
restriction enzymes, except npec digested with Rsa I (see below), produces at least one unique bacterial and archaeal species, 2.) npec digested with Rsa I produces only unique archaeal species, 3.) Hha I and Rsa I generates more bacterial richness but Hhe III generates more archaeal richness, 4.) triticale produces highest bacterial richness and diversity, 5.) nplc produces highest archaeal richness and diversity, 6.) npec diet produces comparatively more even bacterial community structure than other diets included in this study, 7.) triticale produces comparatively more even archaeal community structure than other diets included in this study, 8.) diet pair npec -teff and nplc-triticale produces more similar bacterial and archaeal community structure, 9.) bacterial and archaeal communities associated with diet pairs npec-nplc, npec-triticale, nplc-teff, and teff-triticale are significantly different.

Because discrimination of bacterial and archaeal populations by T-RFLP depends on 16S rDNA T-RF polymorphism, it is important to choose more than one restriction enzyme, and also to choose those restriction enzymes that have better resolving power for a particular community (Moyer, et al., 1996, Liu, et al., 1997, Engebretson \& Moyer, 2003, Schutte, et al., 2008). Previous study using computer simulated restriction fragment length polymorphism of bacterial sequences suggested that for $\geq 99 \%$ coverage of operational taxonomic units (OTU's) it is important to include at least three tetrameric restriction enzymes (Moyer, et al., 1996). Consequently, we used combination of three restriction enzymes (Hha I, Rsa I, and Hhe III) in this study. Bacterial richness and diversity observed with Hha I and Rsa I restriction enzyme were comparable to other similar studies, but extremely low bacterial richness and diversity was observed for all diet with Hhe III restriction enzyme. This may 
be mainly because we considered T-RF's sizes only up to $500 \mathrm{bp}$ in this study and those Hhe III digested bacterial T-RF's that were $>500$ bp didn't get counted for bacterial richness and diversity and it is known from Moyer et. al. (1996) computer simulated study on 10 tetrameric restriction enzymes that majority of Hhe III digested bacterial restriction fragment fall in size class range 400-1000 bp, whereas it was 250-550 bp for Hha I and Rsa I restriction enzymes. It is also possible that Hhe III restriction sites of rumen bacteria are well conserved and hence we observed fewer numbers of terminal fragments with Hhe III restriction enzymes (Schutte, et al., 2008). Interestingly, same was not true in case of rumen archaea (Table 3.2). High bacterial diversity observed with triticale and high archaeal diversity observed with nplc diets, suggests to us that microbial response to nutritional change in rumen is not always same for bacteria and archaea.

Forage maturity at harvest affects supply and utilization of nutrients to ruminants. Generally, mature or late cut forage diets have more dry matter and hence less nutritive quality and digestibility than less mature or early cut forage diets (Kammes, et al., 2012). Lower digestibility associated with mature forage diet also causes greater retention time of these diets in the rumen (Kammes, et al., 2012). We observed greater bacterial richness and diversity associated with late cut (more mature) naturalized pasture diets than in early cut (less mature) naturalized pasture diets (Table 3.2), which may be because of greater retention time and shift in nutritional value of mature (late cut) naturalized pasture diets . Significant difference in microbial community structure between npec and nplc diets suggests to us that nutritional value of naturalized pasture changes significantly with its maturity. Interestingly, mature (late cut) naturalized pasture 
diets produces bacterial and archaeal community more similar to triticale diets than to either less mature (early cut) naturalized pasture diet or teff grass. This may be mainly because both triticale and nplc contains more chloroplast compared to other diets hence are protein rich. Similar bacterial and archaeal community structure between less mature (early cut) naturalized pasture and teff grass may be mainly because they have less amount of chloroplast and hence protein, intermediate amount of non-structural carbohydrate, and similar digestibility compared to other two diets.

This study has several strengths. This is the first study to our knowledge, where effect of different pasture diets (npec, nplc, teff,and triticale) on bacterial and archaeal community structure was studied. We showed for the first time that along with nutritional quality and digestibility, maturity of pasture diets also changes bacterial and archaeal community structure significantly. Use of in-vitro single flow continuous (artificial) fermentors allowed us in having better control over several parameters that are not possible to control in natural rumen fermentors. In this experiment, for each sample we ran PCR in triplicate and again pooled PCR product after restriction digestion were separated thrice using capillary electrophoresis, which helped us in decreasing PCR bias against less abundant bacteria and archaea (Raymond, et al., 2011). Use of three tetrameric restriction enzymes allowed us in having better bacterial and archaeal coverage than what we would have obtained with one or two restriction enzymes (see chapter 2).

Major limitation of this study was inclusion of T-RF's of only up to $500 \mathrm{bp}$ size. We choose DNA ladder of up to 500 bp size (1200 bp DNA ladder didn't yield accurate standard curve), and hence it was not possible to include fragment size larger than 500 
bp in our analyses. This limitation had maximum effect on bacterial diversity and richness associated with Hhe III restriction enzymes (Table 3.2).

Use of $16 \mathrm{~S}$ rDNA based 454 pyrosequencing for estimation of rumen bacterial diversity have gained popularity among scientific community in recent years (Pitta, et al., 2010, Jami \& Mizrahi, 2012, Lee, et al., 2012, Li, et al., 2012), but it is still very expensive for large scale replicated studies, like this one. 454-pyrosequeicng cost is decreasing every day, and hopefully in future, repetition of this study with 454pryrosequencing will give more detail information about bacterial community structure associated with different pasture diets. 


\section{CHAPTER 4: CONCLUSIONS}

This is the first study where effect of six different pastures diets on rumen microbial community structure was tested. We observed that although wooded canopy pasture or silvopasture is better than open canopy pasture in terms of nutritional quality, it has no significant effect on bacterial or archaeal community structure. Similarly harvest time of open or wooded canopy pasture diets had no significant effect on rumen bacterial or archaeal community structure. We did observed significant bacterial and archaeal community structure, when open or wooden canopy pasture was compared with mixture of both wooden and open canopy pasture diets. Bacterial and archaeal diversity was slightly higher in open canopy pasture diets than wooded canopy pasture deits.

Among npec, nplc, teff and triticale pasture diets, bacterial and archaeal community structure of npec was more similar to teff than to other two diets. Similarly, nplc shared more bacterial and archaeal genera to triticale than to other two diets. Triticale and nplc produced highest richness and diversity for bacteria and archaea respectively than to other diets. Majority of T-RF's were shared between different pasture diets included in this study but each diet and restriction enzyme except one had at least one unique bacterial and archaeal fauna. Bacterial community was more evenly distributed in npec whereas archaeal community was more evenly distributed in triticale.

The results from this study is of great importance to cattle owners, because it will help in increasing energy density, improving feed efficiency, and in average daily gain (ADG) of cattle. We can detect microbial community changes among different diets and can fingerprint many pasture types and management system. Although we were not 
able to identify dominant rumen bacteria and archaea associated with these diets, its identification will help in improving meat quality. In long term, knowledge of bacterial and archaeal diversity from the proposed research will help in identification of unidentified grass diets for better meat quality. In future, 454-pyrosequencing based approach should be used for identification of dominant bacteria and archaea associated with theses diets. 


\section{REFERENCES}

Avgustin G, Wright F \& Flint HJ (1994) Genetic Diversity and Phylogenetic Relationships among Strains of Prevotella (Bacteroides) ruminicola from the Rumen. International Journal of Systematic Bacteriology 44: 246-255.

Bevans DW, Beauchemin KA, Schwartzkopf-Genswein KS, McKinnon JJ \& McAllister TA (2005) Effect of rapid or gradual grain adaptation on subacute acidosis and feed intake by feedlot cattle. Journal of Animal Science 83: 1116-1132.

Bond PL, Hugenholtz P, Keller J \& Blackall LL (1995) Bacterial Community Structures of Phosphate-Removing and Non-Phosphate-Removing Activated Sludges from Sequencing Batch Reactors. Applied and Environmental Microbiology 61: 1910-1916.

Bryant MP (1959) Bacterial species of the rumen. Bacteriological Reviews 23: 125-153.

Busquet M, Calsamiglia S, Ferret A, Cardozo PW \& Kamel C (2005) Effects of Cinnamaldehyde and Garlic Oil on Rumen Microbial Fermentation in a Dual Flow Continuous Culture. Journal of Dairy Science 88: 2508-2516.

Cardozo PW, Calsamiglia S, Ferret A \& Kamel C (2004) Effects of natural plant extracts on ruminal protein degradation and fermentation profiles in continuous culture. Journal of Animal Science 82: 3230-3236.

Carro MD, Ranilla MJ, Martin-Garcia AI \& Molina-Alcaide E (2009) Comparison of microbial fermentation of high- and low-forage diets in Rusitec, single-flow continuousculture fermenters and sheep rumen. Chilliard, Y. 3: 527-534.

Clarke RTJ (1964) Ciliates of the rumen of domestic cattle (Bos taurus L.). New Zealand Journal of Agricultural Research 7: 248-257.

Clarke RTJ \& Menna MED (1961) Yeasts from the Bovine Rumen. Journal of General Microbiology 25: 113-117.

Czerkawski JW \& Breckenridge G (1977) Design and development of a long-term rumen simulation technique (Rusitec) British Journal of Nutrition 38: 371-384.

Danovaro R, Luna GM, Dell'Anno A \& Pietrangeli B (2006) Comparison of Two Fingerprinting Techniques, Terminal Restriction Fragment Length Polymorphism and Automated Ribosomal Intergenic Spacer Analysis, for Determination of Bacterial Diversity in Aquatic Environments. Applied and Environmental Microbiology 72: 59825989.

Dehority BA, Damron WS \& McLaren JB (1983) Occurrence of the Rumen Ciliate Oligoisotricha bubali in Domestic Cattle (Bos taurus). Applied and Environmental Microbiology 45: 1394-1397.

Devine AA (2010) Examining complex microbial communities using the terminal restriction fragment length polymorphism method dedicated TRFLPanalysis software. . Thesis, PhD dissertation, North Carolina State University, , Raleigh, USA.

Elsden SR \& Phillipson AT (1948) Ruminant digestion. Annual Review of Biochemistry 17: 705-726. 
Emmanuel B (1974) On the origin of rumen protozoan fatty acids. Biochimica et Biophysica Acta (BBA) - Lipids and Lipid Metabolism 337: 404-413.

Engebretson JJ \& Moyer CL (2003) Fidelity of Select Restriction Endonucleases in Determining Microbial Diversity by Terminal-Restriction Fragment Length Polymorphism. Applied and Environmental Microbiology 69: 4823-4829.

Engebretson JJ \& Moyer CL (2003) Fidelity of select restriction endonucleases in determining microbial diversity by terminal-restriction fragment length polymorphism. Applied and Environmental Microbiology 69: 4823-4829.

Enquist BJ, Economo EP, Huxman TE, Allen AP, Ignace DD \& Gillooly JF (2003) Scaling metabolism from organisms to ecosystems. Nature 423: 639-642.

Fellner V, Sauer FD \& Kramer JKG (1997) Effect of Nigericin, Monensin, and Tetronasin on Biohydrogenation in Continuous Flow-Through Ruminal Fermenters. Journal of Dairy Science 80: 921-928.

Fernando SC, Purvis HT, 2nd, Najar FZ, et al. (2010) Rumen microbial population dynamics during adaptation to a high-grain diet. Applied and Environmental Microbiology 76: 7482-7490.

Hannah SM, Stern MD \& Ehle FR (1986) Evaluation of a dual flow continuous culture system for estimating bacterial fermentation in vivo of mixed diets containing various soya bean products. Animal Feed Science and Technology 16: 51-62.

Hobson PN (1989) The rumen microbial eco-system. Elsevier Applied Science, London.

Hoover WH, Crooker BA \& Sniffen CJ (1976) Effects of Differential Solid-Liquid Removal Rates on Protozoa Numbers in Continous Cultures of Rumen Contents. Journal of Animal Science 43: 528-534.

Hungate RE (1966) The rumen and its microbes. Academic Press New York. Jami E \& Mizrahi I (2012) Composition and Similarity of Bovine Rumen Microbiota across Individual Animals. Martínez Falcón, A. P. 7: e33306.

Jarvis GN, Strompl C, Burgess DM, Skillman LC, Moore ER \& Joblin KN (2000) Isolation and identification of ruminal methanogens from grazing cattle. Current Microbiology 40: 327-332.

Joblin KN, Naylor GE \& Williams AG (1990) Effect of Methanobrevibacter smithii on Xylanolytic Activity of Anaerobic Ruminal Fungi. Applied and Environmental Microbiology 56: 2287-2295.

Kamara DN (2005) Rumen microbial ecosystem. Current Science 89: 124-135.

Kammes KL, Ying Y \& Allen MS (2012) Nutrient demand interacts with legume maturity to affect rumen pool sizes in dairy cows. Journal of Dairy Science 95: 2632-2647.

Kephart KD \& Buxton DR (1993) Forage Quality Responses of C3 and C4 Perennial Grasses to Shade. Crop Sci. 33: 831-837.

Kephart KD, Buxton DR \& Taylor ES (1992) Growth of C3 and C4 Perennial Grasses under Reduced Irradiance. Kephart, Kevin D. 32: 1033-1038. 
Khafipour E, Li SC, Plaizier JC \& Krause DO (2009) Rumen Microbiome Composition Determined Using Two Nutritional Models of Subacute Ruminal Acidosis. Applied and Environmental Microbiology 75: 7115-7124.

Klieve AV, Hennessy D, Ouwerkerk D, Forster RJ, Mackie RI \& Attwood GT (2003) Establishing populations of Megasphaera elsdenii YE 34 and Butyrivibrio fibrisolvens YE 44 in the rumen of cattle fed high grain diets. Journal of Applied Microbiology 95: 621-630.

Kocherginskaya SA, Aminov RI \& White BA (2001) Analysis of the Rumen Bacterial Diversity under two Different Diet Conditions using Denaturing Gradient Gel Electrophoresis, Random Sequencing, and Statistical Ecology Approaches. Klevenhusen, F. 7: 119-134.

Koike S, Yoshitani S, Kobayashi Y \& Tanaka K (2003) Phylogenetic analysis of fiberassociated rumen bacterial community and PCR detection of uncultured bacteria. FEMS Microbiology Letters 229: 23-30.

Krause DO, Denman SE, Mackie RI, Morrison M, Rae AL, Attwood GT \& McSweeney CS (2003) Opportunities to improve fiber degradation in the rumen: microbiology, ecology, and genomics. FEMS Microbiology Reviews 27: 663-693.

Kumar S, Puniya AK, Puniya M, Dagar SS, Sirohi SK, Singh K \& Griffith GW (2009) Factors affecting rumen methanogens and methane mitigation strategies. World Journal of Microbiology \& Biotechnology 25: 1557-1566.

Lee HJ, Jung JY, Oh YK, Lee SS, Madsen EL \& Jeon CO (2012) Comparative survey of rumen microbial communities and metabolites across one caprine and three bovine groups, using bar-coded pyrosequencing and (1) $\mathrm{H}$ nuclear magnetic resonance spectroscopy. Applied and Environmental Microbiology 78: 5983-5993.

Li M, Penner GB, Hernandez-Sanabria E, Oba M \& Guan LL (2009) Effects of sampling location and time, and host animal on assessment of bacterial diversity and fermentation parameters in the bovine rumen. Journal of Applied Microbiology 107: 1924-1934.

Li RW, Connor EE, Li C, Baldwin VIRL \& Sparks ME (2012) Characterization of the rumen microbiota of pre-ruminant calves using metagenomic tools. Bauer, Margarete 14: 129-139.

Lin C, McGraw M, George M \& Garrett H (2001) Nutritive quality and morphological development under partial shade of some forage species with agroforestry potential. Agroforestry Systems 53: 269-281.

Liu WT, Marsh TL, Cheng H \& Forney LJ (1997) Characterization of microbial diversity by determining terminal restriction fragment length polymorphisms of genes encoding 16S rRNA. Applied and Environmental Microbiology 63: 4516-4522.

Lozupone C, Hamady M \& Knight R (2006) UniFrac--an online tool for comparing microbial community diversity in a phylogenetic context. Han, M. V. 7: 371.

Lund A (1974) Yeasts and Moulds in the Bovine Rumen. Journal of General Microbiology 81: 453-462. 
Marchesi JR, Sato T, Weightman AJ, et al. (1998) Design and evaluation of useful bacterium-specific PCR primers that amplify genes coding for bacterial 16S rRNA. Applied and Environmental Microbiology 64: 795-799.

Marsh TL, Saxman P, Cole J \& Tiedje J (2000) Terminal restriction fragment length polymorphism analysis program, a web-based research tool for microbial community analysis. Applied and Environmental Microbiology 66: 3616-3620.

Meng Q, Kerley MS, Ludden PA \& Belyea RL (1999) Fermentation substrate and dilution rate interact to affect microbial growth and efficiency. Journal of Animal Science 77: 206-214.

Miron J, Ben-Ghedalia D \& Morrison M (2001) Invited review: adhesion mechanisms of rumen cellulolytic bacteria. Journal of Dairy Science 84: 1294-1309.

Monteils V, Rey M, Silberberg M, Cauquil L \& Combes S (2012) Modification of activities of the ruminal ecosystem and its bacterial and protozoan composition during repeated dietary changes in cows. Journal of Animal Science.

Mould DL \& Thomas GJ (1958) The enzymic degradation of starch by holotrich Protozoa from sheep rumen. Biochemical Journal 69: 327-337.

Moyer CL, Tiedje JM, Dobbs FC \& Karl DM (1996) A computer-simulated restriction fragment length polymorphism analysis of bacterial small-subunit rRNA genes: efficacy of selected tetrameric restriction enzymes for studies of microbial diversity in nature. Applied and Environmental Microbiology 62: 2501-2507.

Muyzer G, de Waal EC \& Uitterlinden AG (1993) Profiling of complex microbial populations by denaturing gradient gel electrophoresis analysis of polymerase chain reaction-amplified genes coding for $16 \mathrm{~S}$ rRNA. Applied and Environmental Microbiology 59: 695-700.

Nagashima K, Hisada T, Sato M \& Mochizuki J (2003) Application of new primerenzyme combinations to terminal restriction fragment length polymorphism profiling of bacterial populations in human feces. Applied and Environmental Microbiology 69: 1251-1262.

Orpin CG (1975) Studies on the rumen flagellate Neocallimastix frontalis. Journal of General Microbiology 91: 249-262.

Osborn AM, Moore ER \& Timmis KN (2000) An evaluation of terminal-restriction fragment length polymorphism (T-RFLP) analysis for the study of microbial community structure and dynamics. Environ Microbiol 2: 39-50.

Pitta D, Pinchak W, Dowd S, et al. (2010) Rumen Bacterial Diversity Dynamics Associated with Changing from Bermudagrass Hay to Grazed Winter Wheat Diets. Microbial Ecology 59: 511-522.

R Development Core Team (2011) R: A language and environment for statistical computing. R Foundation for Statistical Computing, http://www.R-project.org, Vienna, Austria. 
Raymond S, Recordon-Pinson P, Saliou A, et al. (2011) Improved V3 genotyping with duplicate PCR amplification for determining HIV-1 tropism. Journal of Antimicrobial Chemotherapy 66: 1972-1975.

Ridwan R, Widyastuti Y, Budiarti S \& Dinoto A (2009) Analysis of Rumen Microbial Population of Cattle Given Silage and Probiotics Using Terminal Restriction Fragment Length Polymorphism. Microbiology Indonesia 3: 126-132.

Russell J (2002) Rumen microbiology and its role in ruminant nutrition.

Schutte UME, Abdo Z, Bent SJ, Shyu C, Williams CJ, Pierson JD \& Forney LJ (2008) Advances in the use of terminal restriction fragment length polymorphism (T-RFLP) analysis of 16S rRNA genes to characterize microbial communities. Applied Microbiology and Biotechnology 80: 365-380.

Singh BK, Nazaries L, Munro S, Anderson IC \& Campbell CD (2006) Use of multiplex terminal restriction fragment length polymorphism for rapid and simultaneous analysis of different components of the soil microbial community. Applied and Environmental Microbiology 72: 7278-7285.

Slyter LL (1990) Buffers used in the artificial rumen. ed.^eds.), p.^^p. 9. Northeast ADAS-ASAS Regional Meeting., Chazy, NY.

Swofford DL (2003) PAUP*. Phylogenetic Analysis Using Parsimony ( ${ }^{*}$ and Other Methods). Version 4. Sinauer Associates.

Tajima K, Aminov RI, Nagamine T, Matsui H, Nakamura M \& Benno Y (2001) Dietdependent shifts in the bacterial population of the rumen revealed with real-time PCR. Applied and Environmental Microbiology 67: 2766-2774.

Ushida K (2011) Symbiotic Methanogens and Rumen Ciliates

(Endo)symbiotic Methanogenic Archaea. Vol. 19 (Hackstein JHP, ed. ${ }^{\wedge}$ eds.), p. ${ }^{\wedge}$ pp. $25-$ 34. Springer Berlin / Heidelberg.

van Kessel JAS \& Russell JB (1996) The effect of pH on ruminal methanogenesis. Ramette, Alban 20: 205-210.

Williams AG \& Coleman GS (1985) Hemicellulose-Degrading Enzymes in Rumen Ciliate Protozoa. Current Microbiology 12: 85-90. 